\title{
A Small Quarterly Multi-Country Projection Model with Financial-Real Linkages and Oil Prices
}

Ioan Carabenciov, Igor Ermolaev, Charles Freedman, Michel Juillard, Ondra Kamenik, Dmitry Korshunov, Douglas Laxton, and Jared Laxton 



\title{
IMF Working Paper
}

\author{
Research Department
}

\section{A Small Quarterly Multi-Country Projection Model with Financial-Real Linkages and Oil Prices ${ }^{1}$}

\author{
Prepared by Ioan Carabenciov, Igor Ermolaev, Charles Freedman, Michel Juillard, \\ Ondra Kamenik, Dmitry Korshunov, Douglas Laxton, and Jared Laxton
}

\author{
Authorized for distribution by Charles Collyns
}

December 2008

\begin{abstract}
This Working Paper should not be reported as representing the views of the IMF. The views expressed in this Working Paper are those of the author(s) and do not necessarily represent those of the IMF or IMF policy. Working Papers describe research in progress by the author(s) and are published to elicit comments and to further debate.

This is the third of a series of papers that are being written as part of a larger project to estimate a small quarterly Global Projection Model (GPM). The GPM project is designed to improve the toolkit for studying both own-country and cross-country linkages. In this paper, we estimate a small quarterly projection model of the US, Euro Area, and Japanese economies that incorporates oil prices and allows us to trace out the effects of shocks to oil prices. The model is estimated with Bayesian techniques. We show how the model can be used to construct efficient baseline forecasts that incorporate judgment imposed on the near-term outlook.

JEL Classification Numbers: C51; E31; E52

Keywords: Macroeconomic Modeling; Forecasting; Bayesian Estimation; Monetary Policy Author’s E-Mail Address: dlaxton@imf.org; icarabenciov@imf.org; okamenik@imf.org

\footnotetext{
${ }^{1}$ I. Ermolaev and D. Korshunov are affiliated with the Bank of Russia, C. Freedman with Carleton University, Ottawa, Canada, M. Juillard with the Bank of France and CEPREMAP, and J. Laxton with Virginia Commonwealth University. The authors wish to thank Jeannine Bailliu, Patrick Blagrave, Olivier Blanchard, Jorge Canales, Don Coletti, Charles Collyns, Jörg Decressin, Roberto Garcia-Saltos, Marianne Johnson, Simon Johnson, Alin Mirestean, James Rossiter, Larry Schembri, Kadir Tanyeri and colleagues at other policymaking institutions for encouraging us to do this work. We also gratefully acknowledge the invaluable support of Heesun Kiem and Susanna Mursula in research assistance, and of Laura Leon in the preparation of this paper. The views expressed here are those of the authors and do not necessarily reflect the position of the International Monetary Fund. The DYNARE estimation programs used in this paper can be accessed from www.douglaslaxton.org. Correspondence: dlaxton@imf.org.
} 


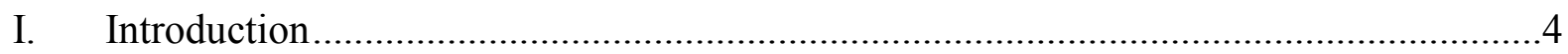

II. Benchmark Model.....................................................................................................4

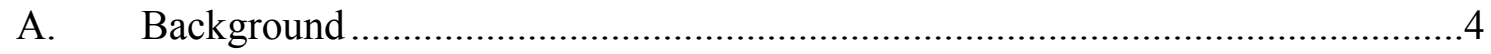

B. The Specification of the Model.................................................................... 6

B.1. Observable variable and data definitios ............................................... 7

B.2. Stochastic processes and model definitions .........................................

B.3 Behavioral equations..................................................................... 10

B.4. Cross corelations of disturbances...................................................13

III. Extending the Model to Include Financial-Real Linkages .........................................15

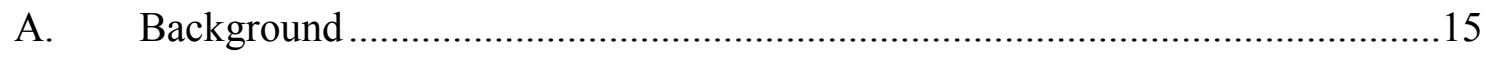

B. Model Specification Incorporating the US Bank Lending Tightening

Variable

IV. Extending the Model to Include Oil Prices..............................................................22

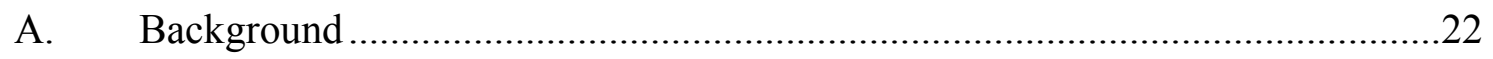

B. Model Specification Incorporating Oil Price ...............................................23

V. Confronting The Model with The Data ...................................................................25

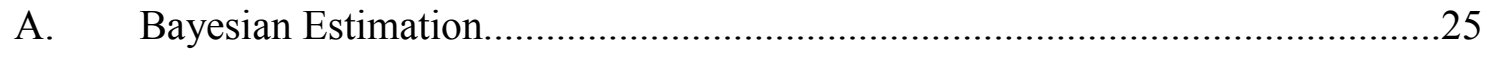

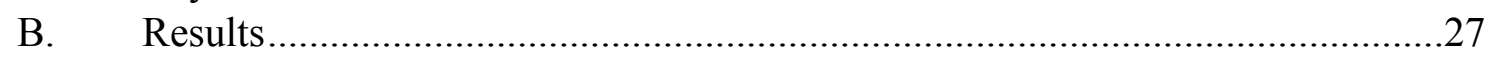

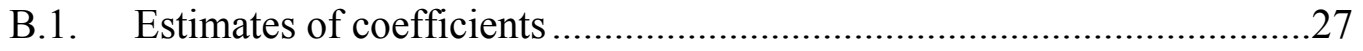

B.2. Estimates of standard deviation of structural shocks and cross

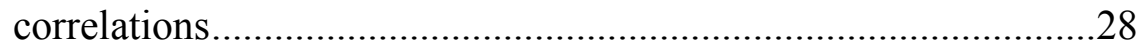

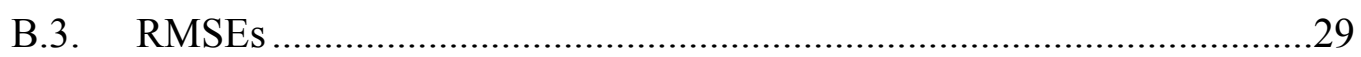

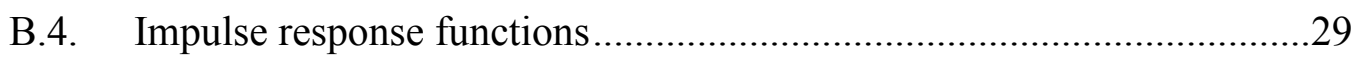

C. Forecasting with Bayesian Estimates....................................................... 31

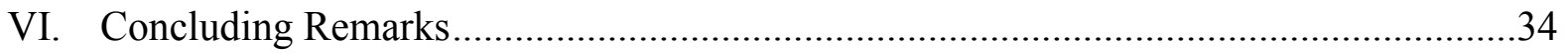

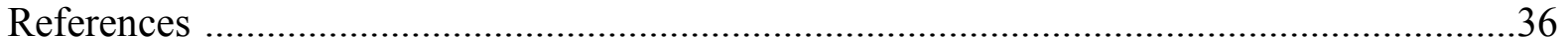

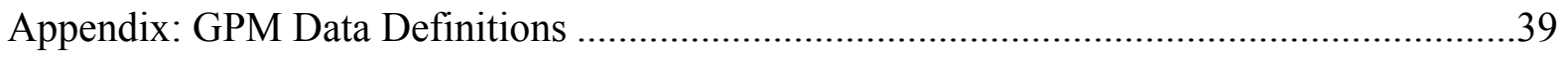

Figure 1. Comparison between Output Gap and BLT indicator ....................................40

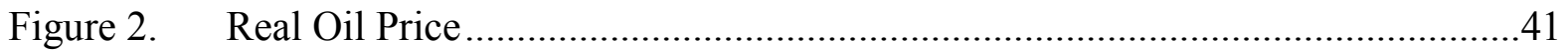

Table 1. Results from posterior maximization (1) ..................................................42

Table 2. Results from posterior maximization (2) .................................................43

Table 3. Results from posterior maximization (3) ................................................44 
Table 4. Results from posterior parameters (standard deviation of structural

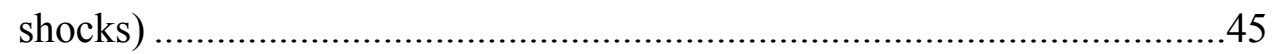

Table 5. Results from posterior parameters (correlation of structural

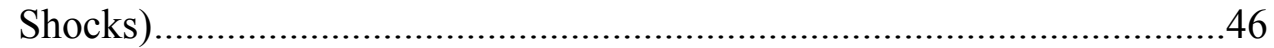

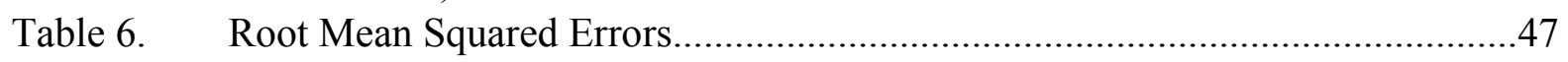

Figure 3 Demand shock in the US (1)

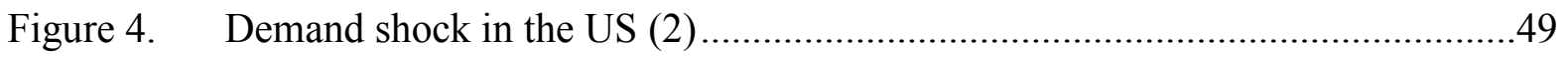

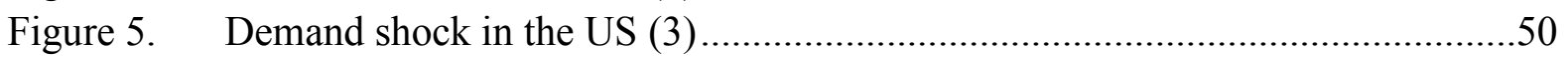

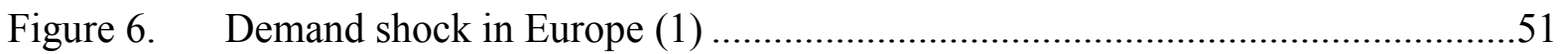

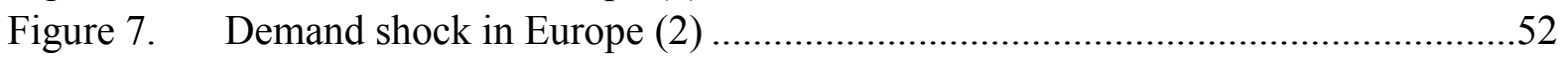

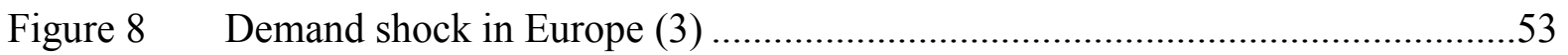

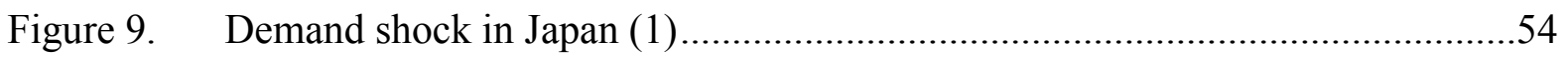

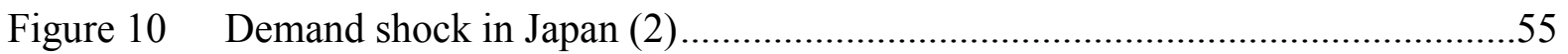

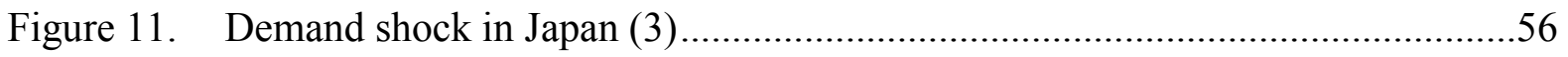

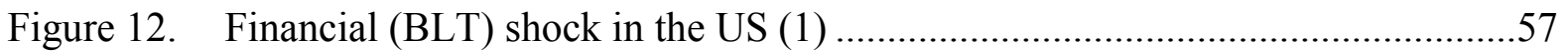

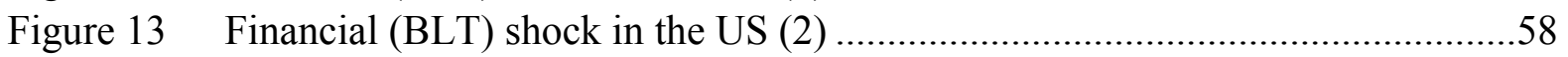

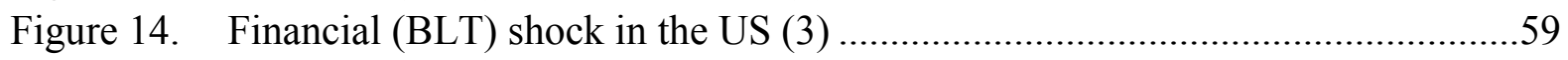

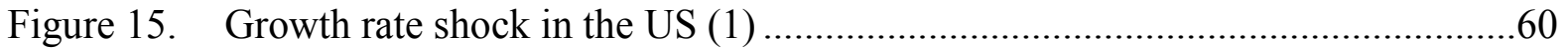

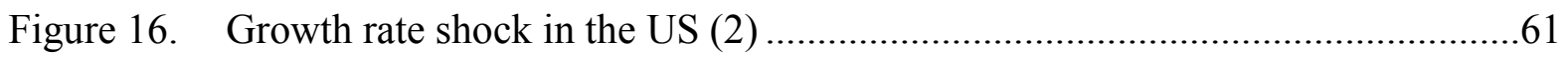

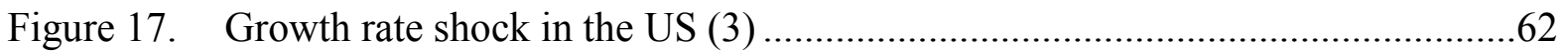

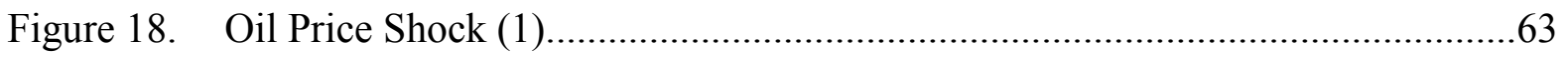

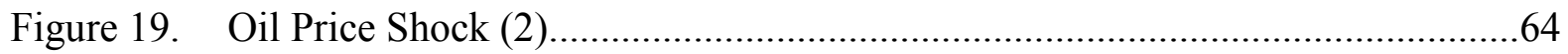

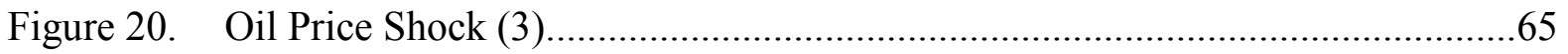

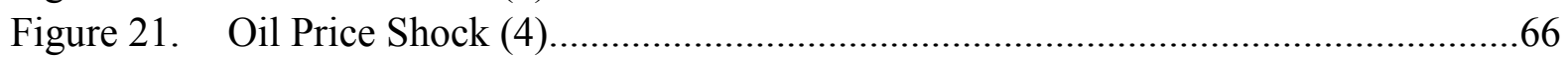

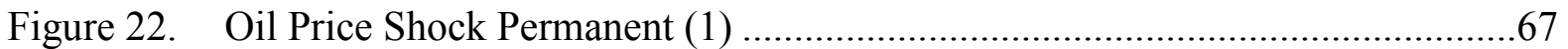

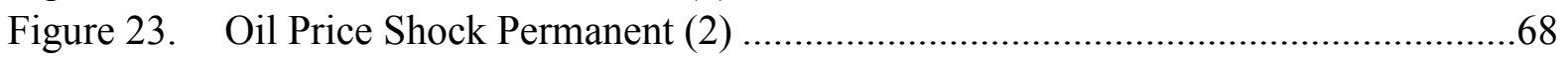

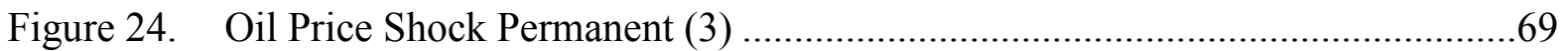

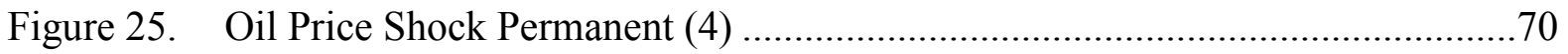

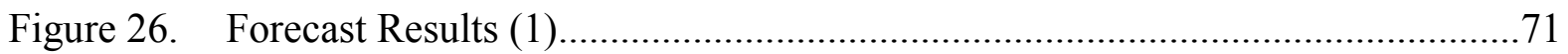

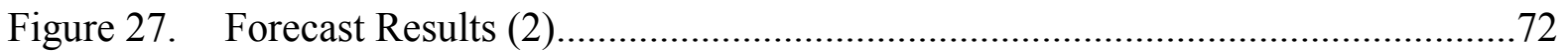

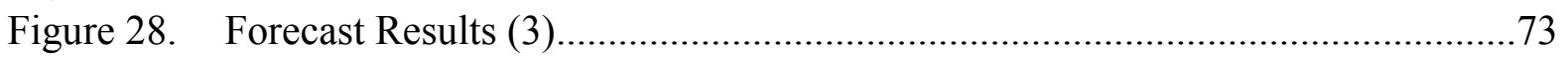

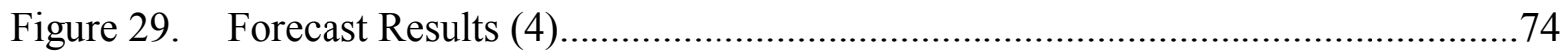




\section{Introduction}

This study is the third of a series of studies designed to develop a full global projection model. The first study in the series, "A small quarterly projection model of the US economy," (Carabenciov and others, 2008a) set out a closed economy version of the model and applied it to the US economy using Bayesian estimation techniques. It incorporated a financial variable for the US economy, enabling us to see the effects of changes in this variable on US output and inflation. The second in the series, "A small quarterly multi-country projection model," (Carabenciov and others, 2008b) extended the model to an open economy. It set out a small quarterly projection model of the US, euro area, and Japanese economies to illustrate the way that such models can be used to understand past economic developments and to forecast future developments in a multi-country setting. It also incorporated the financial variable for the US economy, enabling us to see the effects of changes in this variable on the US economy and on the other economies. In this paper, we add oil prices to the three country model. This permits us to examine the effects of temporary and permanent shocks to the level and growth rate of oil prices on the three economies. We also show how the model can be used to construct efficient baseline forecasts that incorporate judgment imposed on the near-term outlook. ${ }^{2}$ The three studies are preparatory to the next steps in our research agenda - first, to incorporate a more sophisticated oil sector with global demand and supply for oil; second, to extend the model to include financial variables in countries other than the United States; and third, to develop a small quarterly Global Projection Model (GPM) that will integrate a number of large and small country models into a single global model.

\section{Benchmark Model}

\section{A. Background}

In recent years, the IMF has developed two types of macroeconomic models - dynamic stochastic general equilibrium (DSGE) models and small quarterly projection models (QPMs) - that it has used to analyze economic behavior and to forecast future developments. The DSGE models are

\footnotetext{
${ }^{2}$ The forecast is for illustrative purposes only, and is not the official forecast of the IMF. The latter, which is based on the work of desk economists at the Fund, is published twice a year in the IMF's World Economic Outlook (WEO).
} 
based on theoretical underpinnings and have been found to be very useful in analyzing the effects of structural changes in the economy, as well as the effects of longer-term developments such as persistent fiscal deficits and current account deficits. ${ }^{3}$ And multi-country variants of these models have allowed researchers to analyze the effects of shocks in one country on economic variables in other countries. The small quarterly projection models use four or five behavioral equations to characterize the macroeconomic structure of an economy in a way that is both easy to use by modelers and comprehensible to policymakers. They focus on the key macroeconomic variables in the economy - typically output, inflation, a short-term interest rate, and sometimes the exchange rate and/or the unemployment rate. By virtue of their relatively simple and readily understandable structure, they have been used for forecasting and policy analysis purposes in central banks and by country desks in the IMF. ${ }^{4}$ In the past, the parameters of such models have been calibrated on the basis of the knowledge of country experts of the economic structure of the country being studied and that of similar countries.

In the series of papers that we are preparing, four important extensions are being made to the basic model. First, in all the papers in the series, Bayesian techniques are used to estimate the parameters of the model. Bayesian methods allow researchers to input their priors into the model and then to confront them with the data, in order to determine whether their priors are more or less consistent with the data. Although regime shifts in recent years (most notably, the anchoring of inflation expectations to a formal or informal target in many countries) limit the time series to relatively short periods, the estimation approach taken in these papers will be increasingly useful over time as the lengths of usable time series are extended.

Second, in the second and third papers, we expand the model to three economies - United States, the Euro area, and Japan. In a future paper, the small quarterly models of a number of countries (United States, the Euro area, Japan, emerging Asia, oil-exporting countries, Canada, Russia, other industrialized countries, other major oil producers, and the rest of the world) will be integrated into a small quarterly Global Projection Model (GPM), which will enable researchers

\footnotetext{
${ }^{3}$ See Botman and others (2007) for a summary of the applications using these models.

${ }^{4}$ See Berg, Karam, and Laxton (2006a,b) for a description of the basic model as well as Epstein and others (2006) and Argov and others (2007) for examples of applications and extensions. Currently, there are several country desks at the Fund using the model to support forecasting and policy analysis and to better structure their dialogue with member countries. A number of inflation-targeting central banks have used similar models as an integral part of their Forecasting and Policy Analysis Systems - see Coats, Laxton and Rose (2003) for a discussion about how such models are used in inflation-targeting countries,
} 
to analyze the effects on a number of countries of shocks in one country and of global shocks. Moreover, the model will be programmed in such way that researchers will be able to add other countries to the model in a relatively straightforward manner. Such models will give forecasters a new tool to assist them in preparing worldwide forecasts and in carrying out alternative policy simulations in the global context. There is strong demand for such an empirically based multi-country model, both for IMF surveillance work and for helping central bank forecasters to assess the external environment in preparing their projections. Large-scale DSGE models show promise in this regard, but we are years away from developing empirically-based multi-country versions of these models. While global VARs (GVARs) have been developed for forecasting exercises, they are not very useful for policy analysis because they lack the identification restrictions necessary to obtain plausible impulse response functions.

Third, given the importance in recent years of financial-real linkages, we have been experimenting with financial variables that might be helpful in explaining economic developments and in forecasting future movements of the economy. Thus far, we have used a single financial variable, a US bank lending tightening measure $\left(\mathrm{BLT}_{u s}\right)$, which contributed importantly to the explanation of movements of the US economy over the sample period and also improved out-of-sample forecasting. In future papers we will broaden the use of financial variables to include a number of financial measures of risk in the United States and other countries.

Fourth, in this paper we are extending the model to include oil prices. On a number of occasions since 1973, sharp increases or decreases in oil prices have had an important effect on output and inflation in the major economies. And the very steep increase in oil prices in the current episode has raised questions about the severity of the downturn in economic activity that is likely to result, and the extent to which the recent oil-induced increase in the headline inflation rate is likely to spread to inflation expectations and broader inflation pressures. Modeling the linkages between oil prices and output and inflation should therefore be helpful in assessing the economic outlook in the major industrial economies.

\section{B. The Specification of The Model}

We begin our discussion of the model with a small generic open economy model that describes the joint determination of output, unemployment, inflation, a short-term interest rate and the exchange rate for the three economies. The model is fundamentally a gap model, in which the 
gaps of the variables from their equilibrium values play the crucial role in the functioning of the system. A number of definitions and identities are used to complete the model. We present the model specification for a single country labelled $i$. The specification for other countries will be very similar, although the priors for the coefficient estimates and for the standard deviations of the structural shocks will differ across economies on the basis of expert knowledge of those economies. In the next two sections of the paper, we will expand the model to include the US BLT variable and oil prices.

\section{B.1 Observable variables and data definitions}

The benchmark model has 5 observable variables for each economy. ${ }^{5}$ These are real GDP, the unemployment rate, CPI inflation, a short-term interest rate, and the exchange rate. ${ }^{6}$ We use capital letters for the variables themselves and small letters for the gaps between the variables and their equilibrium values. Thus, we define $\mathrm{Y}$ as 100 times the $\log$ of real GDP, $\bar{Y}$ as 100 times the $\log$ of potential output and lowercase $y$ as the output gap in percentage terms $(y=Y-\bar{Y})$. Similarly, we define the unemployment gap, u, as the difference between the actual unemployment rate (U) and the equilibrium unemployment rate or NAIRU, $\bar{U}$. We define the quarterly rate of inflation at annual rates $(\pi)$ as 400 times the first difference of the log of the CPI. In addition, we define the year-on-year measure of inflation $(\pi 4)$ as 100 times the difference of the log of the CPI in the current quarter from its value four quarters earlier. The nominal interest rate is $I$, the real interest rate is $R$, the nominal exchange rate vis-à-vis the US dollar is $S$, and the $\log$ of the real exchange rate vis-à-vis the US dollar is Z. The gap between the real exchange rate, $\mathrm{Z}$, and its equilibrium value, $\bar{Z}$, is denoted as $\mathrm{Z}$.

\section{B.2 Stochastic processes and model definitions}

A major advantage of Bayesian methods is that it is possible to specify and estimate fairly flexible stochastic processes. In addition, unlike classical estimation approaches, it is possible to specify more stochastic shocks than observable variables, which is usually necessary to prevent the model

\footnotetext{
${ }^{5}$ Data definitions are provided in the appendix to this paper.

${ }^{6}$ More accurately, each non-American economy has an exchange rate vis-à-vis the US dollar. So if there are N economies in the model, there will be N-1 exchange rates.
} 
from making large and systematic forecast errors over long periods of time. For example, an important ingredient in specifying a forecasting model, as we will see in this section, is allowing for permanent changes in the underlying estimates of the equilibrium values for potential output and for the equilibrium unemployment rate.

We assume that there can be shocks to both the level and growth rate of potential output. The shocks to the level of potential output can be permanent, while the shocks to the growth rate can result in highly persistent deviations in potential growth from long-run steady-state growth. In equation $1 \overline{\mathrm{Y}}$ is equal to its own lagged value plus the quarterly growth rate $(\mathrm{g} \bar{Y} / 4)$ plus a disturbance term $\left(\varepsilon^{\bar{Y}}\right)$ that can cause permanent level shifts in potential GDP.

$$
\bar{Y}_{i, t}=\bar{Y}_{i, t-1}+g_{i, t}^{\bar{Y}} / 4+\varepsilon_{i, t}^{\bar{Y}}
$$

As shown in equation 2 , in the long run the growth rate of potential GDP, $\mathrm{g}^{\bar{Y}}$, is equal to its steady-state rate of growth, $\mathrm{g}^{\bar{Y} s s}$. But it can diverge from this steady-state growth following a positive or negative value of the disturbance term $\left(\varepsilon^{g^{\bar{Y}}}\right)$, and will return to $\mathrm{g}^{\bar{Y} s s}$ gradually, with the speed of return based on the value of $\tau$.

$$
g_{i, t}^{\bar{Y}}=\tau_{i} g_{i}^{\bar{Y}_{s s}}+\left(1-\tau_{i}\right) g_{i, t-1}^{\bar{Y}}+\varepsilon_{i, t}^{g^{\bar{Y}}}
$$

A similar set of relationships holds for the equilibrium or NAIRU rate of unemployment. $\bar{U}$ is defined in equation 3 as its own past value plus a growth term $\mathrm{g}^{\bar{U}}$ and a disturbance term $\left(\varepsilon^{\bar{U}}\right)$. And in equation $4, \mathrm{~g}^{\bar{U}}$ is a function of its own lagged value and the disturbance term $\left(\varepsilon^{g^{\bar{U}}}\right)$. Thus, the NAIRU can be affected by both level shocks and persistent growth shocks.

$$
\begin{gathered}
\bar{U}_{i, t}=\bar{U}_{i, t-1}+g_{i, t}^{\bar{U}}+\varepsilon_{i, t}^{\bar{U}} \\
g_{i, t}^{\bar{U}}=\left(1-\alpha_{i, 3}\right) g_{i, t-1}^{\bar{U}}+\varepsilon_{i, t}^{g \bar{U}}
\end{gathered}
$$

Equation 5 defines the real interest rate, R, as the difference between the nominal interest rate, I, and the expected rate of inflation for the subsequent quarter.

$$
R_{i, t}=I_{i, t}-\pi_{i, t+1}
$$

Equation 6 defines $r$, the real interest rate gap, as the difference between $\mathrm{R}$ and its equilibrium 
value, $\bar{R}$.

$$
r_{i, t}=R_{i, t}-\bar{R}_{i, t}
$$

Equation 7 defines $\bar{R}$, the equilibrium real interest rate, as a function of the steady-state real interest rate, $\bar{R}^{s s}$. It has the ability to diverge from the steady state in response to a stochastic $\operatorname{shock}\left(\varepsilon^{\bar{R}}\right)$.

$$
\bar{R}_{i, t}=\rho_{i} \bar{R}_{i}^{s s}+\left(1-\rho_{i}\right) \bar{R}_{i, t-1}+\varepsilon_{i, t}^{\bar{R}}
$$

Equation 8 defines $Z_{i}$, the $\log$ of the real exchange rate in country $i$, as equal to 100 times the $\log$ of the nominal exchange rate, $S_{i}$ (defined as the number of units of local currency in country $i$ vis-à-vis the US dollar), times the $\mathrm{CPI}\left(\mathrm{P}_{u s}\right)$ in the United States, divided by the CPI in country $\mathrm{i}$ $\left(\mathrm{P}_{i}\right)$. An increase in $Z_{i}$ is thus a real depreciation of currency i vis-à-vis the US dollar.

$$
Z_{i, t}=100 * \log \left(S_{i, t} P_{u s, t} / P_{i, t}\right)
$$

The change in the log of the real exchange rate is shown in equation 9 as 100 times the change in the log of the nominal exchange rate less the difference between the quarterly inflation rates in country $i$ and the United States. It is therefore approximately equal to the change in percentage terms for small changes.

$$
\Delta Z_{i, t}=100 \Delta \log \left(\mathrm{S}_{i, t}\right)-\left(\pi_{i, t}-\pi_{u s, t}\right) / 4
$$

Equation 10 defines the expected real exchange rate for the next period, $\mathrm{Z}^{e}$, as a weighted average of the lagged real exchange rate and the 1-period model-consistent solution of the real exchange rate.

$$
Z_{i, t+1}^{e}=\phi_{i} Z_{i, t+1}+\left(1-\phi_{i}\right) Z_{i, t-1}
$$

Equation 11 defines the real exchange rate gap, $z$, as equal to the log of the real exchange rate minus the log of the equilibrium real exchange rate, $\bar{Z}$.

$$
z_{i, t}=Z_{i, t}-\bar{Z}_{i, t}
$$

Equation 12 defines the equilibrium real exchange rate, $\bar{Z}$, as equal to its lagged value plus a disturbance term, $\varepsilon^{\bar{z}}$.

$$
\bar{Z}_{i, t}=\bar{Z}_{i, t-1}+\varepsilon_{i, t}^{\bar{z}}
$$




\section{B.3 Behavioral equations}

Equation 13 is a behavioral equation that relates the output gap (y) to its own lead and lagged values, the lagged value of the gap in the short-term real interest rate (r), the output gaps in its trading partners, the effective real exchange rate gap, and a disturbance term $\left(\varepsilon^{y}\right)$. The foreign output gap term is defined as a weighted average of the lagged foreign output gaps, ${ }^{7}$ where the weights $\left(\omega_{i, j, 5}\right)$ are the ratios of the exports of country $i$ to country $j$ to total exports of country $i$ to all the countries in the model. This weighted foreign output gap variable is thus a form of activity variable, with the weights imposed on the basis of past data. The effective real exchange rate gap variable in the equation is a weighted average of the real exchange rate gaps of the foreign countries with which economy $i$ trades. In this case, the weights $\left(\omega_{i, j, 4}\right)$ are the ratio of the sum of exports and imports of country $i$ with country $j$ to the sum of exports and imports with all the countries in the model and are also imposed on the basis of the data.

$$
y_{i, t}=\beta_{i, 1} y_{i, t-1}+\beta_{i, 2} y_{i, t+1}-\beta_{i, 3} r_{i, t-1}+\beta_{i, 4} \sum_{j} \omega_{i, j, 4} z_{i, j, t-1}+\beta_{i, 5} \sum_{j} \omega_{i, j, 5} y_{j, t-1}+\varepsilon_{i, t}^{y}
$$

All variables in this equation are expressed as deviations from their equilibrium values. The own-lag term allows for the inertia in the system, and permits shocks to have persistent effects. The lead term allows more complex dynamics and forward-looking elements in aggregate demand. The real interest rate term and the real exchange rate term provide the crucial direct and indirect links between monetary policy actions and the real economy. And the activity variable allows for the direct trade links among the various economies.

The specification of the real exchange rate gap variables $(z)$ is somewhat complex in a multi-country model. Since all the exchange rate variables are defined in terms of the US dollar, the bilateral real exchange rate gaps for all country pairs except those involving the United States should be in relative terms. Consider, for example, the euro area output gap equation. If the euro area exchange rate were overvalued by $5 \%$ (that is, its $\mathrm{z}$ is minus $5 \%$ ) and if the yen exchange rate were undervalued by $10 \%$ (that is, its $\mathrm{z}$ is plus $10 \%$ ), then the euro is overvalued by $15 \%$ vis-à-vis the yen, and the $z_{e u, j a}$ enters the euro area output gap equation as $\mathrm{z}_{e u}-\mathrm{z}_{j a}$, or $-15 \%$. In contrast, only $z_{e u}$ has to be inserted in the euro area output gap equation as the real exchange rate gap

\footnotetext{
${ }^{7}$ In a future version of the model, we plan to use a weighted average of lagged and contemporaneous foreign output gaps in the domestic output gap equation.
} 
vis-à-vis the US dollar. In the US output gap equation, one can either use the simple $\mathrm{z}$ variables and expect $\beta_{u s, 4}$ to be negative, or, alternatively, use the negatives of the $\mathrm{z}$ variables and expect $\beta_{u s, 4}$ to have the same positive sign as all the other $\beta_{i, 4}$ coefficients. For simplicity, we have chosen to do the latter.

Equation 14 is the inflation equation, which links inflation to its past value and its future value, the lagged output gap, the change in the effective exchange rate of the country, and a disturbance term $\left(\varepsilon^{\pi}\right) .{ }^{8}$ The size of $\lambda_{1}$ measures the relative weight of forward-looking elements and backward-looking elements in the inflation process. The backward-looking elements include direct and indirect indexation to past inflation and the proportion of price setters who base their expectations of future inflation on actual past rates of inflation. The forward-looking element relates to the proportion of price setters who base their expectations on model-consistent estimates of future inflation. The output gap is the crucial variable linking the real side of the economy to the rate of inflation.

The rate of inflation is also influenced by the change in the effective real exchange rate of country i. As in the case of the output gap equation, the treatment of exchange rate movements is somewhat complex. Since the real exchange rates are all based on the US dollar, the change in the bilateral real rate of exchange of currency i relative to currency $j$ (where neither $i$ nor $j$ is the United States) is defined as the change of currency i relative to the US dollar minus the change of currency $\mathrm{j}$ relative to the US dollar, or $\Delta Z_{i}-\Delta Z_{j}$, with a positive value being a real depreciation of currency i vis-à-vis currency $\mathrm{j}$. Where $\mathrm{j}$ is the United States, the relevant variable is $\Delta Z_{i}$. The weights on the changes in the bilateral real exchange rates are based on imports of country i from country $\mathrm{j}$ and the coefficient $\lambda_{i, 3}$ is expected to be positive. For the US inflation equation, the change in the real exchange rate variables can be entered as $\Delta Z_{i}$ and $\lambda_{u s, 3}$ would be expected to be negative, or as $-\Delta Z_{i}$, with $\lambda_{u s, 3}$ expected to be positive. We have chosen to do the latter.

$$
\pi_{i, t}=\lambda_{i, 1} \pi 4_{i, t+4}+\left(1-\lambda_{i, 1}\right) \pi 4_{i, t-1}+\lambda_{i, 2} y_{i, t-1}+\lambda_{i, 3} \sum_{j} \omega_{i, j, 3} \Delta Z_{i, j, t}-\varepsilon_{i, t}^{\pi}
$$

Equation 15 is a Taylor-type equation that determines the short-term nominal interest rate (which can be interpreted either as the policy rate, as we do in this paper for the United States, or as a

\footnotetext{
${ }^{8}$ The disturbance term is entered with a negative sign to simplify the cross correlation relationships that will be discussed later.
} 
short-term market interest rate that is closely linked to the policy rate, as we do for the other two economies). It is a function of its own lag (a smoothing device for the movement of short-term rates) and of the central bank's responses to movements of the output gap and to the deviation of the expected inflation rate from its target. More precisely, the central bank aims at achieving a measure of the equilibrium nominal interest rate over the long run (the sum of the equilibrium real interest rate and expected inflation over the four quarters starting the previous quarter), but adjusts its rate in response to deviations of the expected year-on-year rate of inflation three quarters in the future from the inflation target $\pi^{t a r}$ and to the current output gap. ${ }^{9}$ The equation also includes a disturbance term $\left(\varepsilon^{I}\right)$ to allow for central bank interest rate actions that are not exactly equal to those indicated by the equation.

$$
I_{i, t}=\left(1-\gamma_{i, 1}\right)\left[\bar{R}_{i, t}+\pi 4_{i, t+3}+\gamma_{i, 2}\left(\pi 4_{i, t+3}-\pi_{i}^{t a r}\right)+\gamma_{i, 4} y_{i, t}\right]+\gamma_{i, 1} I_{i, t-1}+\varepsilon_{i, t}^{I}
$$

Equation 16 is a version of uncovered interest parity (or UIP), in which the difference between the real exchange rate of currency $i$ and its expected value the following quarter (multiplied by 4 to transform the quarterly rate of change to an annual rate of change in order to make it comparable to the interest rate differentials) is equal to the difference between the real interest rate in country $i$ and its counterpart in the United States less the difference in the equilibrium real interest rates in the two countries. The latter is equivalent to the equilibrium risk premium. Thus, if the real interest rate in country $i$ is greater than that in the United States, this would be a reflection of one of two possibilities or a combination of the two - either the currency i real exchange rate is expected to depreciate over the coming period ( $Z^{e}$ is higher than $Z$ ), or the equilibrium real interest rates in the two countries differ because of a risk premium on yields of country $i$ assets denominated in the $\mathrm{i}$ currency. There is also a disturbance term, $\varepsilon^{Z-Z^{e}}$, in the equation. The model differs from Dornbusch's (1976) overshooting model insofar as $Z^{e}$ is not fully model consistent, being partly a function of the past levels of the real exchange rate (as shown in equation 10). Note that there are i-1 UIP equations in the model, with no such equation necessary

\footnotetext{
${ }^{9}$ The use of the rate of inflation three quarters in the future follows Orphanides (2003).
} 
in the US block of equations. ${ }^{10}$

$$
4\left(Z_{i, t+1}^{e}-Z_{i, t}\right)=\left(R_{i, t}-R_{u s, t}\right)-\left(\bar{R}_{i, t}-\bar{R}_{u s, t}\right)+\varepsilon_{i, t}^{Z-Z^{e}}
$$

Equation 17 provides a dynamic version of Okun's law where the unemployment gap is a function of its lagged value, the contemporaneous output gap and a disturbance term $\left(\varepsilon^{u}\right)$.

$$
u_{i, t}=\alpha_{i, 1} u_{i, t-1}+\alpha_{i, 2} y_{i, t}+\varepsilon_{i, t}^{u}
$$

This last equation does not play a very important role in the model but is used to help measure the output gap in real time by exploiting the correlation between changes in the output gap and contemporaneous and future changes in the unemployment gap.

\section{B.4 Cross correlations of disturbances}

The model is also able to incorporate cross correlations of error terms. There are three types of cross correlation specified in this version of the model. Other cross correlations can be entered into the model by researchers investigating certain types of shocks. The first of the cross correlations, which is used in each country model, involves a correlation between $\varepsilon^{\bar{Y}}$ and $\varepsilon^{\pi}$. This implements in the model the notion that a positive supply shock to the level of potential output puts downward pressure on costs and prices. This correlation structure is used to roughly mimic the impulse response functions (IRFs) that have been estimated in DSGE models of the US economy and provides an example of how the dynamics of smaller semi-structural models can embody some of the insights from our deeper structural models - see Juillard and others (2007, 2008).

The second of the cross correlations is applied to the Japanese and euro area economies and involves a positive correlation between $\varepsilon^{g^{\bar{Y}}}$ and $\varepsilon^{y}$. The basic idea is that a positive shock to potential output growth that is expected to persist for a considerable period of time will be associated with an increase in expected permanent income, which will raise spending by

\footnotetext{
${ }^{10}$ While the economics of the UIP equation is most easily understood as expressed in the text, the coding of the model is as follows: $\left(R_{i, t}-R_{u s, t}\right)=4\left(Z_{i, t+1}^{e}-Z_{i, t}\right)+\left(\bar{R}_{i, t}-\bar{R}_{u s, t}\right)+\varepsilon_{i, t}^{R_{i}-R_{u s}}$. The only difference between the two versions is that the impulse response function for shocks to this equation would reflect the form of the disturbance shown in this footnote, which is the negative of the disturbance shown in the text.
} 
households even before the level of potential output increases. Similarly, businesses will be motivated to increase their investment spending on the basis of the expected faster growth in potential output. Thus, aggregate demand and actual output will rise before potential output and there will be an increase in the output gap as a result of the shock to the growth rate of potential output.

The third of the cross correlations is applied to the US economy and involves a correlation between $\varepsilon^{g^{\bar{Y}}}$ and $\varepsilon_{U S}^{B L T}$. The latter is the residual from the equation for the US bank lending tightening variable that will be discussed in detail in the next section of the paper. The intuition is that a sustained increase in asset prices (which are not explicitly specified in the model) that is based upon expectations of an increase in potential output growth in the United States will result in an easing of bank lending conditions in the United States (over and above what would normally be associated with near-term expectations of the output gap). By correlating the two disturbance terms, the model may be able to capture significant shifts in market expectations of potential output growth through their effects on asset prices and BLT. And through the effect of BLT on the output gap (to be discussed shortly), such developments would result in an increase in the output gap. $^{11}$

Other possible cross correlations are based on shocks that may or may not be correlated across countries. Thus, for example, if it is believed that aggregate demand shocks tend to be country specific, there would be no correlation of the shocks in the output gap equations across countries and one can examine the impulse response functions across borders of a shock to aggregate demand in a given country by shocking the residual in the output gap equation for that country. If, on the contrary, it is believed that aggregate demand shocks are correlated across countries, one can introduce such correlations into the aggregate demand disturbances across the countries in the model. Confronting the priors with the data will allow us to determine whether the priors with respect to such correlations are consistent with the evidence, and to the extent that it is consistent, will be helpful in determining impulse response functions of shocks to aggregate demand that are common across countries. Similar cross correlations across countries are potentially relevant for shocks to interest rates, exchange rates, and other financial variables that will be discussed in future papers.

\footnotetext{
${ }^{11}$ In future versions of the model that will introduce financial variables for all the economies in the model, consideration will be given to specifying similar cross correlations for economies other than the United States.
} 


\section{Extending the Model to Include Financial-Real Linkages}

\section{A. Background}

For much of the postwar period, downturns in business cycles were precipitated mainly by increases in interest rates initiated by central banks in response to periods of excess demand that gave rise to inflation pressures. Indeed, in some countries (the United Kingdom being a prominent example), actions of the fiscal and monetary authorities were considered to have brought about a stop-go economy, in which policy switched periodically back and forth between an emphasis on unemployment and economic growth, on the one hand, and an emphasis on inflation, on the other. When the economy was weak, policy eased, giving rise to expansionary pressures. When these pressures were sufficiently strong and inflation became the overriding concern, policy was tightened so that the slowing or contraction of the economy would put downward pressure on inflation and prevent it from getting out of hand.

Such policy-induced slowdowns of the economy persisted from the 1950s into the 1990s, with virtually every downturn preceded by inflationary pressures and a resulting tightening of monetary policy. However, this central bank tightening explanation cannot account for the economic slowdown of the early part of this decade, or of the current slowdown of the US and other economies, since inflation pressures and interest rate increases were evidently not the main reason for these downturns. In the context of the apparent linkages between financial developments and the real economy, driven in part through asset price movements, attention has increasingly turned to the ways in which financial developments can affect the real economy. This interest has been aided by the development of theoretical models to describe and explain these linkages, in particular the financial accelerator mechanism. ${ }^{12}$

In our view, the more traditional types of models that allow central bank actions to play a major role in business cycle developments are still needed to explain much of the postwar period. However, the developments over the last decade or so require an extension to those models that have placed central bank actions at the center of the business cycle (and particularly for the downturns). The key factors in these most recent developments, and to a much lesser extent in

\footnotetext{
${ }^{12}$ See, for example, Bernanke and Gertler (1995). Interestingly, the perceived structural change in the way the economy operates has given rise to renewed interest in models of the business cycle from the interwar period in which real factors and financial factors other than central bank actions played a key role. See Laidler (2003).
} 
earlier developments, are the financial developments that have interacted with the real side of the economy in what has come to be called financial-real linkages.

There are many different variants of financial-real linkages. Some refer to developments in financial institutions, while others focus on developments in financial markets. Within the financial institution sector, some relate to the behavior of banks and other financial institutions in dealing with perceptions of the changing risk situation facing their customers or changing attitudes to risk on their own part, while others relate to situations in which banks' capital positions have deteriorated. In the case of financial markets, there have been cases in which liquidity has seized up and prevented potential borrowers from issuing debt, and other cases in which actual or perceived pressures on the balance sheets of lenders and/or borrowers have been the origin of the inability of the financial markets to carry out their normal intermediation functions.

These different variants can be seen in economic episodes in which the financial-real linkages made themselves felt. In normal times financial accelerators may help to explain movements in spending, but interest rate movements can typically capture most of the effects of the accelerators. It may only be in "abnormal" times that the behavior on the financial side is such as to require special treatment to pick up its effects.

What are the episodes that require special treatment? If one goes back sufficiently far into the past, one can find a number of cases. For example, the Federal Reserve Board's MPS model included a specification of financial institution behavior relating to Regulation Q in the United States, where the ceiling on deposit rates meant that financial institutions were unable to meet the demand for mortgage loans at times of high market interest rates because they were unable to raise the needed funds, and this resulted in fluctuations in the supply of mortgages and in expenditures on housing. In the case of Canada, in the early years before banks were able to raise funds through the wholesale deposit market, the Bank of Canada operated on "credit conditions". The ability of banks to extend loans was influenced by the amount of liquid assets on their balance sheet, which they could use to fund loans. The Bank of Canada's RDX2 model attempted to specify the driving factors behind these credit conditions.

Over the years, with regulatory changes (such as the elimination of regulation Q in the United States) and with the increased sophistication of ways in which banks could raise funds, banks became much less constrained in their ability to extend credit, and macro models focused on the 
role of interest rates and other factors in determining the demand for credit. But, from time to time, there were episodes in which the normal functioning of financial institutions was disrupted for some reason and the supply of bank credit (not just its demand) became an important factor in private sector expenditures. At the same time, financial markets became increasingly important both in the direct provision of credit to business and in the development of mechanisms (such as the securitization of loans) that facilitated even further the ability of financial institutions to originate the extension of credit to households and businesses. At times, there were also unusual circumstances that affected the functioning of financial markets and influenced consumption and investment expenditures on goods and services.

A listing of some of the episodes in the relatively recent past in which behavior was affected by the supply of funds to households and businesses illustrates the nature of the issue and perhaps the difficulty of finding a simple specification that would cover all the types. In the early 1990s, in the United States, banks became reluctant to provide loans following a period in which they had suffered severe losses that impaired their capital position. Chairman Greenspan referred to this as the "financial headwinds" period and the Federal Reserve responded by reducing interest rates to levels well below what would normally be needed in the circumstances.

A second episode occurred in 1998, when the near failure of LTCM and the Russian debt default caused financial markets to seize up for a short period of time, and prevented borrowers from carrying out their planned funding. For example, there were cases of real estate developers, which had been funding their activities by short-term construction loans from banks, who were unable for a short period of time to transfer these obligations into longer-term mortgages, as the typical purchasers of such mortgages were either unwilling or unable to extend such credit at a time of market difficulties.

A third episode relates to the rise and fall of the subprime mortgage market in the United States and the associated developments in derivative markets that were associated with this market. With the spread of subprime mortgages (fueled in part by unusually low interest rates and the apparent ability of lenders to transfer their exposure to others via asset-backed securities), expenditures on housing expanded. At the same time, housing prices rose sharply, and the new financial environment in which households were able to draw on the increased value of their homes via bank loans collateralized by home equity values allowed households to increase their consumption expenditures. As interest rates returned towards neutral levels, the default of many subprime mortgage borrowers, the freezing of liquidity in the asset-backed commercial paper 
market, and the associated recognition of the necessity to write down the value of many structured financial instruments (well beyond those based on subprime mortgages) resulted in a situation in which both financial institutions and financial markets faced serious problems. Many financial institutions suffered significant losses (in some cases requiring recapitalization), and in such circumstances their ability and willingness to extend loans was curtailed. And financial markets were faced with considerable uncertainty about the valuation of certain kinds of financial instruments. As well, there were lingering liquidity difficulties in certain segments of the market. The difficulties in financial markets and financial institutions showed up in the increased risk spread on issues by private sector borrowers in financial markets and in the tightening of terms and conditions on loans extended by financial institutions, as shown in the Federal Reserve's quarterly survey of senior loan officers. As a result, investment projects had more difficulty being funded than would normally have been the case.

What does this imply for macro modeling? Consider first financial accelerators. As far as financial accelerator models are concerned, there can be an endogenous element in which the business cycle leads to increases and decreases of collateral values and hence to the ability to access funding, and an exogenous element in which exogenous shocks to asset values result in changes in the ability of borrowers to obtain financing. While the former can typically be captured to a considerable extent by interest rate movements, it will be important to try to model the latter. One issue that requires careful attention in structural DSGE models is whether financial institutions ration credit on the basis of collateral values (such as maximum loan-to-value ratios) or simply tighten terms and conditions on the loans that they are prepared to extend. A second type of financial-real linkage relates to the capital position of financial institutions (most importantly banks) and how it affects the willingness of financial institutions to extend loans. A third type of linkage relates to whether financial markets are functioning normally or are facing either liquidity difficulties or problems in evaluating risks. All the episodes that were listed above and the economic behavior patterns underlying them raise the question of whether financial-real linkages should be part of the central macro model or should be modeled via satellite models. Should they feed into the forecast in normal circumstances or only in unusual episodes? And, if the latter, can they be treated as a form of regime shift?

In this and future papers, we will attempt to integrate financial-real linkages into the type of model described earlier. ${ }^{13}$ There a number of advantages to using a small model in trying to

\footnotetext{
${ }^{13}$ See Lown, Morgan, and Rohatgi (2000), Lown and Morgan (2002), Lown and Morgan (2006), Swiston (2008),
} 
understand and model the role of the linkages for macro economic behavior. First of all, the insights that have been developed in more complex DSGE and other models can be added to a well-understood macro model to see whether they aid in the explanation of macroeconomic developments and forecasting. Second, different measures can be used to see which type of proxy is most helpful in capturing the linkages. Third, the small size of the model allows for experimentation of various types. For example, should a proxy for financial-real linkages be introduced as simply an extra variable in the model that functions continuously or should it only be allowed to affect behavior when it reaches critical threshold levels of the sort that were seen in the episodes discussed above? Fourth, by allowing for persistence in real and financial shocks and in their effects on the real economy, judgmental near-term forecasts of these shocks can play an important role in model-based, medium-term projections through the setting of initial conditions. Fifth, multi-country models with financial-real linkages will allow us to see whether cross-border financial effects have played an important role in transmitting the business cycle internationally, and to assess the relative importance of real linkages and financial linkages in transmitting shocks across countries. $^{14}$

In this paper, we use only one financial variable (over and above interest rates and exchange rates), the bank lending tightening variable for the United States $\left(\mathrm{BLT}_{U S}\right)$. In future papers, we plan to examine the potential role of BLT variables in other countries and a variety of spread measures, such as bond spreads, swap spreads, and credit default swap spreads.

\section{B. Model Specification Incorporating The US Bank Lending Tightening Variable}

The financial variable $\mathrm{BLT}_{U S}$ is an unweighted average of the responses to four questions with respect to tightening terms and conditions in the Federal Reserve Board's quarterly Senior Loan Officer Opinion Survey on Bank Lending Practices. More precisely, for each of four questions on bank credit standards on loan applications, ${ }^{15}$ net tightening is equal to the sum of the percentage

and Bayoumi and Melander (2008) for earlier attempts to assess the effects of financial-real linkages.

\footnotetext{
${ }^{14}$ Bayoumi and Swiston (2007) use VARs to try to achieve the same objective.

${ }^{15}$ Question 1a on C\&I loans or credit lines to large and middle-market firms, question $1 \mathrm{~b}$ on C\&I loans or credit lines to small firms, question 8 on commercial real estate loans, and question 10 on mortgage loans to purchase homes.
} 
of banks responding "tightened considerably" and "tightened somewhat" less the sum of the percentage of banks responding "eased somewhat" and "eased considerably". These net tightening variables are each weighted by one quarter to give the overall BLT variable. It is worth noting that the net tightening responses from the survey outweigh the net easing responses on average over the sample period, indicating a bias of about $5 \%$ in the variable. See figure 1 for a comparison of the base case US output gap from the US model without BLT $_{U S}$ (Carabenciov and others, 2008a) with the results of a regression of that output gap on $\mathrm{BLT}_{U S}$ five quarters earlier.

The model with financial-real linkages makes two substantive changes to the benchmark model set out earlier. In equation 18, $\mathrm{BLT}_{U S}$ is a function of $\overline{B L T}_{U S}$, the equilibrium level of $\mathrm{BLT}_{U S}$, which itself is a random walk (equation 19), and a disturbance term, $\varepsilon_{U S}^{B L T} .{ }^{16}$

$$
\begin{gathered}
B L T_{U S, t}=\overline{B L T}_{U S, t}-\kappa_{U S} y_{U S, t+4}-\varepsilon_{U S, t}^{B L T} \\
\overline{B L T}_{U S}=\overline{B L T}_{U S, t-1}+\varepsilon_{U S, t}^{\overline{B L T}}
\end{gathered}
$$

As shown in equation 18, banks are assumed to tighten or ease their lending practices in part depending on their view of the expected behavior of the economy 4 quarters ahead. That is, if the output gap is assumed to be positive (a strong economy), there will be a tendency to ease lending conditions, while if it is assumed to be negative (a weak economy), there will be a tendency to tighten lending conditions.

In equation 20, the output gap is explained by the same variables as in the US version of equation 13 (a lead and lag of the output gap, the real interest rate gap, the foreign activity gap and the effective exchange rate gap), as well as by $\eta_{U S}$, a distributed lag of $\varepsilon_{U S}^{B L T}$. Thus, if lending conditions are easier than might have been anticipated on the basis of expectations of future economic behavior (positive $\varepsilon_{U S}^{B L T}$ ), the effect will be a larger output gap and a stronger economy.

$$
\begin{aligned}
y_{U S, t}= & \beta_{U S, 1} y_{U S, t-1}+\beta_{U S, 2} y_{U S, t+1}-\beta_{U S, 3} r_{U S, t-1}+\beta_{U S, 4} \sum_{j} \omega_{U S, 4, j}\left(-z_{j, U S, t-1}\right) \\
& +\beta_{U S, 5} \sum_{j} \omega_{U S, j, 5} y_{j, t-1}+\theta_{U S} \eta_{U S, t}+\varepsilon_{U S, t}^{y}
\end{aligned}
$$

\footnotetext{
${ }^{16}$ The disturbance term is entered with a negative sign to simplify the cross correlations.
} 


$$
\begin{aligned}
\eta_{U S, t}= & 0.04 \varepsilon_{U S . t-1}^{B L T}+0.08 \varepsilon_{U S, t-2}^{B L T}+0.12 \varepsilon_{U S, t-3}^{B L T}+0.16 \varepsilon_{U S, t-4}^{B L T}+0.20 \varepsilon_{U S, t-5}^{B L T}+0.16 \varepsilon_{U S, t}^{B L T}\left(2_{6} 1\right) \\
& +0.12 \varepsilon_{U S, t-7}^{B L T}+0.08 \varepsilon_{U S, t-8}^{B L T}+0.04 \varepsilon_{U S, t-9}^{B L T}
\end{aligned}
$$

The values of the coefficients imposed in equation 21 are intended to reflect a pattern in which an increase of $\varepsilon_{U S}^{B L T}$ (an easing of the bank lending conditions variable) is expected to positively affect spending by firms and households in a hump-shaped fashion, with an initial buildup and then a gradual rundown of the effects.

There are two ways of thinking about the way that the $\varepsilon_{U S}^{B L T}$ variable functions in the model. In the first, this proxy variable for financial tightening can be thought of as capturing the exogenous element in bank lending that has the potential to set in motion a weakening or strengthening economic situation. That is, those responsible for bank lending look forward to economic conditions about a year in the future and tighten or loosen in part on the basis of their expectations. If their actions are typical for the stage of the cycle, the interest rate variable itself may pick up the normal tightening and easing of terms and conditions on bank lending, and BLT would play little role in driving future economic developments. If, on the other hand, their actions are greater or less than is typical in light of the expected economic situation, this could have a direct effect on the ability of borrowers to access funds and to make expenditures. A second interpretation puts less emphasis on the direct effects on expenditures of the tightening or easing of bank lending conditions. Rather, from this perspective, one can consider the $\varepsilon_{U S}^{B L T}$ variable as reflecting the views of experts on the lending side of the economy with respect to future economic and financial conditions and thereby functioning as a very useful leading indicator of economic developments.

There are a number of issues surrounding this variable. First, in the interpretation that focuses on the exogenous part of this variable, it is assumed that the part of financial-real linkages that propagates other typical shocks to the system is captured by the interest rate. This is not an unreasonable assumption, since the endogenous part of the financial accelerator mechanism intensifies the effects on the economy of other shocks and, in a macro sense, could be thought of as simply increasing the coefficient on the interest rate variable. Second, there could be an asymmetry between positive and negative shocks to $\mathrm{BLT}_{U S}$. While financial conditions that are tighter than typical will have the effect of preventing liquidity-constrained households and businesses from achieving their desired expenditures, beyond a certain point the easing of financial conditions may be less powerful in leading to increased spending. That is, once there is 
sufficient collateral to satisfy lenders of the safety of their loans, a further increase in the value of the collateral may not affect their behavior very much. ${ }^{17}$ Third, it is possible that small changes in financial conditions will have relatively minor effects, and only changes beyond a certain critical threshold will have the capacity to bring about economically significant changes. Fourth, given the complexity of the financial-real linkages in the economy, BLT $_{U S}$ may not be able to capture all of these types of linkages, and other variables (such as risk spreads) will be introduced into the output gap equations in future papers to try to pick up some of the other effects.

\section{Extending the Model to Include Oil Prices}

\section{A. Background}

Movements in the real price of oil have played an important role in macroeconomic developments since the early 1970s. Driven by both fundamental economic developments as well as, at times, by political factors, there have been sharp increases and decreases in real oil prices over the last 35 years. (See figure 2.) These in turn have had significant effects on output and measured inflation, and possibly on potential output growth. Moreover, depending on whether the central bank reacted with sufficient vigor to the inflationary impact of oil price increases, they have in some cases triggered much wider inflationary pressures. Thus, while demand pressures in the early 1970s played an important role in the oil price increases, in many countries the latter triggered an increase in the headline rate of inflation, and in combination with central bank actions that focused more on supporting the weaker economy than on combating the spread of inflation expectations, contributed to the Great Inflation of the 1970s.

The most recent surge in oil prices has been driven, in the view of most observers, largely by fundamental factors. The most important demand considerations related to the rapid growth and expected future rapid growth in China, India, and other emerging economies, while the most important supply considerations related to concerns about the ability of the industry to increase output over time, particularly if global oil production was viewed as reaching its "peak" in the next few years. Also, exploration in both conventional and nonconventional energy sources in some countries may have been hampered by concerns about the treatment over the long term of

\footnotetext{
${ }^{17}$ It could, however, affect borrower behavior.
} 
foreign investment. There have also been shorter-term pressures on oil prices, as markets were concerned about the effect on production in some countries of current or future military activities.

The next section of this study sets out a small, very basic model of oil prices and the way that oil price movements affect potential output and inflation. A future version of the model will incorporate a more sophisticated version of the determination of the real price of oil, with equations for oil production and oil consumption by regions. In addition, the model will take into account the long lead times needed to increase capacity in the oil sector and the adjustment costs of increasing production from existing sources. By distinguishing between oil-exporting countries or regions and oil-importing countries or regions, this future version of the model will allow us to examine the way in which different kinds of shocks that influence the real price of oil affect the world economy. It will also allow us to incorporate feedback effects, such as the increase in imports by oil exporters of nonenergy goods and services from other countries following an increase in the price of oil. The size of such an increase will depend in part on decisions in oil-exporting countries as to the extent that increased revenues will be saved, perhaps in the form of financial investments by a sovereign wealth fund.

\section{B. Model Specification Incorporating Oil Prices}

The block of equations 22 through 28 determines the level and rate of change of real oil prices denominated in the currencies of the various countries included in the model. In the subsequent equations 29 and 30, changes in the rate of inflation in real oil prices lead to changes in the level of potential output and in the headline rate of inflation.

In equation 22, the log of the equilibrium real price of oil in US dollar terms, $\overline{R P O I L}_{U S}$, is defined as its own lagged value plus the growth in the real price of oil in US dollar terms, $g_{U S}^{\overline{R P O I L}}$, plus a disturbance term, $\varepsilon_{U S}^{\overline{R P O I L}}$ that reflects shocks to the level of real oil prices in US dollar terms.

$$
\overline{\operatorname{RPOIL}}_{U S, t}=\overline{\operatorname{RPOIL}}_{U S, t-1}+g_{U S, t}^{\overline{R P I L}}+\varepsilon_{U S, t}^{\overline{R P I L}}
$$

The growth rate in real US dollar oil prices is shown in equation 23 as equal to lagged growth plus a disturbance term, $\varepsilon_{U S}^{g^{\overline{R P O I L}}}$, that reflects shocks to the growth rate.

$$
g_{U S, t}^{\overline{R P I L}}=\left(1-\rho_{g, U S}\right) g_{U S, t-1}^{\overline{R P I L}}+\varepsilon_{U S, t}^{g^{\overline{R P I L}}}
$$


Equation 24 defines the log of the level of real oil prices, $R P O I L_{U S}$, as the sum of the $\log$ of the equilibrium level of real oil prices and the gap between the level of real prices and its equilibrium value, rpoil $_{U S}$ (in the deviation in the log level, which is approximately equal to the percentage deviation).

$$
R P O I L_{U S, t}=\overline{\operatorname{RPOIL}}_{U S, t}+\operatorname{rpoil}_{U S, t}
$$

In equation 25, this gap between the level of the real oil price and its equilibrium value is a function of its own lagged value and the disturbance term $\varepsilon_{U S}^{r p o i l}$.

$$
\text { rpoil }_{U S, t}=\rho_{\text {rpoil,us }} \text { rpoil }_{U S, t-1}+\varepsilon_{U S, t}^{\text {rpoil }}
$$

Equation 26 defines the rate of inflation in US dollar real oil prices, $\pi_{U S, t}^{R P I L}$, as equal to the first difference in the log of the level of real oil prices multiplied by 4 to annualize the quarterly inflation rate.

$$
\pi_{U S, t}^{R P I L}=4\left(R P O I L_{U S, t}-R P O I L_{U S, t-1}\right)
$$

Equation 27 defines the log of the nominal US dollar price of oil as equal to the log of the real US dollar price of oil plus the log of the US CPI, $P_{U S}$.

$$
P O I L_{U S, t}=R P O I L_{U S, t}+\log P_{U S, t}
$$

Finally. equation 28 defines the rate of inflation of real oil prices denominated in the currency country $\mathrm{i}, \pi_{i}^{R P O I L}$, as the US dollar rate of inflation in real oil prices plus 4 times the first difference in the log of the real rate of exchange between currency $i$ and the US dollar.

$$
\pi_{i, t}^{R P O I L}=\pi_{U S, t}^{R P I L}+4\left(Z_{i, t}-Z_{i, t-1}\right)
$$

The effects of changes in the real price of oil and the various currencies in potential output and the overall or headline read inflation are shown in equations 29 and 30. In equation 29, the level of potential output in country $\mathrm{i}, \bar{Y}_{i}$ (where i can be the United States, the euro area or Japan), is equal to the sum of its lagged value, the growth rate in its potential output, a function of the average quarterly rate of inflation in real oil prices denominated in the currency of country $i$, and a disturbance term, $\varepsilon_{i}^{\bar{Y}}$. Thus, the higher inflation in real oil prices results in a permanent decline in the level of potential output. Or, to put it slightly differently, the level of potential output in any 
country is inversely related to the level of real oil prices in that country.

$$
\bar{Y}_{i, t}=\bar{Y}_{i, t-1}+g_{i, t}^{\bar{Y}} / 4-\sigma_{i}\left(\sum_{j=0}^{3} \pi_{i, t-j}^{R P O I L}\right)+\varepsilon_{i, t}^{\bar{Y}}
$$

Equation 30 shows that the rate of inflation in country $i$ (where i can be the United States, the euro area or Japan) is equal to the weighted average of the lead and the lag of inflation, the output gap in that country, the change in the real exchange rate, ${ }^{18}$ and the current and lagged rate of inflation in the real price of oil denominated in the currency of country $i$. The higher is the rate of increase in the real price of oil, the higher is the overall rate of inflation.

$\pi_{i, t}=\lambda_{i, 1} \pi 4_{i, t+4}+\left(1-\lambda_{i, 1}\right) \pi 4_{i, t-1}+\lambda_{i, 2} y_{i, t-1}+\lambda_{i, 3} \sum_{j} \omega_{i, j, 3} \Delta Z_{i, j, t}++v_{i, 1} \pi_{i, t}^{R P O I L}+v_{i, 2} \pi_{i, t-1}^{R P O I L}-\varepsilon_{i, t}^{\pi}$

In short, increases in real oil prices are a particularly unfavorable form of supply shock, in that they put upward pressure on the overall rate of inflation and downward pressure on output. But they are even more difficult to cope with than simple supply shocks since they affect the level of potential output and not just the level of actual output.

\section{Confronting the Model with the Data}

\section{A. Bayesian Estimation}

Bayesian estimation provides a middle ground between classical estimation and the calibration of macro models. The use of classical estimation in a situation of a relatively small sample size (which is almost always the case for time series data) often gives model results that are strange, and are inconsistent with the views of macroeconomists as to the functioning of the economy. This problem is accentuated by the simultaneity challenges to macro models, which are not handled well by simultaneous equation methods in small samples. For example, because an aggregate demand shock can lead to persistent inflationary pressures and to central bank actions to raise interest rates to offset the shock, classically estimated models using time series data will

\footnotetext{
${ }^{18}$ As discussed earlier, the specification of the change in real exchange rates differs in the United States from that in other countries. See the discussions preceding equation 14.
} 
sometimes show an increase in interest rates leading to an increase in inflation. This is particularly problematic when the model is to be used for policy simulations, since it may well indicate the need for an interest rate decline to slow the rate of inflation.

Models with calibrated parameters avoid this problem, but are often criticized as representing no more than the modelers' judgment, which may or may not be consistent with the data. While calibration is typically based on the understanding of experts of the functioning of the economy, the desire to confront the model with the data in a statistical sense has led researchers to use Bayesian estimation techniques to estimate models.

The Bayesian approach has the benefit of putting some weight on the priors of the researchers and some weight on the data over the sample period. By changing the specification of the tightness (e.g., the standard deviation) of the distribution on the priors, the researcher can change the relative weights on the priors and the data in determining the posterior distribution for the parameters. In the limit, a diffuse or noninformative distribution puts more weight on the data while a distribution with a very tight prior distribution (e.g., a small standard deviation) puts more weight on the priors.

There are a number of criteria by which researchers evaluate the success of Bayesian estimated models and decide between models with different weights placed on priors and the data. First, if an estimated model yields coefficients that are close to the priors in spite of allowing considerable weight to be placed on the data, this indicates that the priors are not inconsistent with the data. A second criterion involves seeing whether the impulse response functions (IRFs) from the model estimated with Bayesian techniques are compatible with the views of the researchers (and in the case of models built at central banks with the views of the management of the central bank) with respect to the functioning of the economy in response to shocks. Third, in comparing different variants of a given macro model (for example, one that treats shocks to output as largely demand determined and another that treats shocks as largely supply determined), researchers can use the relative magnitudes of the log data density and root mean squared errors (RMSEs) as indications of which model is more consistent with the data. And, fourth, the plausibility of the variance decomposition of the variables in the model can help to indicate whether the model is sensible. ${ }^{19}$

\footnotetext{
${ }^{19}$ For example, in a two country model, if the variance decomposition showed that a shock to the output gap equation of the large country had a smaller effect on the output gap of the small country than the reverse, considerable doubt would be thrown on the validity or usefulness of the model results.
} 
Bayesian estimated models are likely to have better model properties than classically estimated models, but may sometimes not fit the data as well as simple VAR models, since the sole purpose of the latter is to maximize fit. It is the combination of reasonable fit, appropriate structural results from a theoretical perspective, and the ability to give sensible results for policy simulations that gives estimated Bayesian models their strength. Also, the use of such models along with judgmental inputs for the first two quarters of the forecast period is likely to give better and more sensible forecasting results than most other models. A comparison of Bayesian-estimated Global Projection Models with competitor global models will be presented in one of the future papers in this series.

\section{B. Results}

\section{B.1 Estimates of coefficients}

The model is estimated over the sample period 1994Q1 to 2008Q1. Tables 1 through 3 set out estimation results for the parameters for the three countries in this version of the model, showing the distribution used in the estimation, the prior mean, the prior standard deviation, the posterior mode, and the posterior standard deviation.

Beginning with the output gap equations, we find that while all three economies have much more weight on the backward-looking component, $\beta_{1}$, than on the forward-looking component, $\beta_{2}$, the euro area economy has considerably more weight on the backward-looking component than do the other two economies. Also, the sum of the coefficients on the backward-looking component and the forward-looking component is appreciably higher in the euro area economy than in the other two economies. The Japanese economy has a somewhat weaker coefficient on the real interest rate gap, $\beta_{3}$, than the other two economies. The posterior estimates of the coefficient on the real exchange rate gap, $\beta_{4}$, are about the same for all three economies, a very different outcome than would have been expected on the basis of the prior estimates. In contrast, the coefficients on the activity variable, $\beta_{5}$, are in line with the priors, with the US coefficient being smaller than the Japanese coefficient, which in turn is smaller than that of the euro area. This result is consistent with the relative openness of the respective economies. The response of US output gap to unexpected tightening in BLT, $\theta_{u s}$, is somewhat higher than anticipated.

Turning to the inflation equations, we see that all three economies are more forward looking than 
assumed by the priors, $\lambda_{1}$, while the effect of the output gap on inflation in each country, $\lambda_{2}$, is somewhat smaller than assumed by the priors. And the effect of exchange rate changes on inflation, $\lambda_{3}$, is much smaller than anticipated in all three economies.

In the interest rate reaction functions, the smoothing coefficient, $\gamma_{1}$, is larger than anticipated in all three economies, especially in Japan with a posterior estimate close to unity. The response to deviations of inflation from target, $\gamma_{2}$, is lower than anticipated in all three economies. ${ }^{20}$ The coefficients on the output gap, $\gamma_{4}$, are about as expected for all three economies.

The effect of real oil price inflation on potential output, $\sigma$, is very much in line with the prior expectations, with the effect in the United States being significantly higher than that in the euro area and Japan. Similarly, the effect of real oil price inflation on overall inflation, $v_{1}$ plus $v_{2}$, is highest in the United States and lowest in Japan.

There are a number of other results of interest. In all three economies, the response of the unemployment gap to the output gap, or the Okun coefficient, $\alpha_{2}$, is much smaller than anticipated. Also, in all three economies, the persistence of growth in the NAIRU to shocks, (1$\alpha_{3}$ ), is greater than anticipated. This is also the case for persistence of growth in potential output to shocks, $(1-\tau)$. Indeed, in all three economies the latter coefficient is close to unity. Similarly, the persistence of the equilibrium real interest rate to shocks, $(1-\rho)$, is much higher than anticipated in the United States, although not in the other two economies. Finally, the expected real exchange rate is very forward looking, $\phi$, for both the euro and the yen.

\section{B.2 Estimates of standard deviation of structural shocks and cross correlations}

Table 4 presents the same information for the standard deviation of the structural shocks, making use of more diffuse priors. Table 5 does the same for the cross correlations in the model. Given that the priors for the estimates of the standard deviation of the structural shocks and for the cross correlations are held with much less confidence than the priors for the coefficients, it is not surprising that the posterior results differ more from the priors than was the case for the coefficients. Particularly worth noting are the much higher posteriors than expected for the

\footnotetext{
${ }^{20}$ Note, however, that because of the specification of the equation, the response of interest rates to an increase in forecast inflation, $\pi 4_{i, t+3}$, is $\gamma_{2}$ plus 1 . The stability requirement that the response of the rate of interest to an increase in the rate of inflation must exceed unity is easily met in all three economies.
} 
standard deviations of the $\mathrm{BLT}_{U S}$ shock, the equilibrium real exchange rate shocks, the inflation shocks for all three economies, and the shock to equilibrium real interest rates in the United States. There were also a number of much lower than expected posteriors for the standard deviations of shocks, including the shocks in the two UIP equations, and the shocks to the equations for the unemployment rate gap, NAIRU, and NAIRU growth in all three economies. These results indicate that, compared to prior expectations, there is considerably less uncertainty about the shock terms pertaining to unemployment and UIP, and considerably more about the shock terms pertaining to real exchange rates and inflation.

As shown in Table 5, the posterior results for the three types of cross correlations are all in line with their priors.

\section{B.3 RMSES}

Table 6 presents the model's RMSEs for the United States, the euro area, and Japan, which are based on the intra-sample forecasts without any judgmental input. By and large, the euro area shows the greatest stability (smallest RMSE) of the three economies.

\section{B.4 Impulse response functions}

Figures 3 through 25 present a selection of the model's most important impulse response functions, which show reasonable and expected patterns. The first set of figures -3 through $11-$ show the effects of demand shocks in the United States, the euro area, and Japan. Demand shocks to the US economy result in the expected increase in US output, inflation and nominal and real interest rates, declines in US unemployment and in the effective real exchange rate (i.e., an appreciation in the US dollar), and an initial easing of the bank lending tightening variable in the United States. By and large, the shock to US demand has qualitatively similar, but quantitatively smaller, effects in the euro area and Japan, with one obvious exception, i.e., that the effective real exchange rate depreciates in the other economies. It should also be noted that, quantitatively, the effects of the US demand shock on the euro area economy are typically somewhat larger than those on the Japanese economy, and that the relative size of the effects in Japan and especially in the euro area compared to those in the United States are larger for financial variables than for non-financial variables. 
Demand shocks in the euro area have similar effects on output and unemployment in the euro area economy as the corresponding shocks in the United States have on the US economy. However, the inflation effects, the interest rate response and the exchange rate response are all larger in the euro area than in the United States. In the case of a Japanese demand shock, the effects on output, inflation and interest rates in Japan are similar to those in the United States from a US demand shock, while the effects on unemployment are smaller and the effects on the real interest rate are larger. For the most part, the spillover effects from a euro area shock to the United States and Japan are very similar to those from the United States to the euro area and Japan. Similar, although smaller, responses can be seen in the spillover effects of demand shocks in Japan.

Figures 12 through 14 show the effect of a shock to the BLT $_{U S}$ variable on the key variables in the three economies. An easing in bank lending tightening in the United States results in a considerably stronger US economy and qualitatively similar effects in the euro area and Japan that are about one fourth the size of those in the United States for output and a somewhat higher ratio for inflation.

Figures 15 through 17 set out the results of a shock to potential output growth in the United States. The shock to potential output growth is accompanied by an increase in the output gap because of the cross correlation between the shock to potential output growth and that to the bank lending tightening variable. As discussed earlier, a positive shock to potential output growth that is expected to persist for a considerable period of time may be associated with an easing in bank lending tightening (along with an increase in implicit increase in asset prices). The easing in bank lending tightening results in an increase in the output gap and output growth, a reduction in the unemployment gap, a rise in inflation, an increase in nominal and real interest rates, and an appreciation of the real exchange rate. The spillover to the euro area and Japan involves qualitatively similar, but quantitatively smaller, effects, with the exception of the depreciation of the exchange rate in the two overseas economies. Comparing the effects of the shock to potential output with the shocks to the output gap, one sees that the former gives rise to more persistence, more cumulative output growth and inflation, and larger movements in interest rates and the exchange rate.

Figures 18 through 25 show the results of two types of oil price shock, the first a temporary shock to the growth rate of oil prices denominated in US dollars $\left(\varepsilon_{U S, t}^{g^{\overline{R P I L}}}\right)$ and the second a permanent shock to the equilibrium level of oil prices denominated in US dollars $\left(\varepsilon_{U S, t}^{\overline{R P I L}}\right)$. Both result in a permanent effect on oil prices and have very similar results qualitatively on the three economies. 
The quantitative differences arise from the fact that the first shock leads to a larger increase in the equilibrium level of real oil prices than the second shock, because there is some persistence to the growth rate of oil prices following the initial shock. The shocks result in an initial short-lived increase in the output gap of the three economies, followed by a longer period of negative output gap, a fairly extended period of higher inflation, an increase in interest rates, and a tightening in the $\mathrm{BLT}_{U S}$ variable. Quantitatively, the effects of the oil price movement are largest in the United States and smallest in Japan. This is primarily because the estimated coefficients for the effects of oil price movements on equilibrium output and inflation are higher in the United States than in the other economies, and secondarily because the movement in $\mathrm{BLT}_{U S}$ affects the US economy more than the others. The real exchange rate appreciates in the United States and Japan but depreciates in the euro area. This result should not be taken at face value because the model includes only oil importing countries and does not capture the important shifts in the equilibrium exchange rate between oil exporters and oil importers. ${ }^{21}$

\section{Forecasting with Bayesian Estimates}

There are various ways in which models can be used for out-of-sample forecasting in central banks. The simplest, but least useful, way involves allowing the model to forecast the next few quarters by itself, without any judgmental input. These are typically called unconditional forecasts. A much more sophisticated approach to forecasting, of the sort that is used in central banks and the IMF, makes use of the judgment of country experts to forecast the endogenous variables in the model for the first two quarters or so, and are called conditional forecasts. The basic notion is that these very short-term forecasts (or "nowcasts" as they are sometimes called) are dependent not only on the basic driving forces of the economy but also on many special factors. The influence of such factors is typically not included in basic macro models but is part of the knowledge base of the specialists working in such institutions. As a result, it is very likely that these experts can outperform any model in near-term forecasting, and in this way they can establish a good starting point for the model in forecasting over the medium term, the period when the underlying driving forces of the economy become more important than special factors. In the rest of this section, we provide an illustrative example of a conditional forecast to show the way in which judgmental information can be introduced into the first two or three quarters of the

\footnotetext{
${ }^{21}$ The future extension of the model to more countries and more regions will allow us to capture such effects.
} 
projection (by "tuning" the model in those quarters), following which the model is allowed to determine the forecast for the rest of the projection period. ${ }^{22}$ We also compare the results of this conditional forecast with those of an almost-unconditional forecast (henceforward to be called the unconditional forecast), in which all the endogenous variables are determined by the model except for oil prices in U.S. dollars, which are based on the futures market for the entire projection period. The projection of oil prices in the conditional forecast is also based on the futures market.

Figure 26 presents the summary results of the conditional forecast and a comparison with the unconditional forecast, while figures 27,28 and 29 provide more detailed information for the United States, the euro area and Japan. Oil prices are based on futures market data for July 18, 2008 for both the conditional and unconditional forecasts. All the other actual data for the unconditional forecasts are based on information available for 2008Q1. The same is true for the actual data for the conditional forecasts, with the following exceptions. Actual data for 2008Q2 are used for the short-term interest rates in all three countries, the two bilateral exchange rates, the US unemployment rate, and the bank lending tightening variable. All the figures in the tables present the central forecast along with $30 \%, 50 \%, 70 \%$ and $95 \%$ confidence intervals, the latter reflecting two standard deviations from the central case. ${ }^{23}$ These confidence intervals give some indication of the degree of confidence that can be placed in the forecast of the different variables and the range within which one would expect the different variables to fall. The figures also show the unconditional forecasts (the dashed line), thereby allowing us to assess the effect of using actual data (where available) and judgmental inputs for two or three quarters in the conditional forecasts. Similar information with respect to the difference between the conditional and unconditional forecasts is provided in square brackets in the bottom half of each table.

Let us begin our analysis of the conditional forecast with the US economy. Judgment is provided for quarterly real GDP growth for 2008Q2 and Q3. The strength in Q2 is largely a result of the effect of the rebate cheques on household expenditures, along with some unexpected strength in nonresidential construction, the combination of which helped to offset the weakness in residential

\footnotetext{
${ }^{22}$ Note that this forecast is not an official forecast of the IMF or of the Bank of Russia, but rather is provided solely for illustrative purposes.

${ }^{23}$ The standard production version of the model that has been used in preparing this paper is linear and does not put any non-negativity restrictions on nominal interest rates, with the result that the forecast nominal interest rate does at times become negative in the lower confidence intervals. An alternative, non-linear procedure has been developed that prevents interest rates from becoming negative, but use of this procedure is very time consuming. See Chen and others (2008).
} 
construction. Net exports are also expected to provide support to aggregate demand in Q2. The relatively weak real output growth in the subsequent three quarters suggests that the strength in Q2 involved some borrowing from future spending. There is no judgmental input into potential GDP growth, which declines through much of 2008 and 2009 because of the impact of tightening in the BLT variable on potential output growth, as both respond to the sustained decrease in asset prices. Potential output growth returns to its steady-state rate of about $2.5 \%$ in 2010 and thereafter. Judgment was used to increase total CPI inflation in Q2, Q3, and Q4. The strong positive judgment in the conditional forecast for CPI inflation is partly related to the sharp increase in oil prices over the preceding period in two ways. First, margins in the retail price of oil had declined over the earlier period as it takes some time to pass on increases in the price of crude oil, and they were likely to be restored in the rest of 2008. Second, there has been a tendency to underestimate the response of retail energy prices to increases in crude oil prices, based on a historical relationship in which specific taxes on energy were a much higher proportion of total retail prices than is the case at present. Moreover, sharp increases in producers prices in food, energy and other commodities indicated significant upward pressure on the total CPI. The output gap, which involves no judgmental input, troughs in 2009 and remains negative in 2010, thereby providing downward pressure on the rate of inflation as oil prices stop rising, although they remain at a high level. Finally, the increase in the short-term interest rate in the United States in Q3 is based on market sentiment that anticipates a one-time increase in the policy interest rate. Interest rates remain below equilibrium for a couple of years, as the monetary authorities provide stimulus to a relatively weak economy in the context of forecast declining inflation.

Turning to the euro area and Japan, there is a sharper decline in quarterly real GDP growth in Q2 than in the United States, partly because of the fiscal support in the United States in Q2, and perhaps partly because of the leap year effect in Q1 in Japan. While euro area inflation is high through 2008 (although less than in the United States), Japanese inflation remains considerably lower. This difference is somewhat surprising in the light of the greater appreciation of the currency in the euro area and the similarity in the path of the output gap. Euro area interest rates remain high in 2008 in the face of continuing relatively high inflation, while Japanese interest rates move up very gradually through the year. The cyclical movements of the euro area economy and especially those of the Japanese economy are somewhat more muted than those of the US economy. As was apparent in the impulse response functions to shocks to oil prices and the $\mathrm{BLT}_{U S}$ variable, the US economy is more sensitive to movements in oil prices and US bank lending tightening than are the other two economies. 
Actual forecasts in policymaking institutions reflect a combination of judgment by experts, particularly for the near term, and the model dynamics for the medium term. The results of this section of the paper indicate how such forecasts can be affected by the judgmental projection of the exogenous variables and the tuning of endogenous variables. Typically, this judgment reflects a much more detailed understanding of the various sectors of the economy based on earlier empirical work, recent data, and anecdotal information than can be captured in a small macro model. And the difference between the conditional forecast and the unconditional forecast shows the extent to which the judgments are affecting the forecast results. The model itself imposes consistency on the forecast in the medium term and long term.

\section{Concluding Remarks}

This is the third of a series of papers that are being written as part of a larger project to estimate a small quarterly Global Projection Model (GPM). The GPM project is designed to improve the toolkit to which economists have access for studying both own-country and cross-country macro linkages and financial-real linkages. In this paper, we developed a small quarterly projection model of three economies (United States, euro area, and Japan) in which the key variables were output gaps, unemployment gaps, inflation rates, short-term interest rates, and exchange rates. We

also introduced a financial variable (in the form of a US bank lending tightening variable) into the model to allow for financial-real linkages and a block of equations for the oil price sector. The model was estimated with Bayesian techniques, which provide a very efficient way of imposing restrictions to produce both plausible dynamics and sensible forecasting properties. An important advantage of these techniques is that they allow researchers to estimate models with flexible stochastic processes, which can provide timely and more efficient model-consistent measures of potential output and other latent variables in the system. After presenting the posterior estimates, impulse response functions, and RMSEs for intra-sample forecasts, we showed how the model can be used to construct efficient baseline out-of-sample forecasts that incorporate judgment imposed on the near-term outlook.

The next phases of the project will be to develop a more sophisticated model of the oil market, to expand the model to include financial variables in other countries, and to build a global version of the model (with several countries and a residual economy) and use it to assess whether spillovers across countries are generated more through financial linkages than through conventional trade 
linkages. It can also be used to compare forecasting results with those of competitor models of the global economy. 


\section{References}

Argov, E., N. Epstein, P. Karam, D. Laxton, and D. Rose, 2007, “Endogenous Monetary Policy Credibility in a Small Macro Model of Israel,’ IMF Working Paper 07/207 (August), available at www.imf.org.

Bayoumi, T. and A. Swiston, 2007, "Foreign Entanglements: Estimating the Source and Size of Spillovers Across Industrial Countries,” IMF Working Paper No. 07/182 (July), available at www.imf.org.

Bayoumi, T. and O. Melander, 2008, “Credit Matters: Empirical Evidence on U.S. Macro-Financial Linkages,” IMF Working Paper No. 08/169 (July), available at www.imf.org.

Berg, A., P. Karam, and D. Laxton, 2006a, “A Practical Model-Based Approach to Monetary Policy Analysis - Overview,” IMF Working Paper 06/080 (April), available at www.imf.org.

Berg, A., P. Karam, and D. Laxton, 2006b, "Practical Model-Based Monetary Policy Analysis-A How-to Guide,” IMF Working Paper 06/081 (April), available at www.imf.org.

Bernanke, B. S. and M. Gertler, 1995, "Inside the Black Box: The Credit Channel of Monetary Policy Transmission," Journal of Economic Perspectives (Fall), 27-48.

Botman, D., P. Karam, D. Laxton, and D. Rose, 2007, "DSGE Modeling at the Fund: Applications and Further Developments," IMF Working Paper 07/200 (August), available at www.imf.org.

Carabenciov, I., I. Ermolaev, C. Freedman, M. Juillard, O. Kamenik, D. Korshunov and D. Laxton, 2008a, "A small quarterly projection model of the US economy," IMF Working Paper, forthcoming.

Carabenciov, I., I. Ermolaev, C. Freedman, M. Juillard, O. Kamenik, D. Korshunov, D. Laxton, and J. Laxton, 2008b, “A small quarterly multi-country projection model,” IMF Working Paper, forthcoming. 
Chen, H., K. Clinton, O. Kamenik, and D. Laxton, 2008, “Constructing Forecast Confidence Bands with GPM, IMF Working Paper, forthcoming.

Coats, W., D. Laxton and D. Rose, 2003, The Czech National Bank's Forecasting and Policy Analysis System. Prague, Czech Republic: Czech National Bank.

Dornbusch, R., 1976, “Expectations and Exchange Rate Dynamics,” Journal of Political Economy, December, 1161-76.

Epstein, N., D. Laxton. P. Karam and D. Rose, 2006, "A Simple Forecasting and Policy Analysis System for Israel: Structure and Applications” in Israel: Selected Issues, IMF Country Report No. 06/121 (March), available at www.imf.org.

Juillard, M., O. Kamenik, M. Kumhof, and D. Laxton, 2007, "Measures of Potential Output from an Estimated DSGE Model of the United States" paper presented at a workshop on Issues in Measuring Potential Output, Ankara Turkey, January 16, 2007.

Juillard, M., O. Kamenik, D. Laxton, and M. Kumhof, 2008, “Optimal Price Setting and Inflation Inertia in a Rational Expectations Model," forthcoming in the Journal of Economic Dynamics and Control.

Laidler D., 2003, "The price level, relative prices and economic stability: aspects of the interwar debate,’ BIS Working Papers No. 136 (September), available at www.bis.org.

Lown, C., D. Morgan, and S. Rohatgi, 2000, "Listening to Loan Officers: The Impact of Commercial Credit Standards on Lending and Output," Federal Reserve Bank of New York Economic Policy Review (July), pp. 1-16.

Lown, C. and D. Morgan, 2002, “Credit Effects in the Monetary Mechanism,” Federal Reserve Bank of New York Economic Policy Review (May), pp. 217-35.

— 2006, "The Credit Cycle and the Business Cycle: New Findings Using the Loan Officer Opinion Survey,' Journal of Money, Credit, and Banking, Vol. 38 (September), pp. 1575-97.

Orphanides, A., 2003, "Historical monetary policy analysis and the Taylor rule," Journal of Monetary Economics (July), 983-1022. 
Swiston, A., 2008, “A U.S. Financial Conditions Index: Putting Credit Where Credit is Due," IMF Working Paper No. 08/161 (June), available at www.imf.org. 


\section{Appendix: GPM Data Definitions}

\begin{tabular}{|c|c|}
\hline \multicolumn{2}{|l|}{ United States } \\
\hline GDP U.S.: & Gross Domestic Product (SAAR, Bil.Chn.2000.Dollars) \\
\hline Interest rates & Federal Open Market Committee: Fed Funds Target Rate (percent) (period average) \\
\hline CPI U.S.: & Consumer Price Index (SA, 1982-84=100) \\
\hline Core CPI & U.S.: CPI-U: All Items Less Food and Energy (SA, 1982-84=100) \\
\hline Unemployment & U.S.: Civilian Unemployment Rate (SA, percent) \\
\hline \multicolumn{2}{|l|}{ Bank lending } \\
\hline \multirow[t]{5}{*}{ tightening (BLT) } & Average of: \\
\hline & FRB Sr Officers Survey: Banks Tightening C.I Loans to Large Firms (percent) \\
\hline & FRB Sr Officers Survey: Banks Tightening C.I Loans to Small Firms (percent) \\
\hline & FRB Sr Loan Off Survey: Tightening Standards for Commercial Real Estate (percent) \\
\hline & FRB Sr Loan Survey: Res Mortgages: Net Share, Banks Tightening (Haver Est, percent) \\
\hline \multirow[t]{2}{*}{ Oil Price } & Crude Oil (petroleum), simple average of three spot prices; Dated Brent, \\
\hline & West Texas Intermediate, and the Dubai Fateh, US dollar per barrel (period average) \\
\hline \multicolumn{2}{|l|}{ Euro Area } \\
\hline GDP Euro & Area15: Gross Domestic Product (SA/WDA, Mil.Chn.00.Euros) \\
\hline Interest rates & Euro Area11-15: 3-Month EURIBOR Rate (AVG, percent) \\
\hline CPI Euro & Area15: Monetary Union Index of Consumer Prices (SA, 2005=100) \\
\hline Core CPI & Euro Area15: MUICP: Total excl Energy, Food, Alcohol and Tobacco(SA, 2005=100) \\
\hline Unemployment & Euro Area15: Unemployment Rate (SA,percent) \\
\hline Exchange Rates & Period averages; increase is depreciation \\
\hline \multicolumn{2}{|l|}{ Japan } \\
\hline GDP Japan: & Gross Domestic Product (SAAR, Bil.Chn.2000.Yen) \\
\hline Interest rates & Japan: Call Rate: Uncollateralized 3-Month (EOP, percent) \\
\hline CPI Japan: & Consumer Price Index (SA, 2005=100) \\
\hline Core CPI & Japan: CPI: All Items excluding Food and Energy (SA, 2005=100) \\
\hline Unemployment & Japan: Unemployment Rate (SA, percent) \\
\hline Exchange Rates & Period averages; increase is depreciation \\
\hline
\end{tabular}

Real Effective

Exchange Rates Weighted averages of the bilateral exchange rates.

Weights are based on bilateral trade data from IMF Direction of Trade database (2006).

The rates in the inflation equations are defined with import weights, while the rates

in the output gap equations use total trade (imports+exports) weights.

Foreign Outp. Gaps Weighted averages of the lagged foreign output gaps.

Weights are based on bilateral trade data (exports) from IMF Direction of Trade db (2006). 
Figure 1: Comparison between Output Gap and BLT indicator

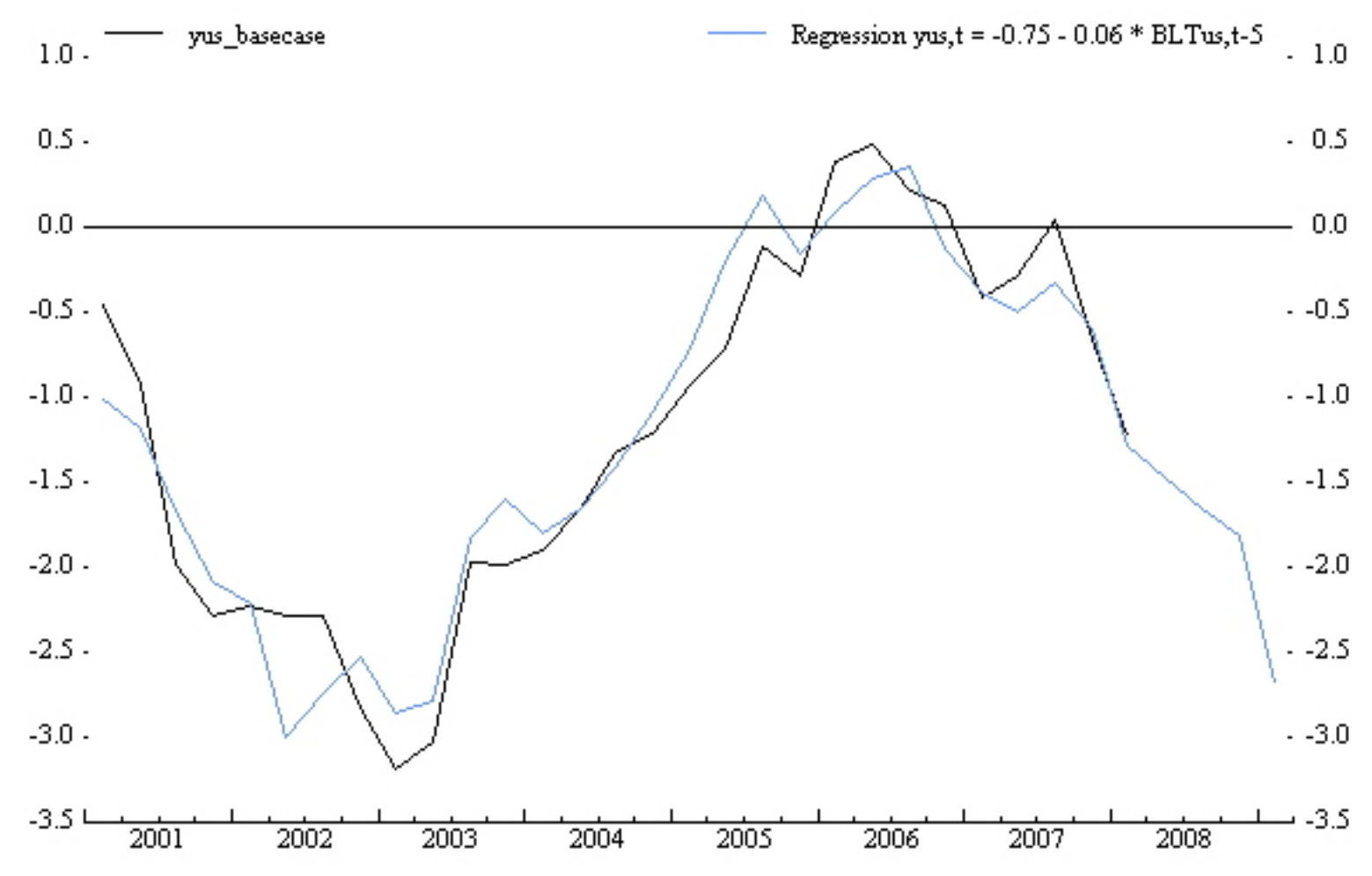


Figure 2: Real Oil Price

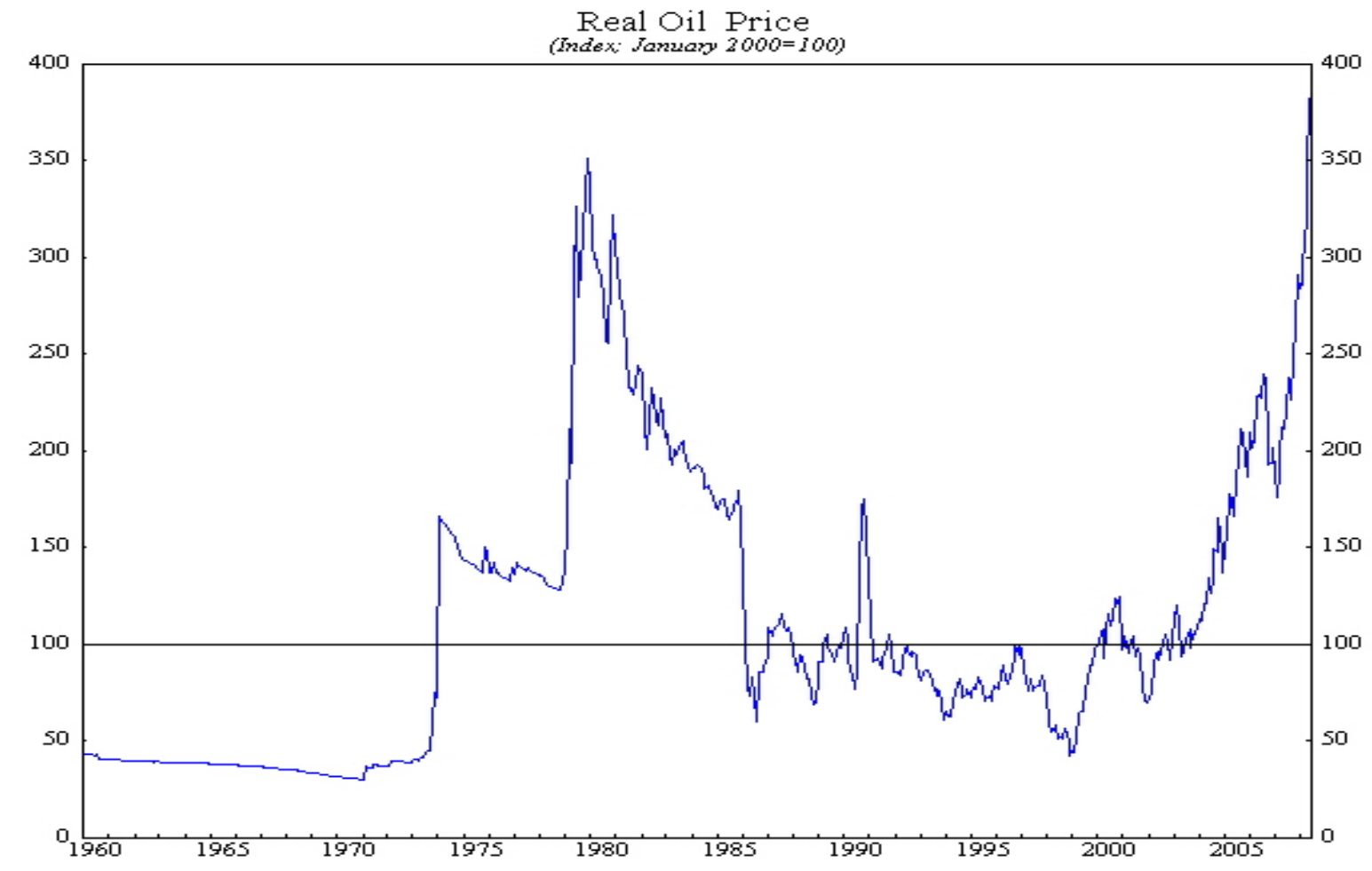


Table 1: Results from posterior maximization [1]

\begin{tabular}{|c|c|c|c|c|c|}
\hline & Prior distribution & Prior mean & Prior s.d. & Posterior mode & s.d. \\
\hline$\alpha_{e u, 1}$ & beta & 0.750 & 0.1000 & 0.7118 & 0.0720 \\
\hline$\alpha_{j a, 1}$ & beta & 0.750 & 0.1000 & 0.7439 & 0.0979 \\
\hline$\alpha_{u s, 1}$ & beta & 0.750 & 0.1000 & 0.7816 & 0.0613 \\
\hline$\alpha_{e u, 2}$ & gamma & 0.300 & 0.1000 & 0.1312 & 0.0269 \\
\hline$\alpha_{j a, 2}$ & gamma & 0.100 & 0.0500 & 0.0628 & 0.0248 \\
\hline$\alpha_{u s, 2}$ & gamma & 0.300 & 0.1000 & 0.1769 & 0.0270 \\
\hline$\alpha_{e u, 3}$ & beta & 0.500 & 0.2000 & 0.1049 & 0.0462 \\
\hline$\alpha_{j a, 3}$ & beta & 0.500 & 0.2000 & 0.1768 & 0.0904 \\
\hline$\alpha_{u s, 3}$ & beta & 0.500 & 0.2000 & 0.2918 & 0.1895 \\
\hline$\beta_{e u, 1}$ & gamma & 0.750 & 0.1000 & 0.9361 & 0.0707 \\
\hline$\beta_{j a, 1}$ & gamma & 0.750 & 0.1000 & 0.6035 & 0.0666 \\
\hline$\beta_{u s, 1}$ & gamma & 0.750 & 0.1000 & 0.6828 & 0.0632 \\
\hline$\beta_{e u, 2}$ & beta & 0.100 & 0.0500 & 0.1670 & 0.0675 \\
\hline$\beta_{j a, 2}$ & beta & 0.100 & 0.0500 & 0.0528 & 0.0322 \\
\hline$\beta_{u s, 2}$ & beta & 0.100 & 0.0500 & 0.0754 & 0.0437 \\
\hline$\beta_{e u, 3}$ & gamma & 0.200 & 0.0500 & 0.2113 & 0.0453 \\
\hline$\beta_{j a, 3}$ & gamma & 0.200 & 0.0500 & 0.1313 & 0.0352 \\
\hline$\beta_{u s, 3}$ & gamma & 0.200 & 0.0500 & 0.1936 & 0.0449 \\
\hline$\beta_{e u, 4}$ & gamma & 0.104 & 0.0400 & 0.0517 & 0.0205 \\
\hline$\beta_{j a, 4}$ & gamma & 0.090 & 0.0400 & 0.0447 & 0.0232 \\
\hline$\beta_{u s, 4}$ & gamma & 0.060 & 0.0200 & 0.0440 & 0.0151 \\
\hline$\beta_{e u, 5}$ & gamma & 0.052 & 0.0100 & 0.0528 & 0.0102 \\
\hline$\beta_{j a, 5}$ & gamma & 0.045 & 0.0100 & 0.0429 & 0.0097 \\
\hline$\beta_{u s, 5}$ & gamma & 0.030 & 0.0100 & 0.0254 & 0.0089 \\
\hline
\end{tabular}


Table 2: Results from posterior maximization [2]

\begin{tabular}{l|lcccc}
\hline \hline & & & & & \\
& Prior distribution & Prior mean & Prior s.d. & Posterior mode & s.d. \\
\hline & & & & & \\
$\gamma_{e u, 1}$ & beta & 0.500 & 0.0500 & 0.6972 & 0.0362 \\
$\gamma_{j a, 1}$ & beta & 0.500 & 0.2500 & 0.9944 & 0.0075 \\
$\gamma_{u s, 1}$ & beta & 0.500 & 0.0500 & 0.7255 & 0.0342 \\
$\gamma_{e u, 2}$ & gamma & 1.500 & 0.2000 & 1.2521 & 0.1611 \\
$\gamma_{j a, 2}$ & gamma & 1.500 & 0.2000 & 1.1349 & 0.1516 \\
$\gamma_{u s, 2}$ & gamma & 1.500 & 0.3000 & 0.8771 & 0.1861 \\
$\gamma_{e u, 4}$ & gamma & 0.200 & 0.0500 & 0.1982 & 0.0503 \\
$\gamma_{j a, 4}$ & gamma & 0.200 & 0.0500 & 0.1666 & 0.0436 \\
$\gamma_{u s, 4}$ & gamma & 0.200 & 0.0500 & 0.2086 & 0.0531 \\
$g_{e u}^{Y_{s s}}$ & norm & 2.000 & 0.0500 & 2.0055 & 0.0499 \\
$g_{j a}^{Y_{s s}}$ & norm & 1.700 & 0.0500 & 1.6945 & 0.0497 \\
$g_{u s}^{Y}$ & norm & 2.200 & 0.0500 & 2.2040 & 0.0500 \\
$\kappa_{u s}$ & gamma & 20.000 & 0.5000 & 20.0239 & 0.4965 \\
$\lambda_{e u, 1}$ & beta & 0.500 & 0.1000 & 0.6851 & 0.0676 \\
$\lambda_{j a, 1}$ & beta & 0.500 & 0.1000 & 0.6450 & 0.0638 \\
$\lambda_{u s, 1}$ & beta & 0.500 & 0.1000 & 0.7293 & 0.0614 \\
$\lambda_{e u, 2}$ & gamma & 0.250 & 0.0500 & 0.2134 & 0.0402 \\
$\lambda_{j a, 2}$ & gamma & 0.250 & 0.0500 & 0.1674 & 0.0385 \\
$\lambda_{u s, 2}$ & gamma & 0.200 & 0.0500 & 0.1735 & 0.0375 \\
$\lambda_{e u, 3}$ & gamma & 0.208 & 0.0500 & 0.0965 & 0.0216 \\
$\lambda_{j a, 3}$ & gamma & 0.180 & 0.0500 & 0.0834 & 0.0225 \\
$\lambda_{u s, 3}$ & gamma & 0.120 & 0.0500 & 0.0596 & 0.0227 \\
\hline \hline & & & & & \\
\end{tabular}


Table 3: Results from posterior maximization [3]

\begin{tabular}{|c|c|c|c|c|c|}
\hline & Prior distribution & Prior mean & Prior s.d. & Posterior mode & s.d. \\
\hline$\phi_{e u}$ & beta & 0.500 & 0.2000 & 0.8302 & 0.0675 \\
\hline$\phi_{j a}$ & beta & 0.500 & 0.2000 & 0.8260 & 0.0626 \\
\hline$\rho_{e u}$ & beta & 0.500 & 0.1000 & 0.4682 & 0.1180 \\
\hline$\rho_{j a}$ & beta & 0.500 & 0.1000 & 0.4964 & 0.1077 \\
\hline$\rho_{u s}$ & beta & 0.500 & 0.1000 & 0.2965 & 0.0700 \\
\hline$\overline{r r}_{e u}$ & norm & 2.000 & 0.3000 & 1.9539 & 0.1837 \\
\hline$\overline{r r}_{j a}$ & norm & 2.000 & 0.3000 & 0.6731 & 0.2144 \\
\hline$\overline{r r}_{u s}$ & norm & 2.000 & 0.3000 & 1.7461 & 0.2515 \\
\hline$\tau_{e u}$ & beta & 0.050 & 0.0300 & 0.0226 & 0.0151 \\
\hline$\tau_{j a}$ & beta & 0.050 & 0.0300 & 0.0331 & 0.0222 \\
\hline$\tau_{u s}$ & beta & 0.050 & 0.0300 & 0.0234 & 0.0153 \\
\hline$\theta_{u s}$ & gamma & 1.000 & 0.5000 & 1.1100 & 0.5652 \\
\hline$\sigma_{e u}$ & gamma & 0.003 & 0.0010 & 0.0016 & 0.0006 \\
\hline$\sigma_{j a}$ & gamma & 0.002 & 0.0010 & 0.0010 & 0.0006 \\
\hline$\sigma_{u s}$ & gamma & 0.004 & 0.0010 & 0.0033 & 0.0008 \\
\hline$v_{e u, 1}$ & gamma & 0.003 & 0.0010 & 0.0035 & 0.0011 \\
\hline$v_{j a, 1}$ & gamma & 0.003 & 0.0010 & 0.0018 & 0.0008 \\
\hline$v_{u s, 1}$ & gamma & 0.005 & 0.0010 & 0.0057 & 0.0011 \\
\hline$v_{e u, 2}$ & gamma & 0.003 & 0.0010 & 0.0022 & 0.0007 \\
\hline$v_{j a, 2}$ & gamma & 0.003 & 0.0010 & 0.0024 & 0.0010 \\
\hline$v_{u s, 2}$ & gamma & 0.005 & 0.0010 & 0.0045 & 0.0009 \\
\hline$\rho_{g, u s}$ & gamma & 0.750 & 0.0500 & 0.7391 & 0.0488 \\
\hline$\rho_{\text {rpoil }, u s}$ & gamma & 0.750 & 0.1000 & 0.7838 & 0.1037 \\
\hline
\end{tabular}


Table 4: Results from posterior parameters (standard deviation of structural shocks)

\begin{tabular}{|c|c|c|c|c|c|}
\hline & Prior distribution & Prior mean & Prior s.d. & Posterior mode & s.d. \\
\hline$\overline{\varepsilon_{\nu s} \overline{B L T}}$ & invg & 0.200 & Inf & 0.0922 & 0.0376 \\
\hline 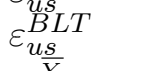 & invg & 0.400 & Inf & 0.8818 & 0.4511 \\
\hline$\varepsilon_{e u}^{g^{\bar{Y}}}$ & invg & 0.100 & 0.0500 & 0.1261 & 0.0422 \\
\hline$\varepsilon_{j a}^{g^{\bar{Y}}}$ & invg & 0.100 & 0.0500 & 0.0804 & 0.0294 \\
\hline$\varepsilon_{u s}^{g^{\frac{a}{Y}}}$ & invg & 0.100 & $\operatorname{Inf}$ & 0.2646 & 0.0781 \\
\hline$\varepsilon_{e u}^{\bar{Y}}$ & invg & 0.200 & 0.0500 & 0.1923 & 0.0375 \\
\hline$\varepsilon_{j a}^{\bar{Y}}$ & invg & 0.200 & 0.0500 & 0.4365 & 0.0940 \\
\hline$\varepsilon_{u s}^{\bar{Y}}$ & invg & 0.050 & 0.0500 & 0.0289 & 0.0110 \\
\hline$\varepsilon_{e u}^{\frac{\omega 0}{Z}}$ & invg & 1.000 & Inf & 4.3598 & 0.5762 \\
\hline$\varepsilon_{j a}^{\frac{Z}{Z}}$ & invg & 4.000 & Inf & 6.1233 & 0.9146 \\
\hline$\varepsilon_{e u}^{\pi^{a}}$ & invg & 0.500 & Inf & 0.9800 & 0.1130 \\
\hline$\varepsilon_{j a}^{\pi u}$ & invg & 1.000 & Inf & 1.4022 & 0.1518 \\
\hline$\varepsilon_{\underline{u s}}^{\pi}$ & invg & 0.700 & $\operatorname{Inf}$ & 1.0844 & 0.1083 \\
\hline$\varepsilon_{\underline{e u}}^{\bar{R}}$ & invg & 0.200 & 0.0400 & 0.1896 & 0.0361 \\
\hline$\varepsilon_{j a}^{\bar{R}}$ & invg & 0.100 & 0.0400 & 0.0794 & 0.0231 \\
\hline & invg & 0.200 & Inf & 0.9993 & 0.1708 \\
\hline$\varepsilon^{R_{e u}-R_{u s}}$ & invg & 1.000 & Inf & 0.4614 & 0.1890 \\
\hline$\varepsilon^{R_{j a}-R_{u s}}$ & invg & 0.500 & Inf & 0.2303 & 0.0940 \\
\hline$\varepsilon_{\rho u}^{r s}$ & invg & 0.250 & Inf & 0.2585 & 0.0334 \\
\hline$\varepsilon_{j a}^{r u}$ & invg & 0.250 & Inf & 0.2598 & 0.0330 \\
\hline$\varepsilon_{u s}^{T_{s}^{u}}$ & invg & 0.700 & Inf & 0.2417 & 0.0415 \\
\hline$\varepsilon_{\underline{e u}}^{\frac{\omega_{s}}{U}}$ & invg & 0.100 & Inf & 0.0301 & 0.0064 \\
\hline$\varepsilon_{j a}^{\bar{U}}$ & invg & 0.100 & Inf & 0.0508 & 0.0266 \\
\hline$\varepsilon_{u s}^{\underline{J u}}$ & invg & 0.100 & Inf & 0.0468 & 0.0195 \\
\hline$\varepsilon_{e u}^{\bar{g}}$ & invg & 0.100 & Inf & 0.0410 & 0.0074 \\
\hline$\varepsilon_{j a}^{\bar{g}}$ & invg & 0.100 & Inf & 0.0427 & 0.0123 \\
\hline$\varepsilon_{u s}^{g_{u}^{\bar{U}}}$ & invg & 0.100 & Inf & 0.0481 & 0.0175 \\
\hline$\varepsilon_{\rho u}^{u}$ & invg & 0.200 & Inf & 0.0428 & 0.0060 \\
\hline$\varepsilon_{j a}^{u}$ & invg & 0.100 & Inf & 0.0754 & 0.0183 \\
\hline$\varepsilon_{u s}^{u a}$ & invg & 0.200 & Inf & 0.0958 & 0.0152 \\
\hline$\varepsilon_{e u}^{y s}$ & invg & 0.300 & 0.0500 & 0.2535 & 0.0321 \\
\hline$\varepsilon_{j a}^{y}$ & invg & 0.500 & 0.1000 & 0.4491 & 0.0682 \\
\hline$\varepsilon_{u s}^{y}$ & invg & 0.250 & Inf & 0.3337 & 0.0399 \\
\hline$\varepsilon_{u s}^{g^{\overline{R P O I L}}}$ & invg & 5.000 & Inf & 6.8398 & 1.9062 \\
\hline$\varepsilon_{\underline{u s}}^{\text {rpoil }}$ & invg & 5.000 & Inf & 7.6225 & 2.1380 \\
\hline$\varepsilon_{u s}^{\overline{R P O I L}}$ & invg & 5.000 & Inf & 2.3613 & 1.0142 \\
\hline
\end{tabular}


Table 5: Results from posterior parameters (correlation of structural shocks)

\begin{tabular}{l|lcccc}
\hline \hline & Prior distribution & Prior mean & Prior s.d. & Posterior mode & s.d. \\
\hline$\varepsilon_{u s}^{\bar{Y}}, \varepsilon_{u s}^{\pi}$ & beta & 0.100 & 0.0300 & 0.0913 & 0.0292 \\
$\varepsilon_{u s}^{B L T}, \varepsilon_{u s}^{g^{\bar{Y}}}$ & beta & 0.650 & 0.0500 & 0.6424 & 0.0507 \\
$\varepsilon_{e u}^{\bar{Y}}, \varepsilon_{e u}^{\pi}$ & beta & 0.100 & 0.0300 & 0.0957 & 0.0303 \\
$\varepsilon_{e u}^{y}, \varepsilon_{e u}^{g^{\bar{Y}}}$ & beta & 0.250 & 0.1000 & 0.2487 & 0.1144 \\
$\varepsilon_{j a}^{\bar{Y}}, \varepsilon_{j a}^{\pi}$ & beta & 0.100 & 0.0300 & 0.0891 & 0.0282 \\
$\varepsilon_{j a}^{y}, \varepsilon_{j a}^{g^{\bar{Y}}}$ & beta & 0.250 & 0.1000 & 0.2241 & 0.1057 \\
\hline \hline
\end{tabular}


Table 6: Root Mean Squared Errors

\begin{tabular}{l|lccc}
\hline \hline & & & & \\
& 1 Q Ahead & 4 Q Ahead & 8 Q Ahead & 12 Q Ahead \\
\hline & & & & \\
& & 0.69 & 0.93 & 1.10 \\
Output Gap US $y_{u s}$ & 0.50 & 2.10 & 2.34 & 2.15 \\
GDP Quarterly Growth at annual rates US $4\left(Y_{u s}-Y_{u s,-1}\right)$ & 1.90 & 1.31 & 1.72 & 1.62 \\
GDP Year-on-Year Growth US $Y_{u s}-Y_{u s,-4}$ & 0.61 & 0.43 & 0.84 & 1.16 \\
Unemployment Rate US $U_{u s}$ & 0.15 & 0.80 & 0.71 & 0.73 \\
CPI Year-on-Year Inflation US $\pi 4_{u s}$ & 0.33 & 1.04 & 1.48 & 1.75 \\
Short-term Interest Rate (RS) US $r s_{u s}$ & 0.33 & 13.40 & 16.80 & 17.10 \\
Bank Lending Tightening US $B L T_{u s}$ & 7.56 & 0.81 & 0.80 & 1.00 \\
Output Gap EU Yeu & 0.41 & 1.82 & 1.47 & 1.39 \\
GDP Quarterly Growth at annual rates EU $4\left(Y_{e u}-Y_{e u,-1}\right)$ & 1.61 & 1.24 & 1.08 & 1.14 \\
GDP Year-on-Year Growth EU $Y_{e u}-Y_{e u,-4}$ & 0.47 & 0.30 & 0.70 & 1.17 \\
Unemployment Rate EU $U_{e u}$ & 0.07 & 0.77 & 0.68 & 0.45 \\
CPI Year-on-Year Inflation EU $\pi 4_{e u}$ & 0.26 & 0.84 & 0.84 & 1.01 \\
Short-term Interest Rate (RS) EU $r s_{e u}$ & 0.26 & 0.51 & 0.53 & 0.60 \\
Output Gap JA $y_{j a}$ & 0.35 & 2.77 & 2.84 & 2.87 \\
GDP Quarterly Growth at annual rates JA $4\left(Y_{j a}-Y_{j a,-1}\right)$ & 3.03 & 1.70 & 1.62 & 1.67 \\
GDP Year-on-Year Growth JA $Y_{j a}-Y_{j a,-4}$ & 0.76 & 0.34 & 0.61 & 0.83 \\
Unemployment Rate JA $U_{j a}$ & 0.12 & 1.02 & 1.30 & 1.40 \\
CPI Year-on-Year Inflation JA $\pi 4_{j a}$ & 0.34 & 0.73 & 1.19 & 1.38 \\
Short-term Interest Rate (RS) JA $r s_{j a}$ & 0.25 & &
\end{tabular}


Figure 3: Demand shock in the US (1)
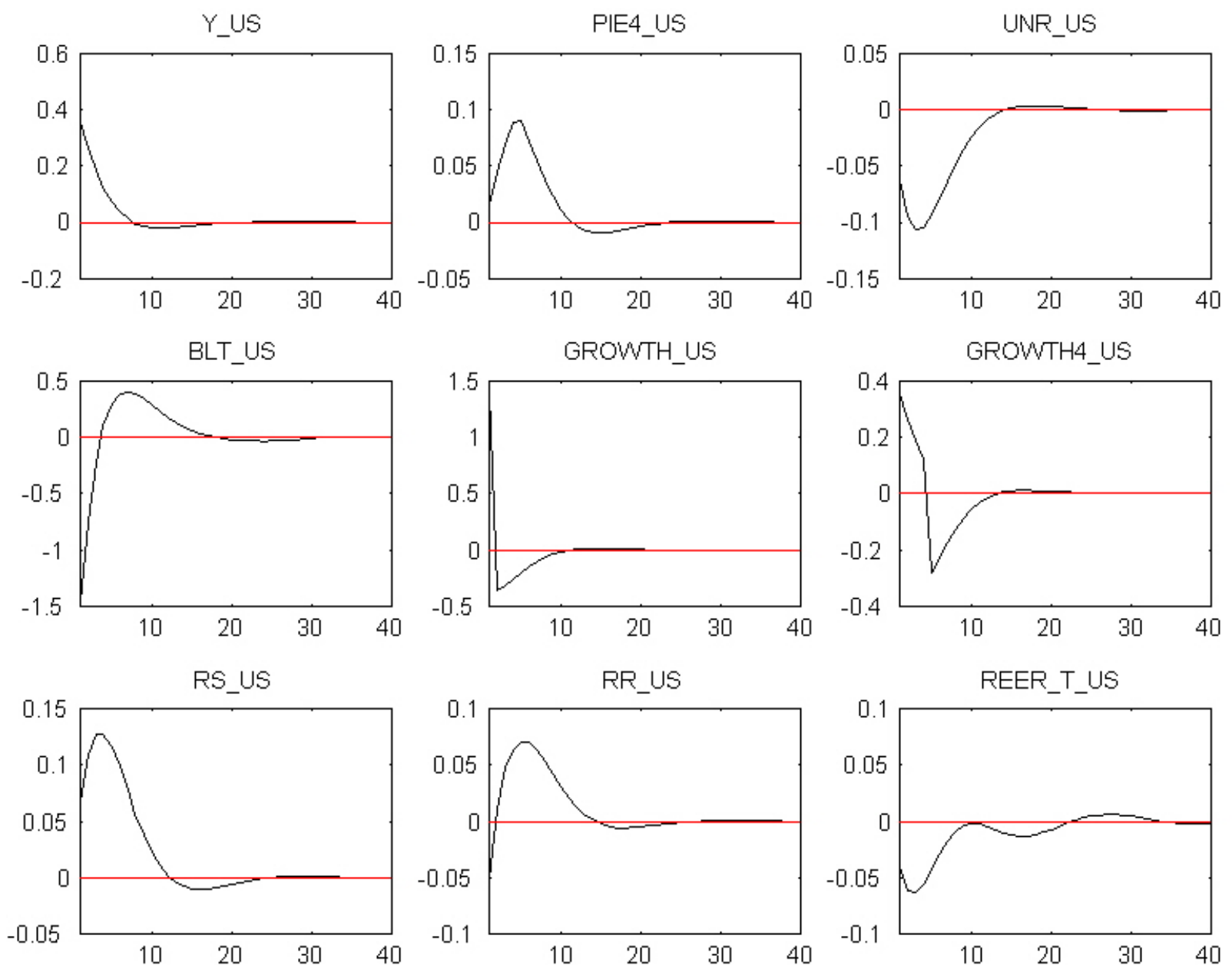
Figure 4: Demand shock in the US (2)
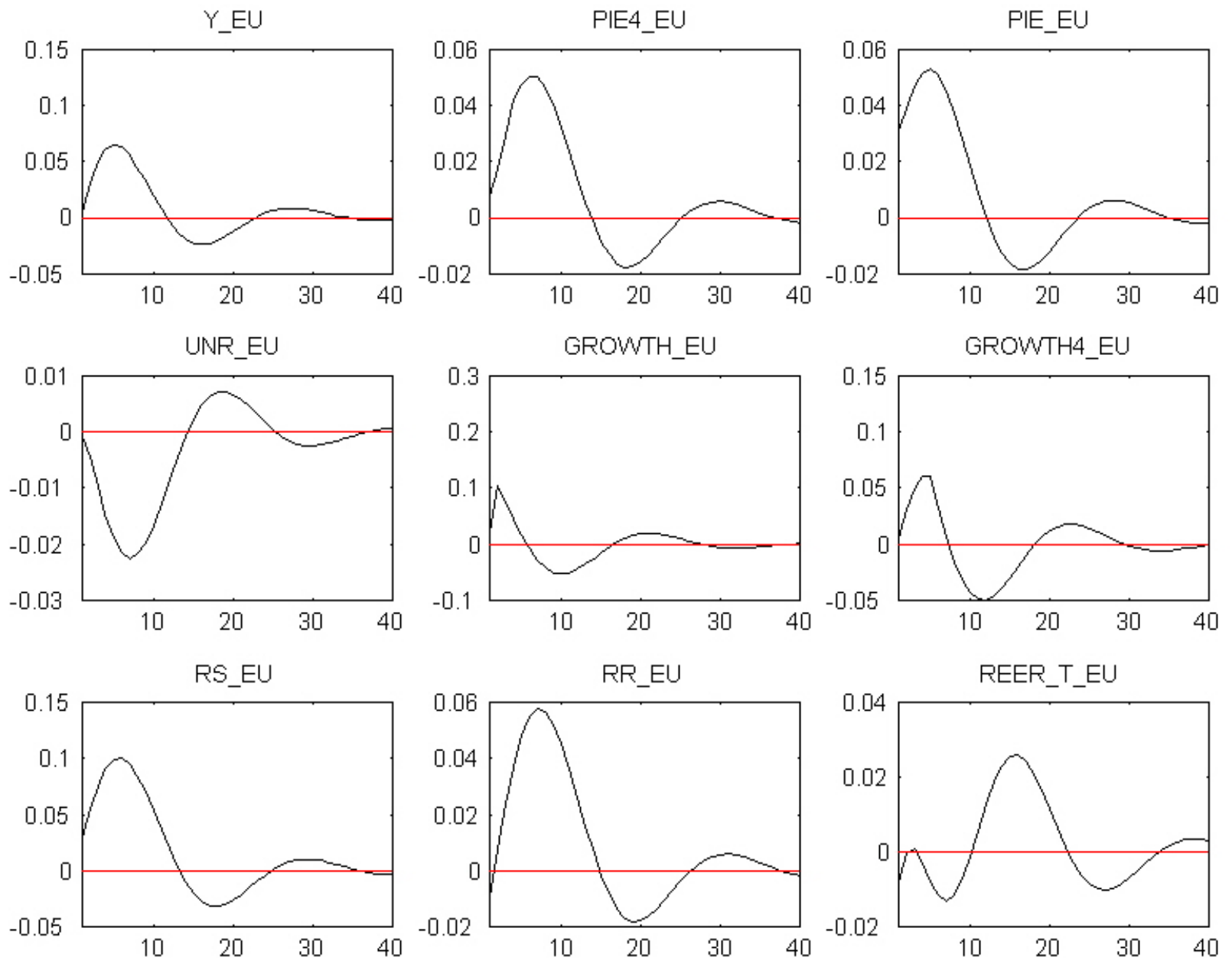
Figure 5: Demand shock in the US (3)
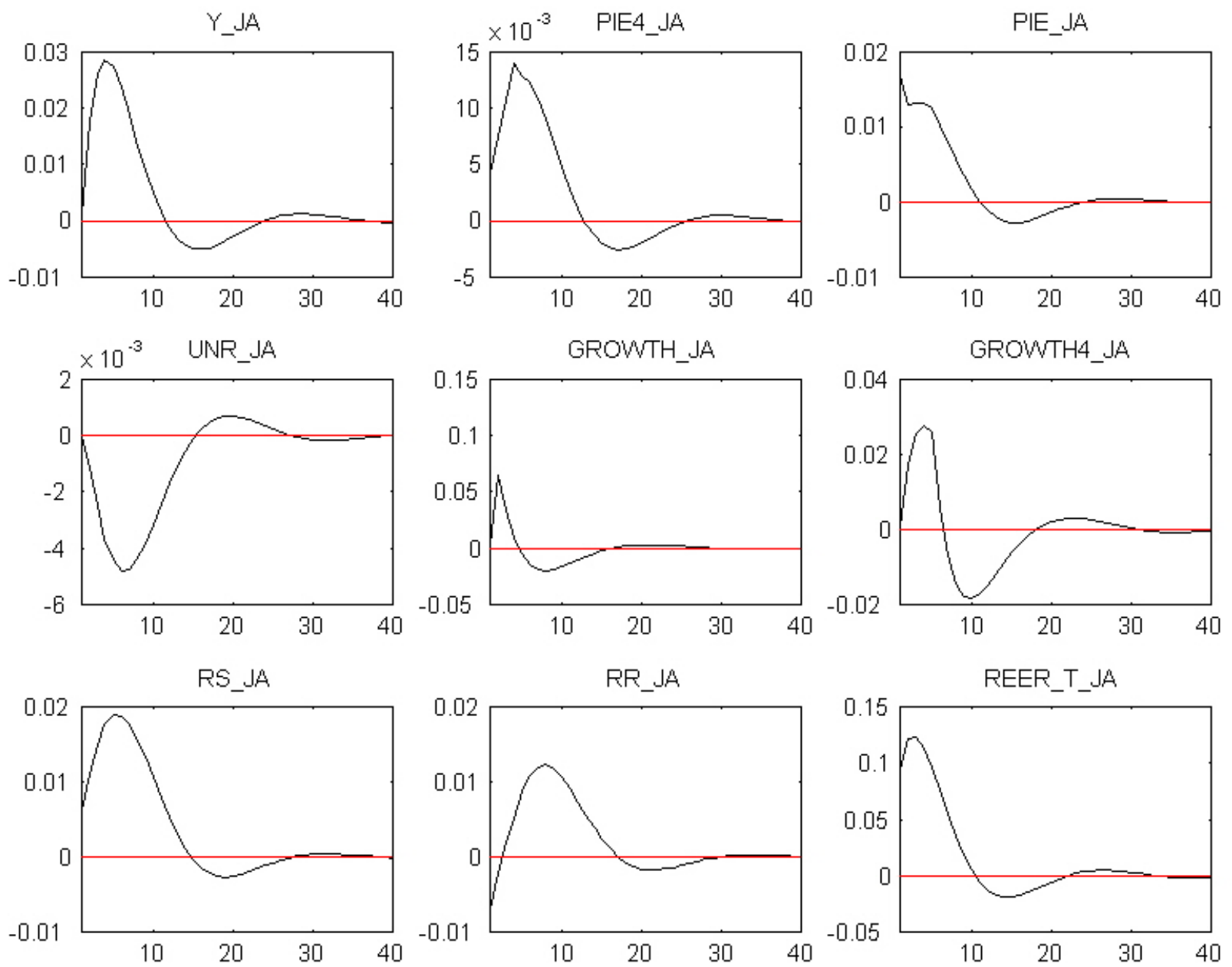
Figure 6: Demand shock in Europe (1)
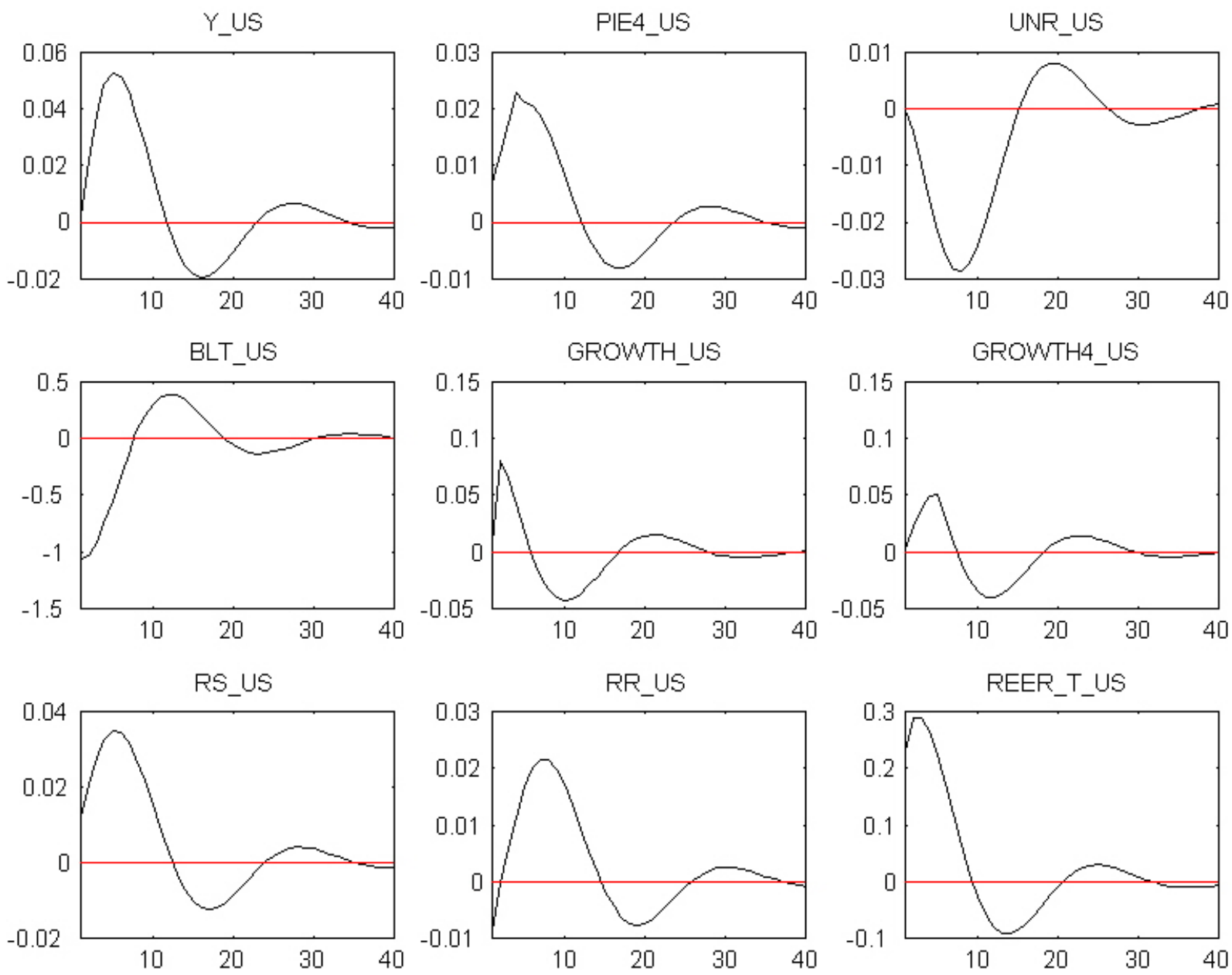
Figure 7: Demand shock in Europe (2)
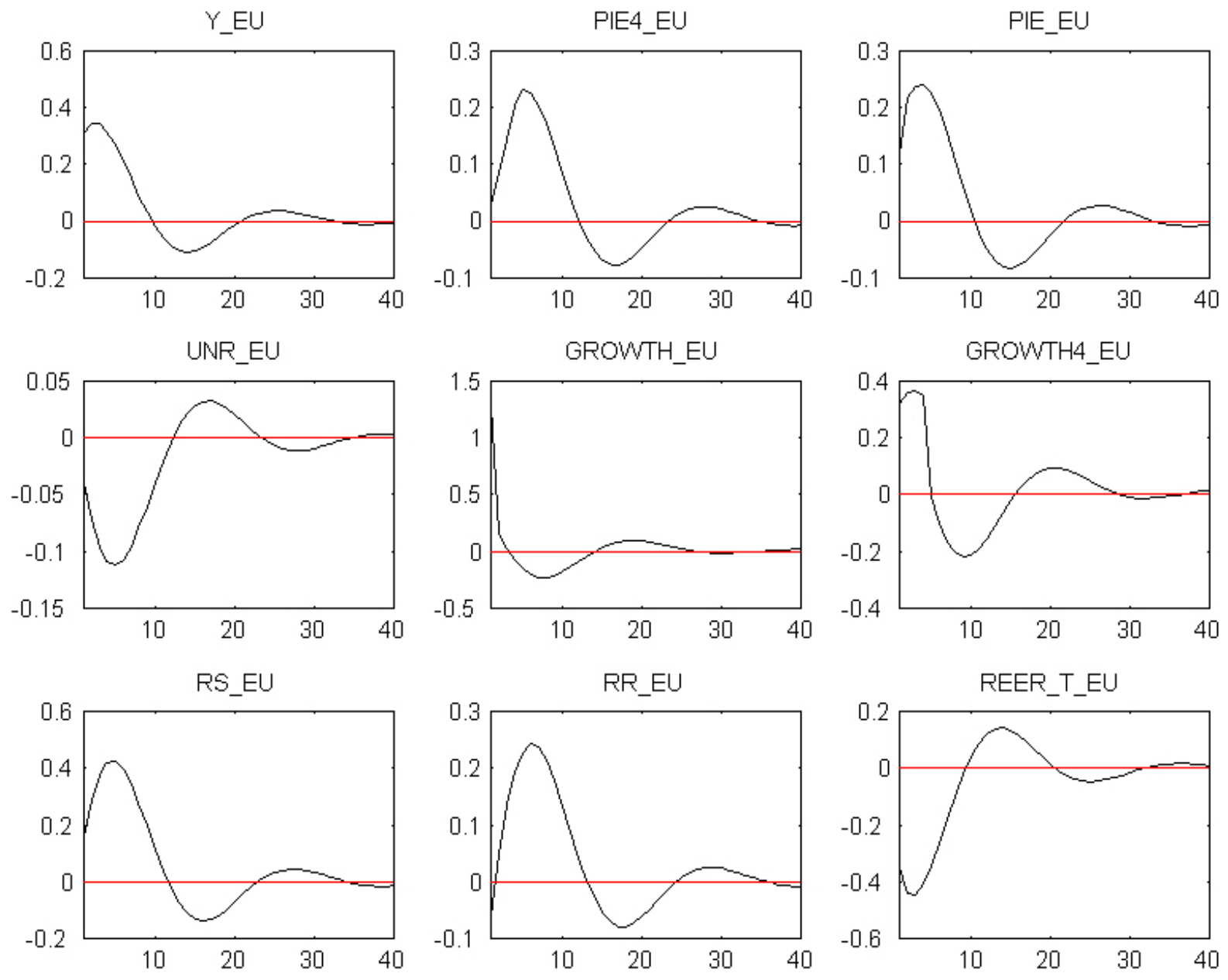
Figure 8: Demand shock in Europe (3)
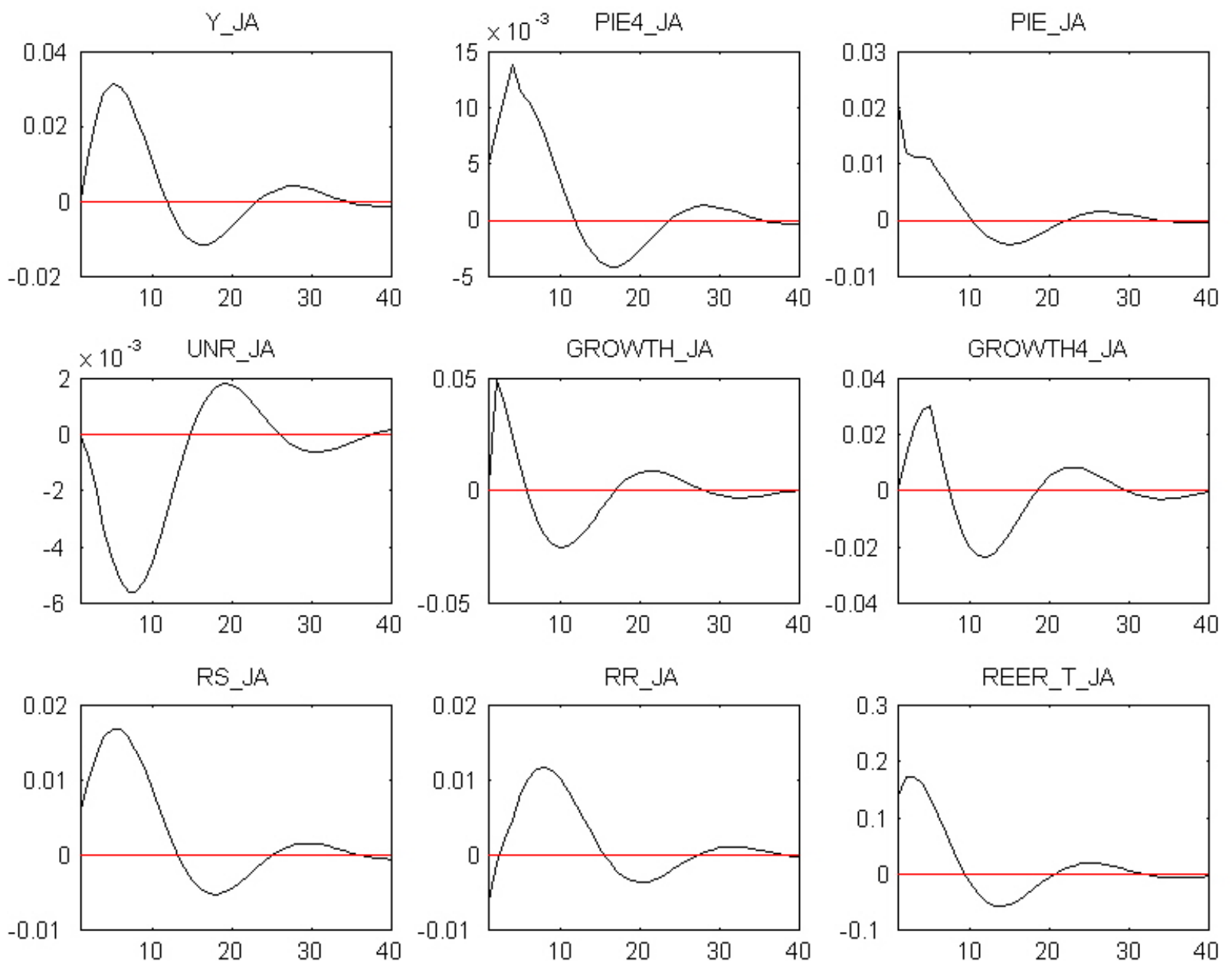
Figure 9: Demand shock in Japan (1)
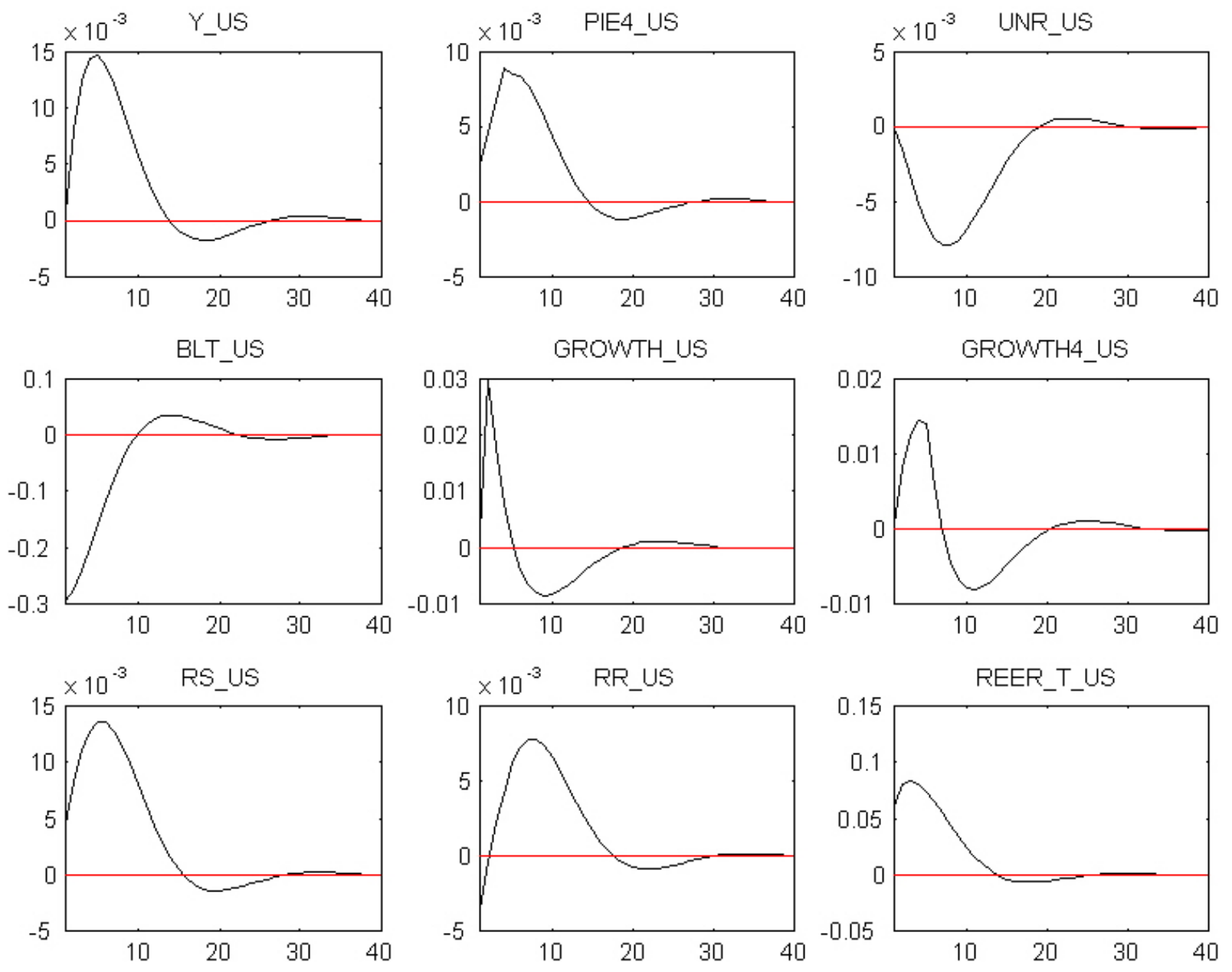
Figure 10: Demand shock in Japan (2)
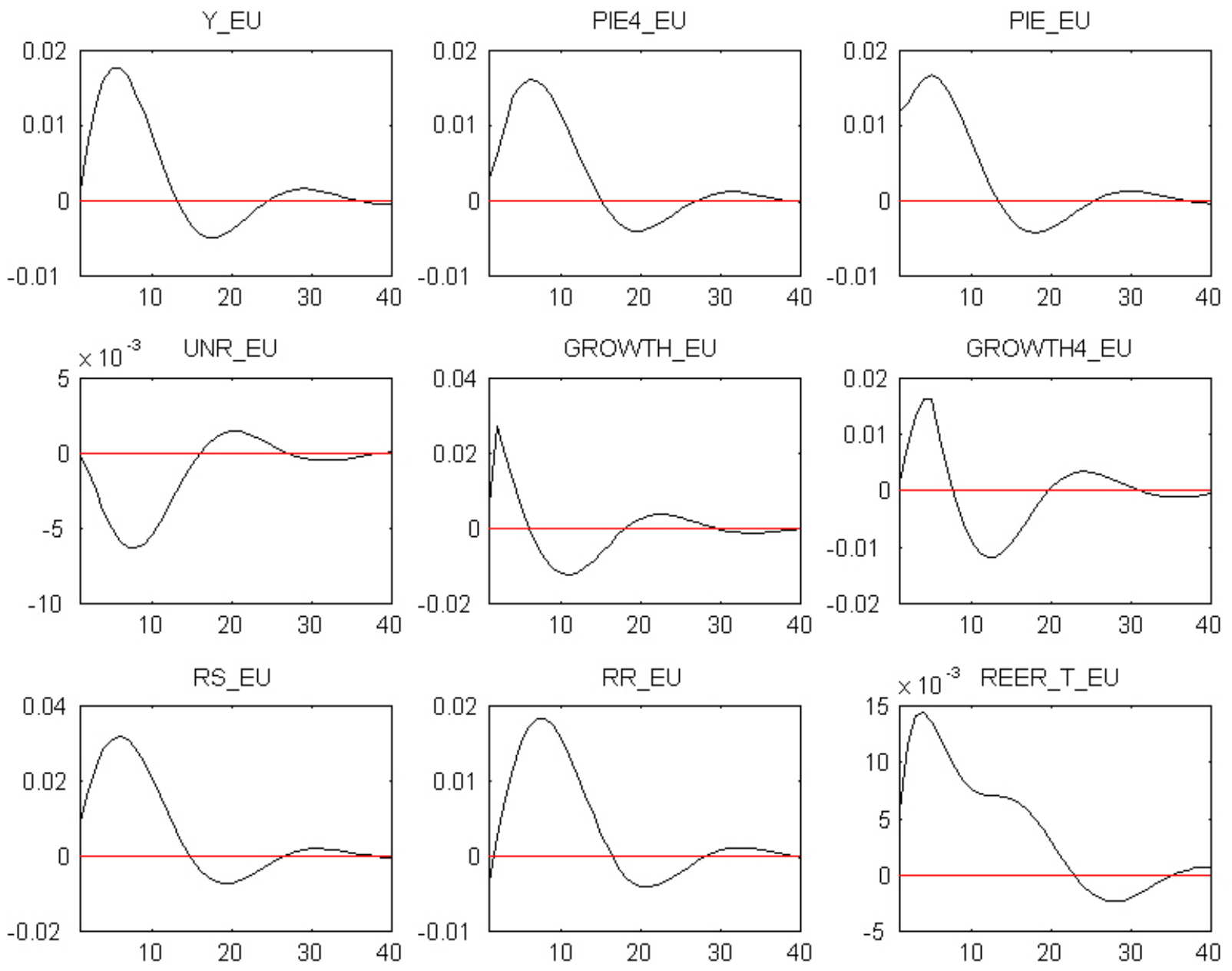
Figure 11: Demand shock in Japan (3)
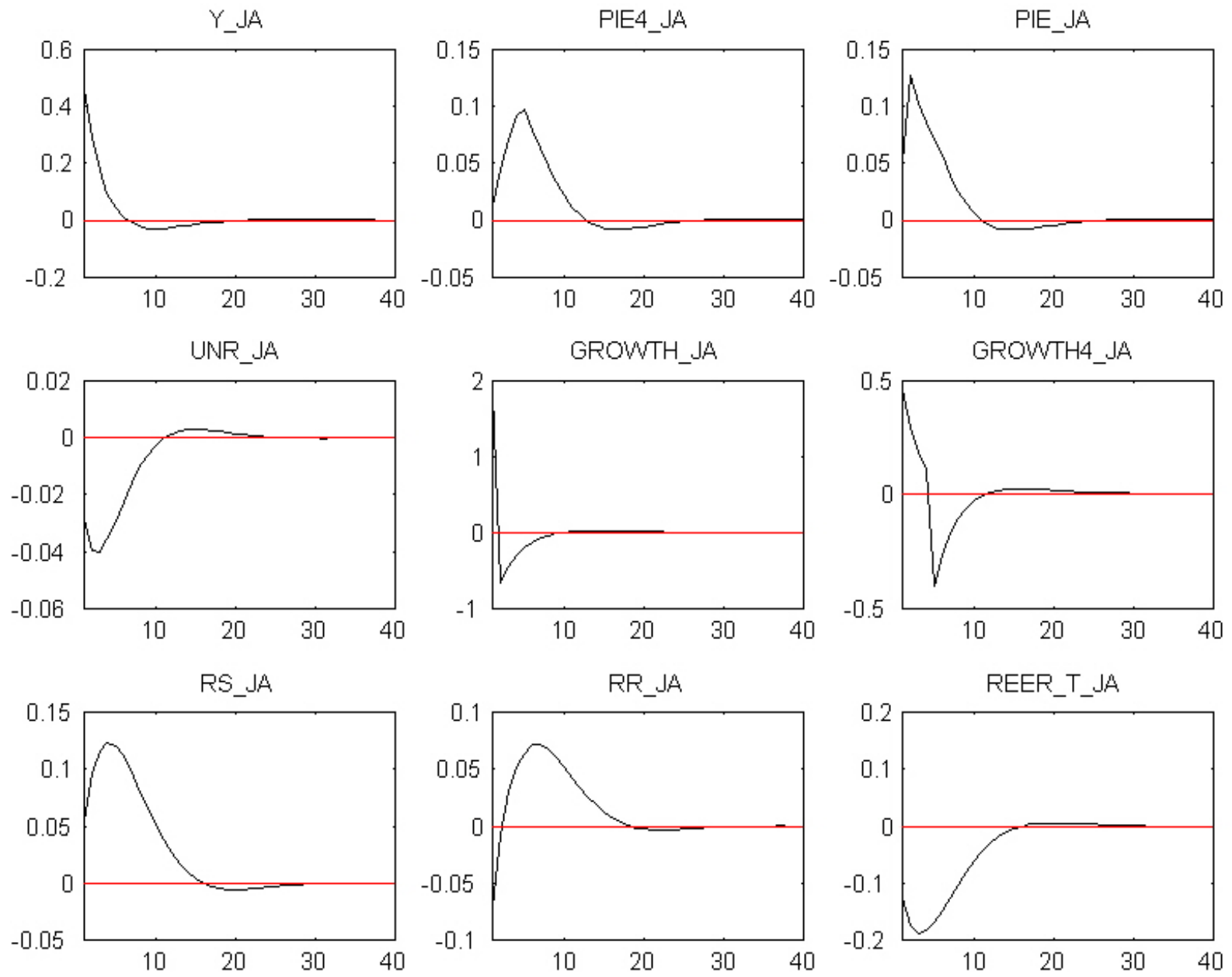
Figure 12: Financial (BLT) shock in the US (1)
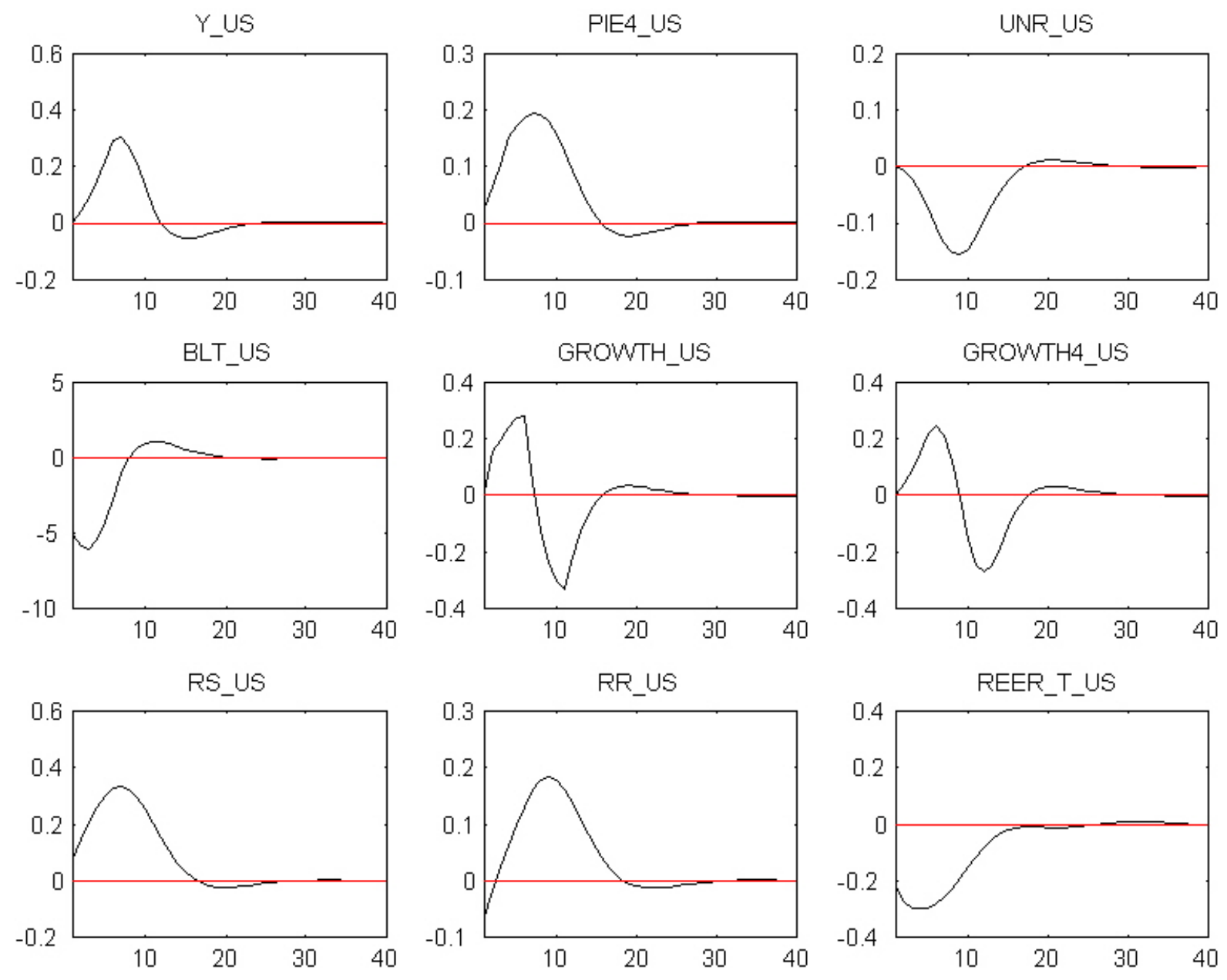
Figure 13: Financial (BLT) shock in the US (2)
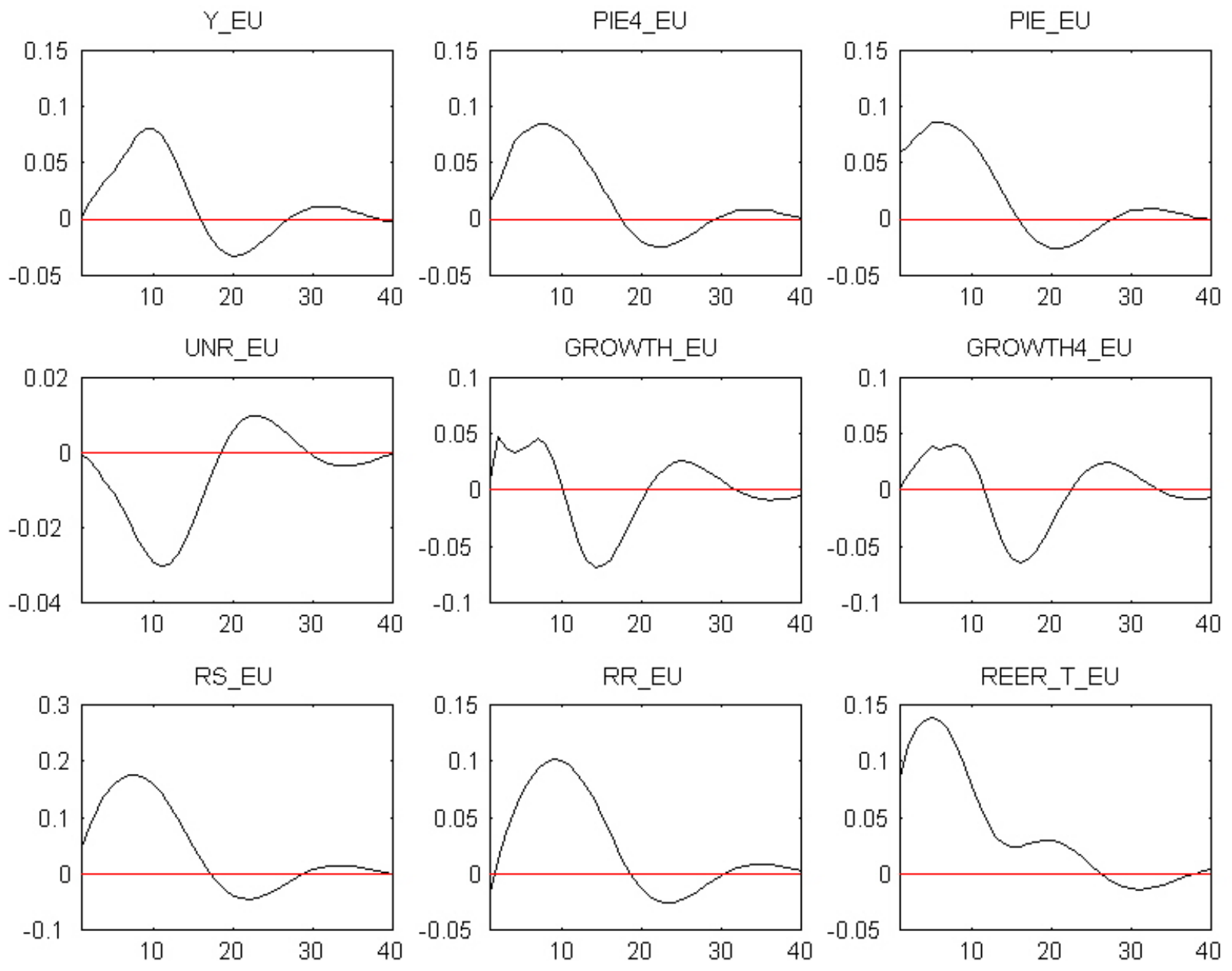
Figure 14: Financial (BLT) shock in the US (3)
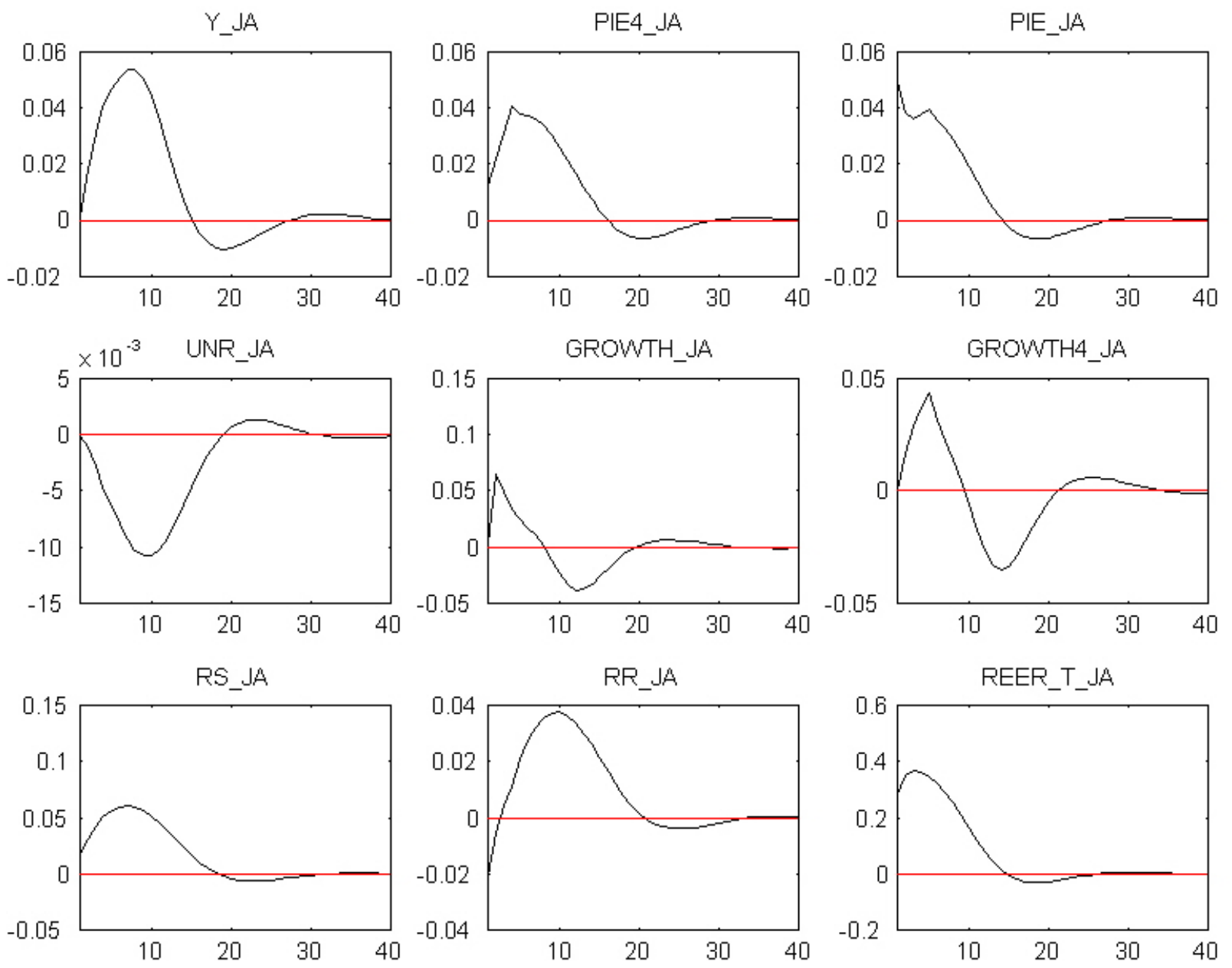
Figure 15: Growth rate shock in the US (1)
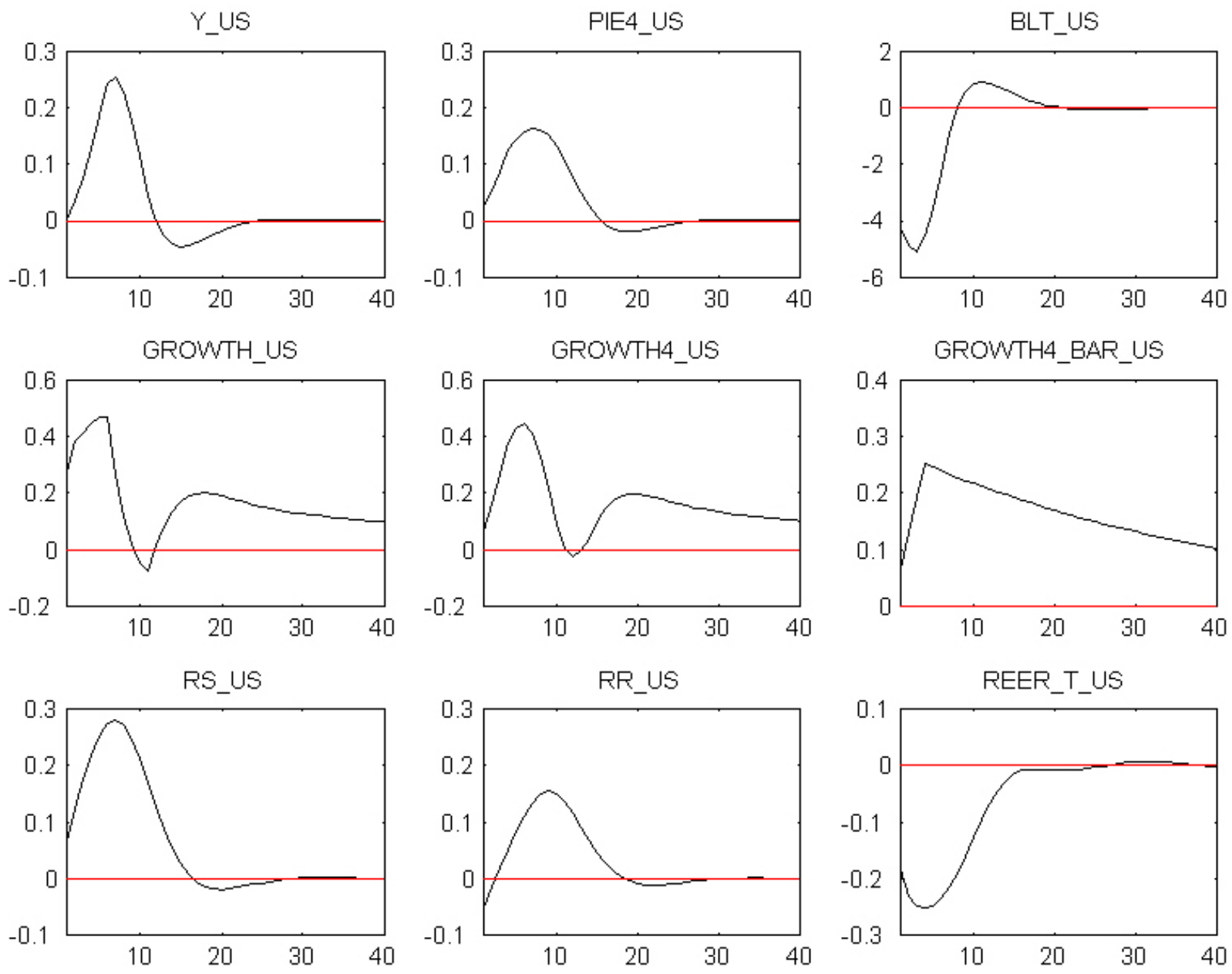
Figure 16: Growth rate shock in the US (2)
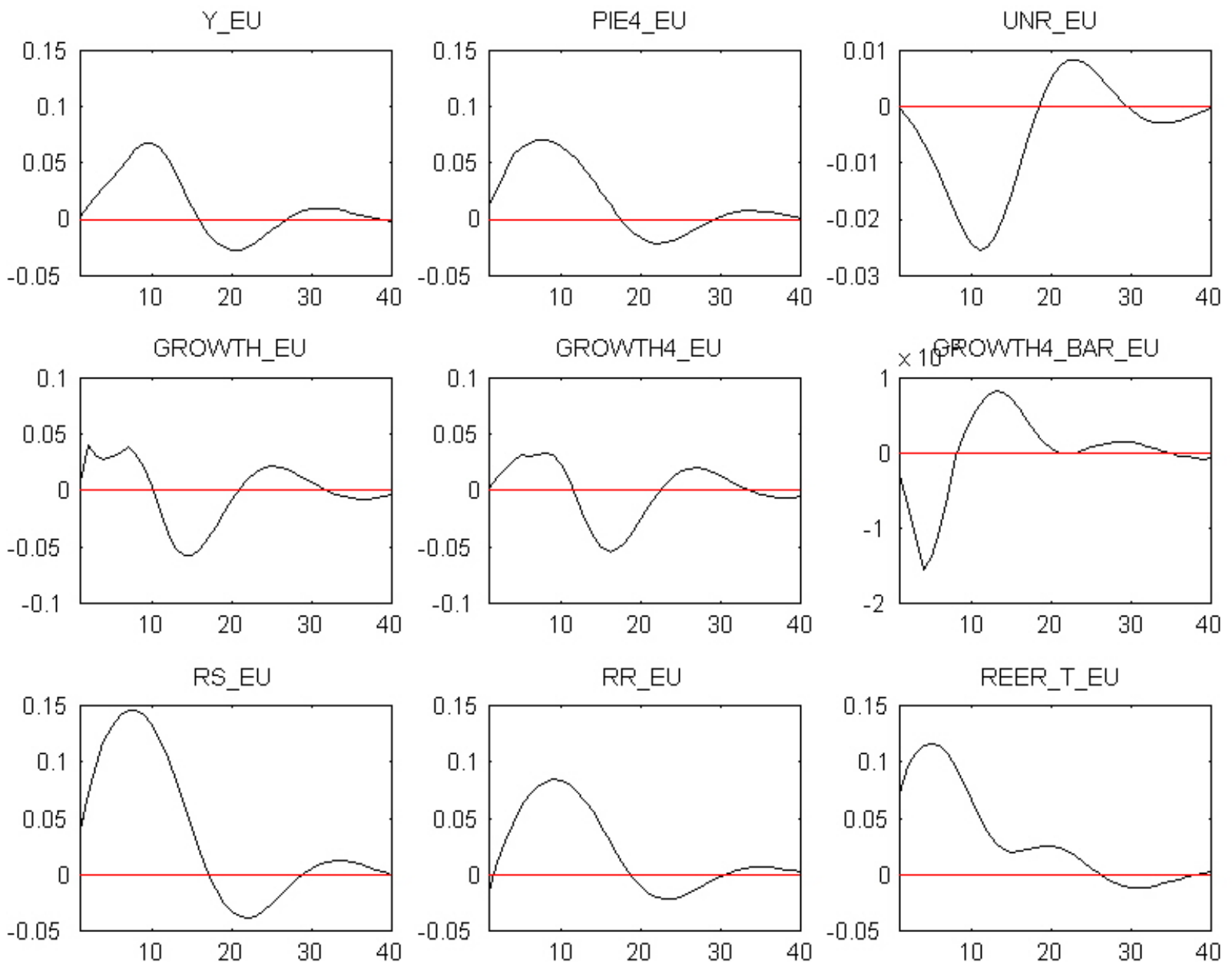
Figure 17: Growth rate shock in the US (3)
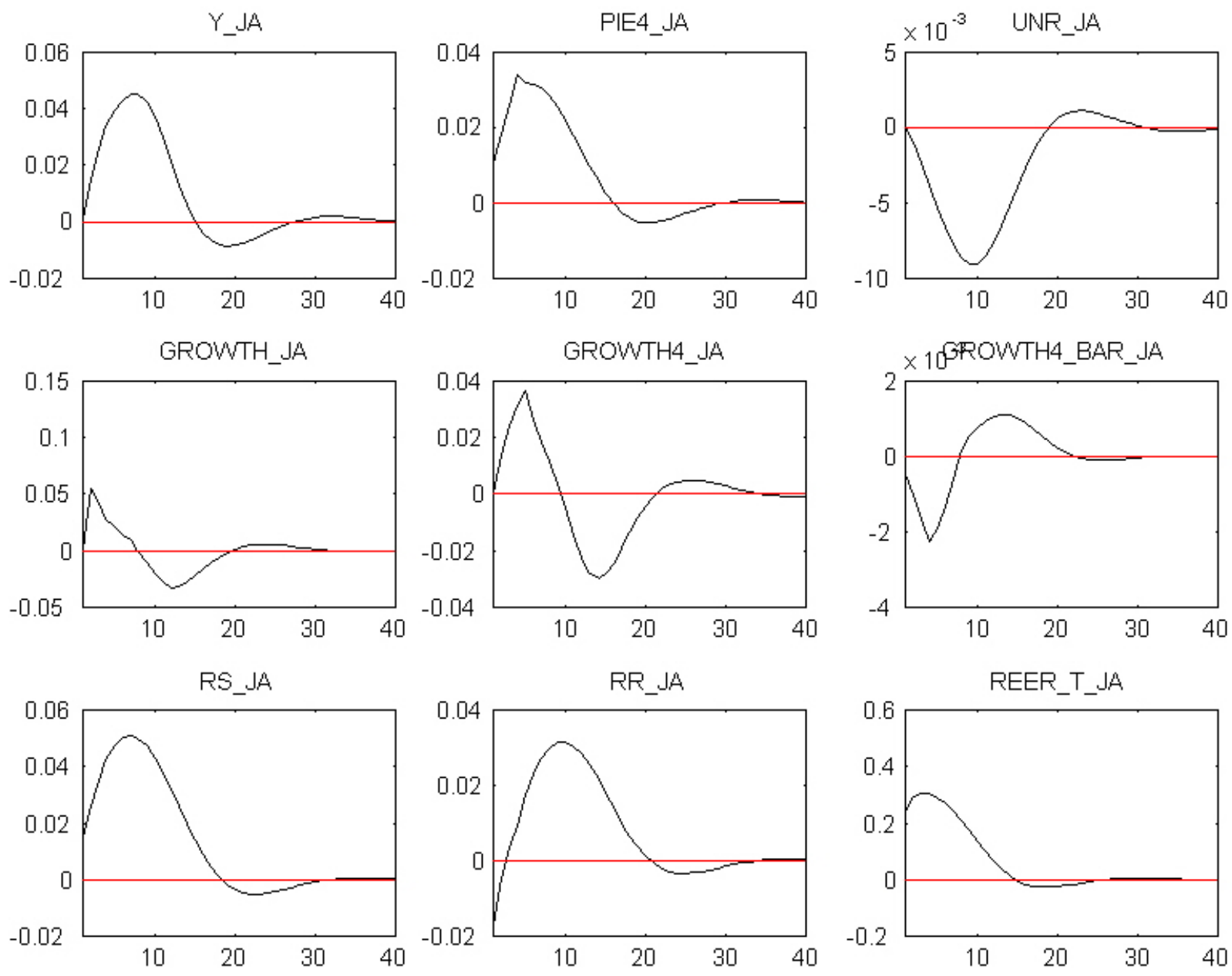
Figure 18: Oil Price Shock (1)
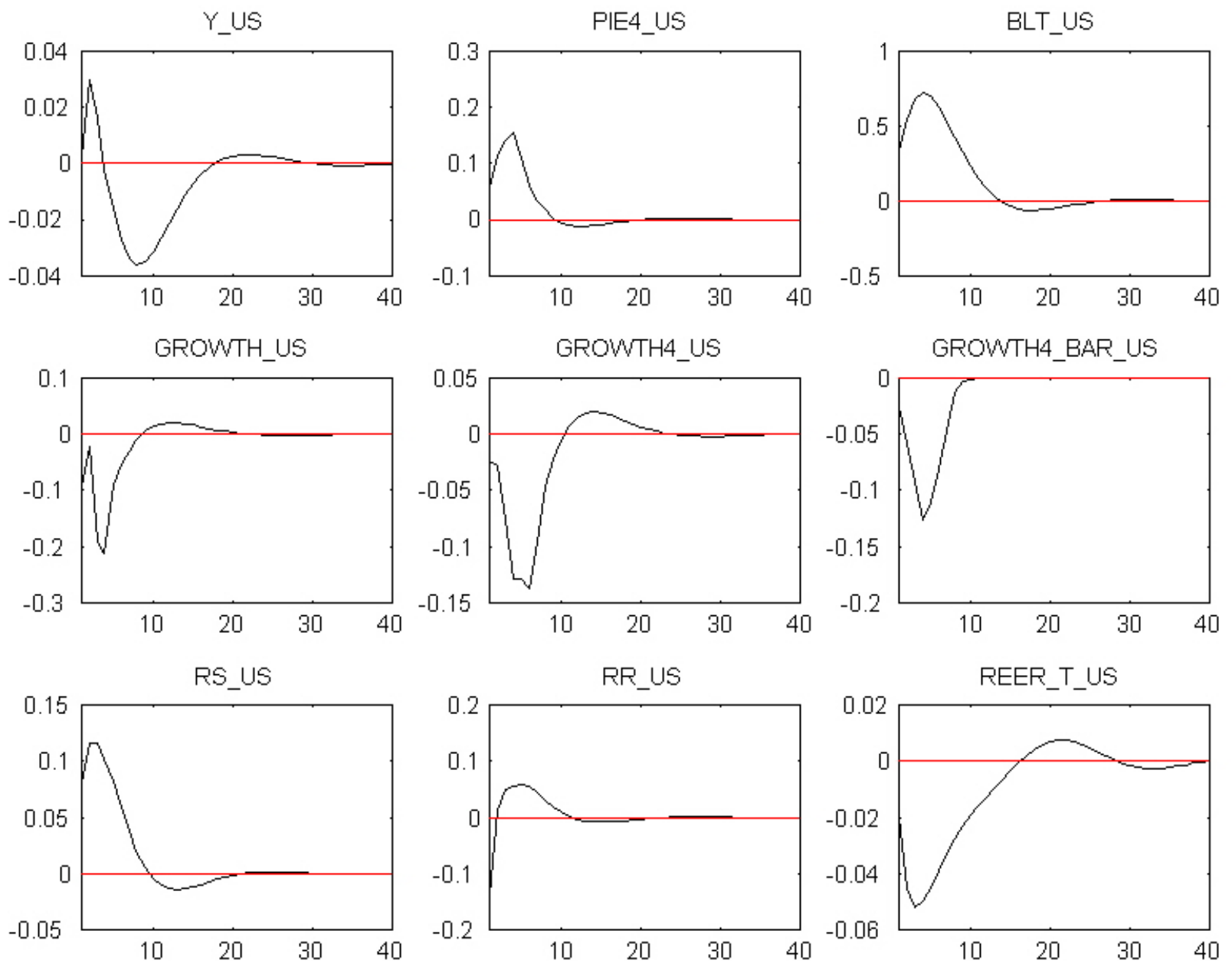
Figure 19: Oil Price Shock (2)
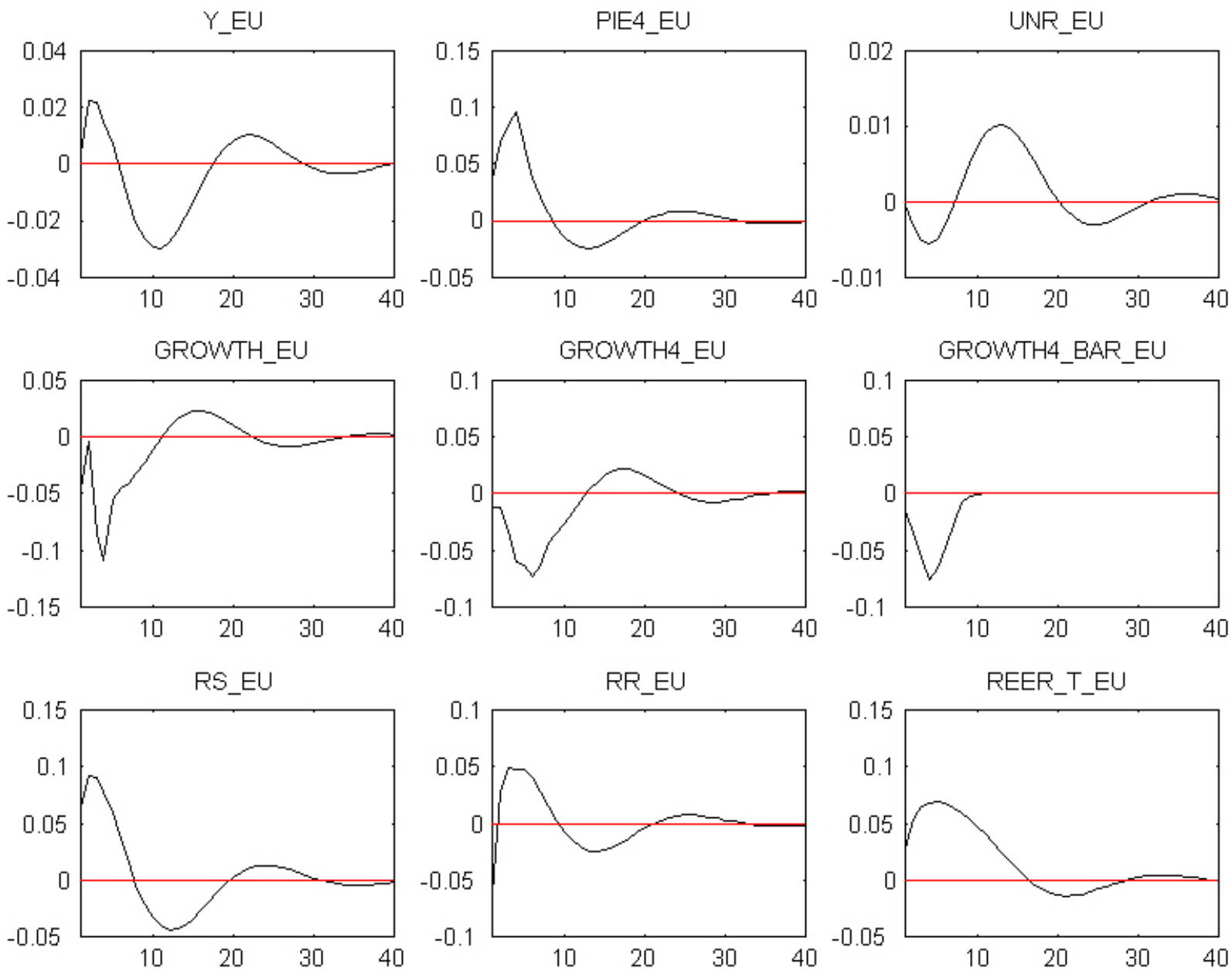
Figure 20: Oil Price Shock (3)
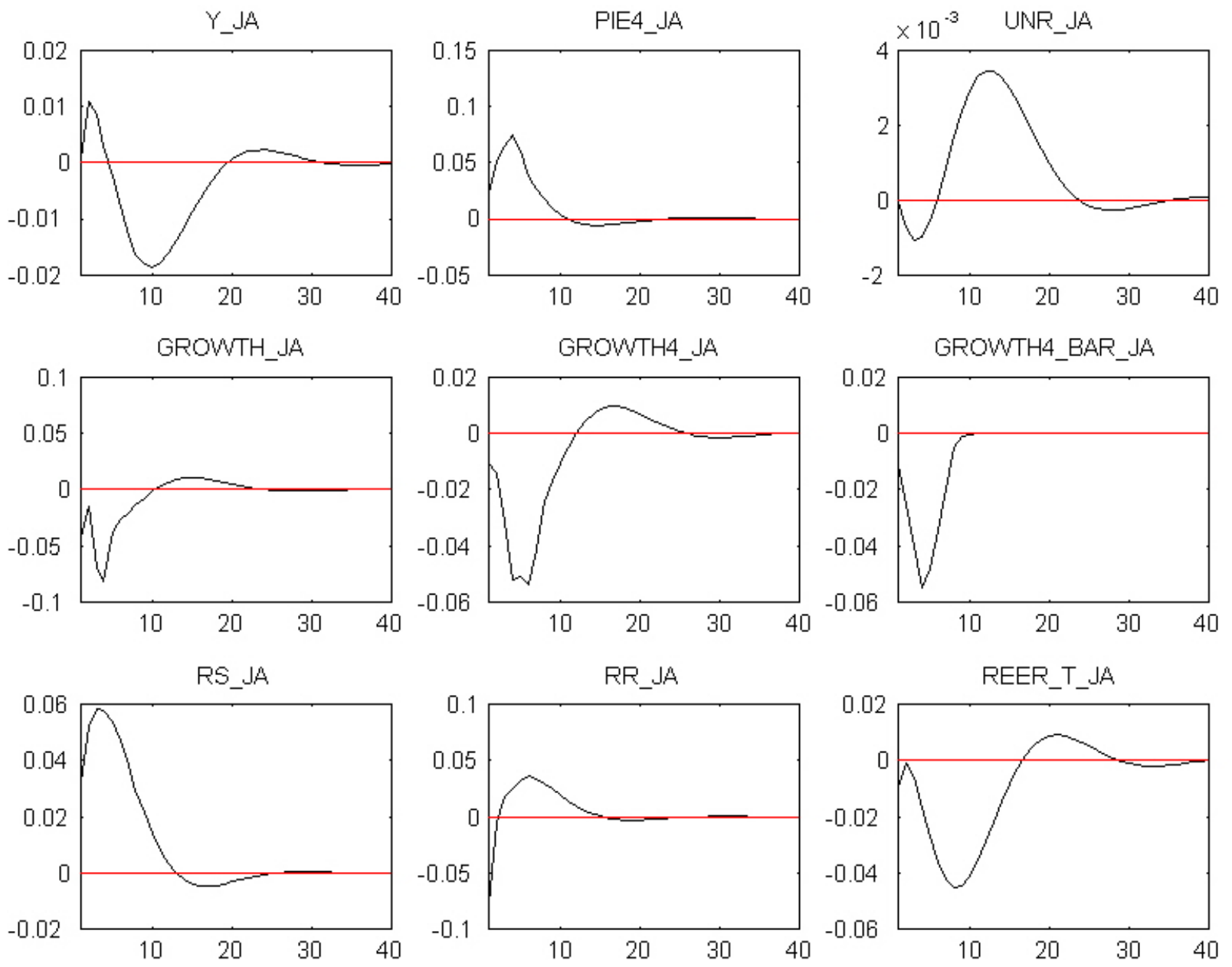
Figure 21: Oil Price Shock (4)

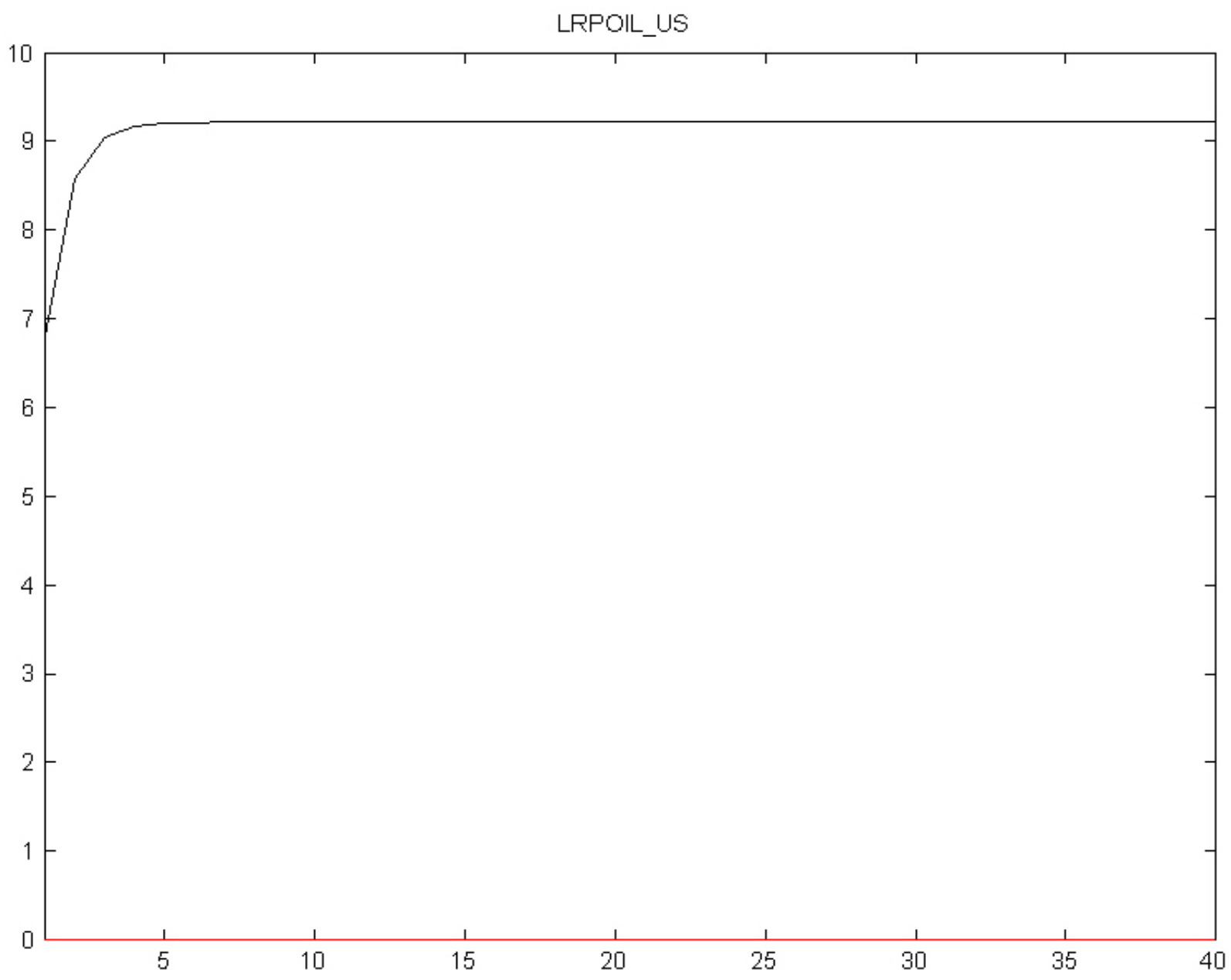


Figure 22: Oil Price Shock Permanent (1)
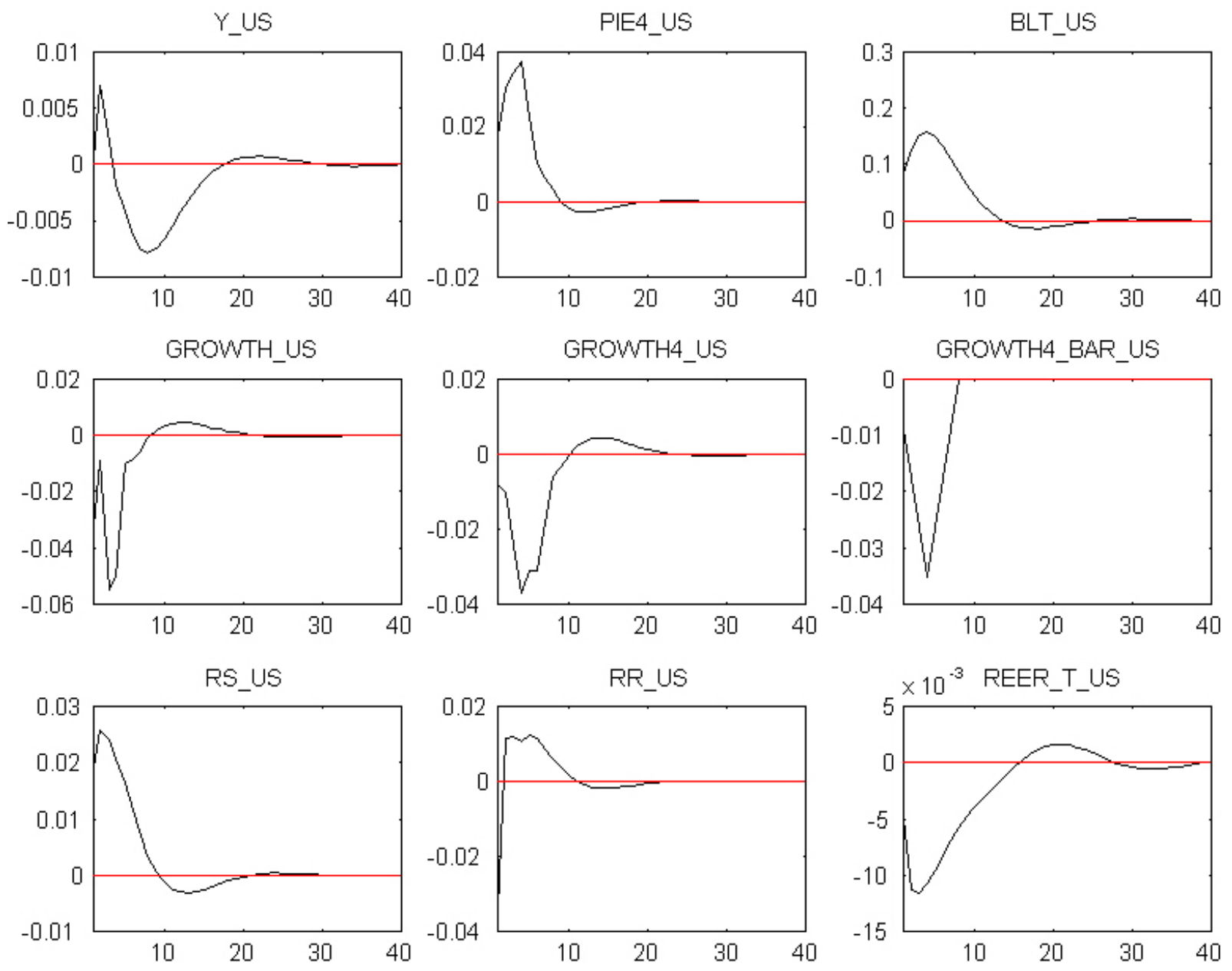
Figure 23: Oil Price Shock Permanent (2)
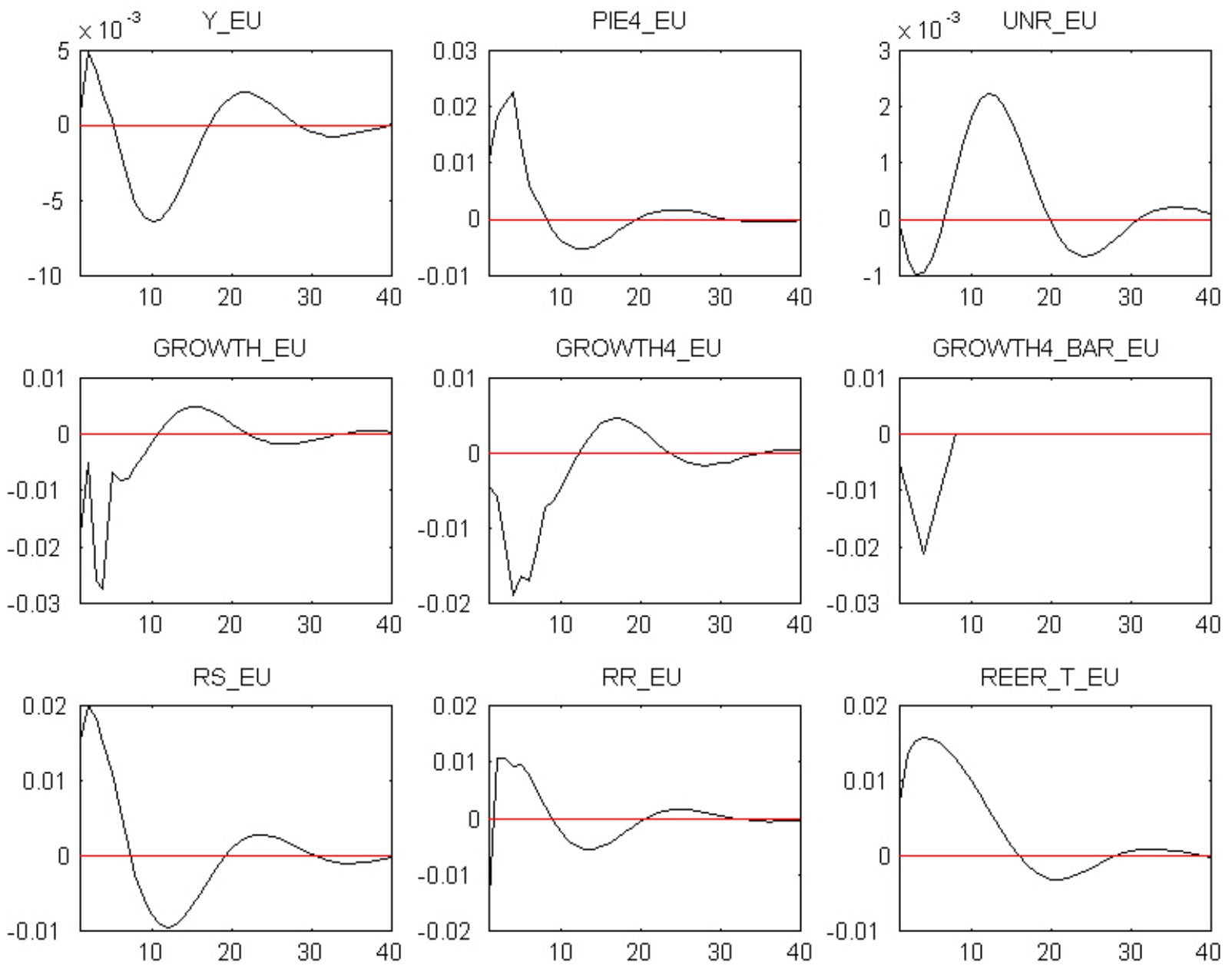
Figure 24: Oil Price Shock Permanent (3)
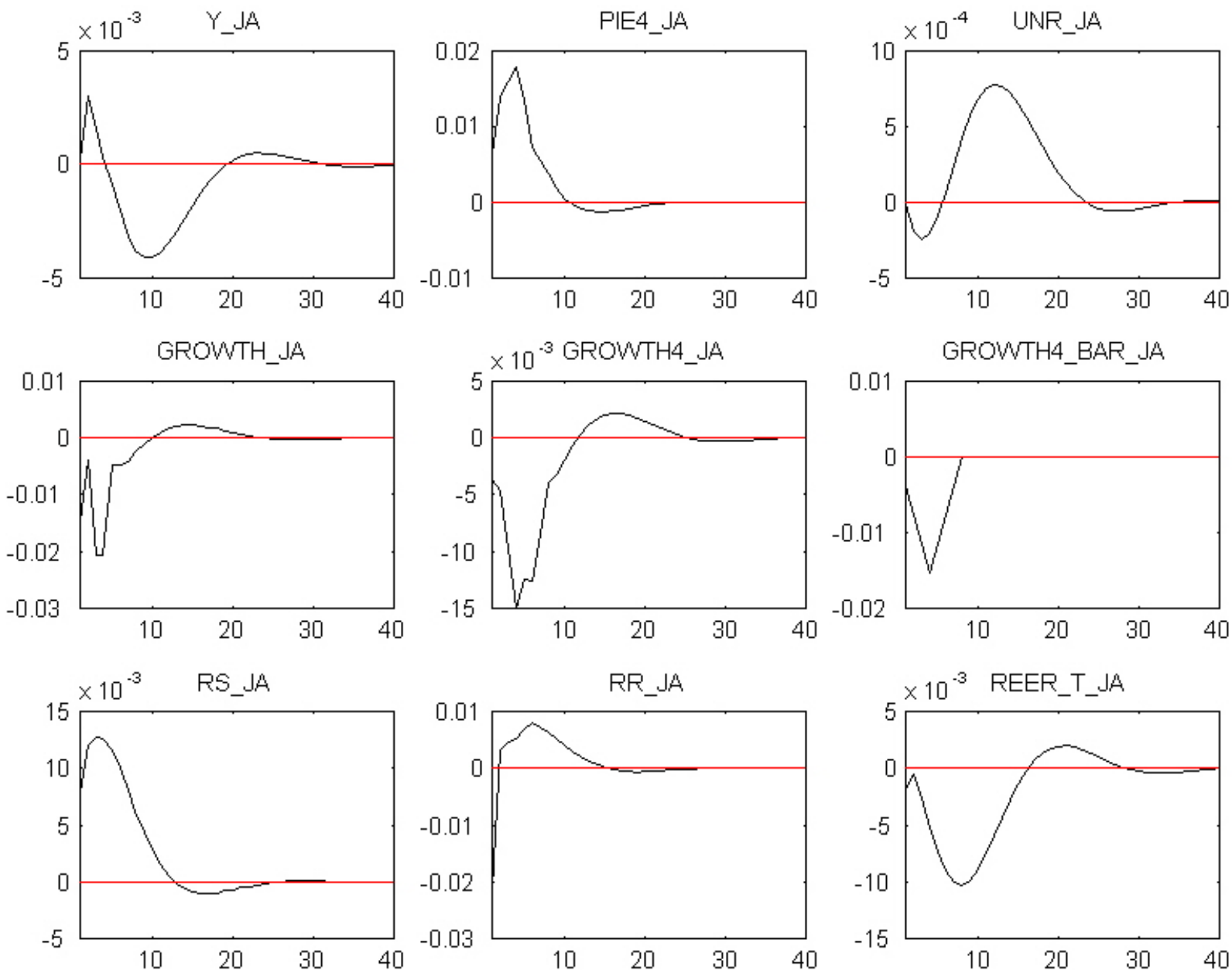
Figure 25: Oil Price Shock Permanent (4)

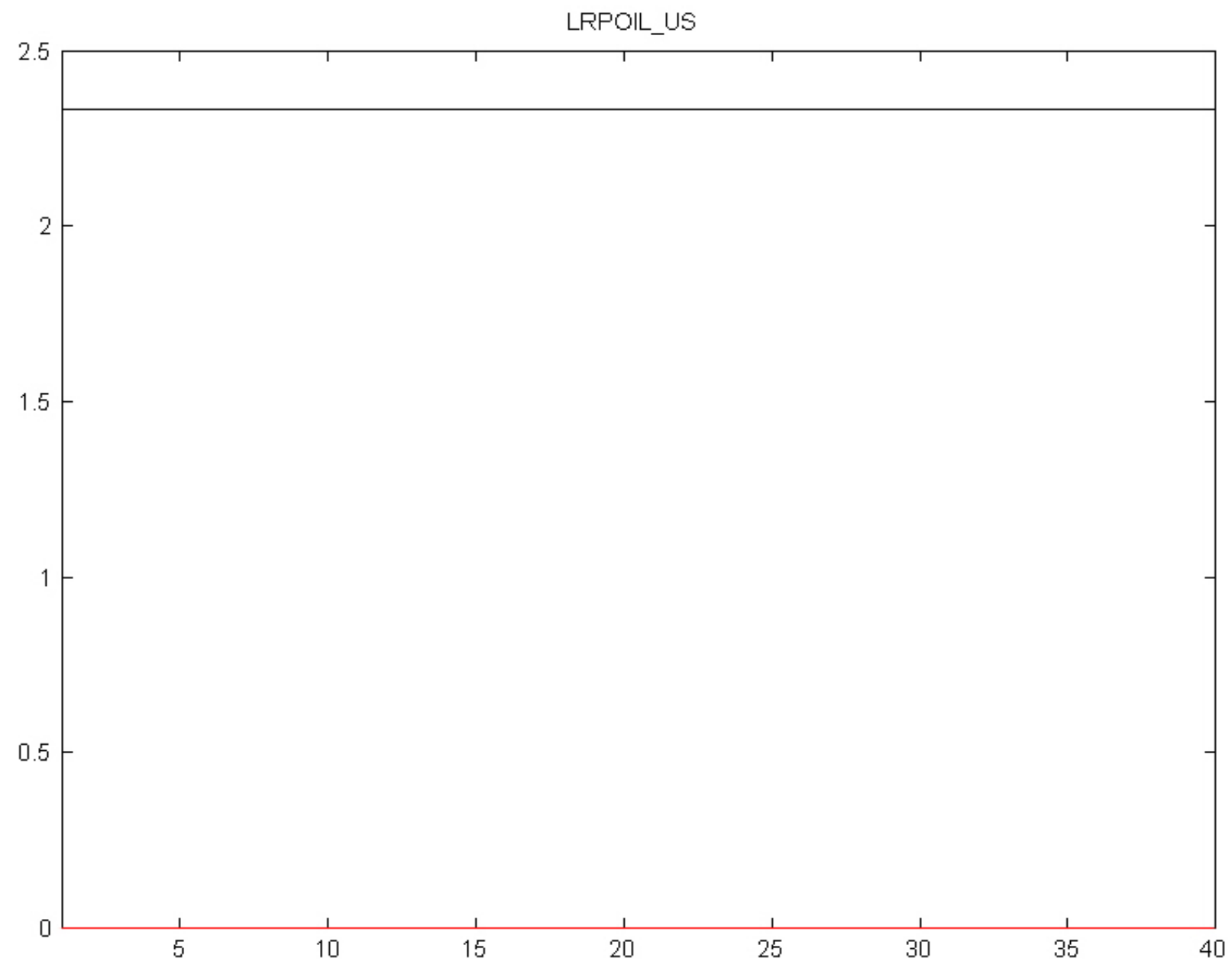


Figure 26: Forecast Results [1]

\section{Summary: July 182008 Conditional Compared to July 182008 Unconditional}

(Solid line=July 18 Conditional with $30 \%, 50 \%, 70 \%$ and $95 \%$ confidence bands; dashed line=July 18 Unconditional)
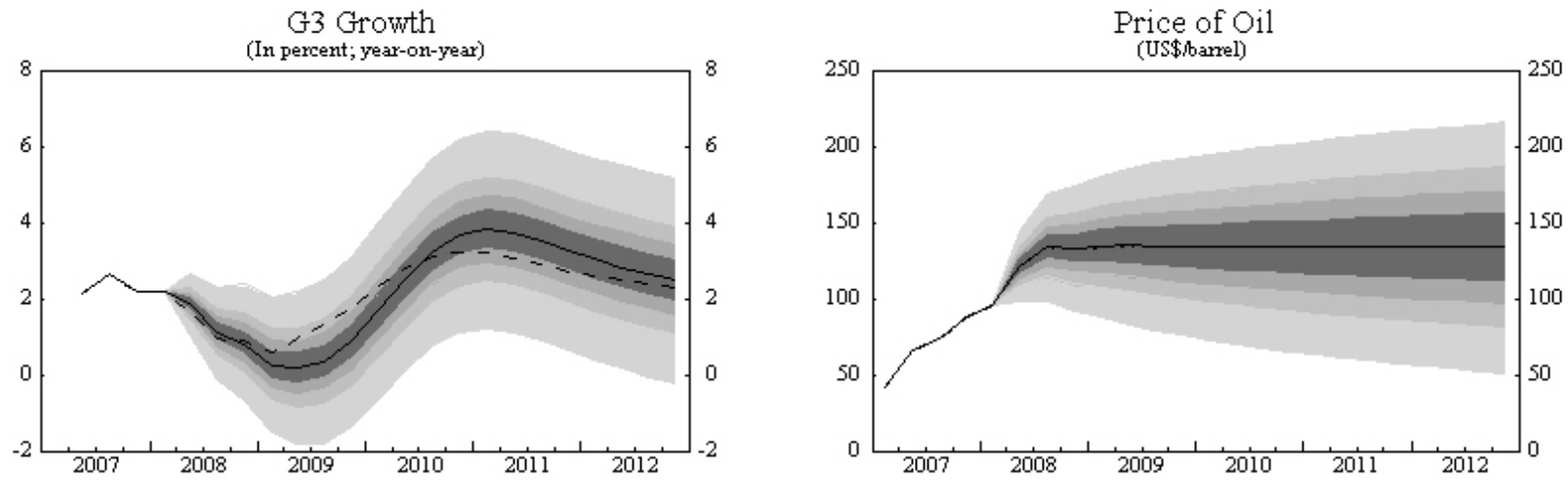

\begin{tabular}{|c|c|c|c|c|c|c|c|c|c|c|c|c|c|}
\hline \multicolumn{8}{|c|}{ Quarterly } & \multicolumn{6}{|c|}{ Annual } \\
\hline & & & & & & 20 & & & & & & & \\
\hline $\mathrm{Q3}$ & Q4 & Q1 & $\mathrm{Q} 2$ & $\mathrm{Q3}$ & Q4 & Q1 & $\mathrm{Q} 2$ & 2007 & 2008 & $\underline{2009}$ & 2010 & $\underline{2011}$ & 2012 \\
\hline
\end{tabular}

Real GDP Growth (\% y-0-y)

\begin{tabular}{|c|c|c|c|c|c|c|c|c|c|c|c|c|c|c|}
\hline G3 Growth & $\begin{array}{r}2.6 \\
{[+0.0]}\end{array}$ & $\begin{array}{r}2.2 \\
{[+0.0]}\end{array}$ & $\begin{array}{r}2.2 \\
{[+0.0]}\end{array}$ & $\begin{array}{r}1.9 \\
{[+0.2]}\end{array}$ & $\begin{array}{r}1.1 \\
{[+0.2]}\end{array}$ & $\begin{array}{c}0.8 \\
{[-0.1]}\end{array}$ & $\begin{array}{r}0.3 \\
{[-0.3]}\end{array}$ & $\begin{array}{r}0.2 \\
{[-0.8]}\end{array}$ & $\begin{array}{r}2.3 \\
{[+0.0]}\end{array}$ & $\begin{array}{r}1.5 \\
{[+0.1]}\end{array}$ & $\begin{array}{r}0.4 \\
{[-0.7]}\end{array}$ & $\begin{array}{c}2.8 \\
{[-0.1]}\end{array}$ & $\begin{array}{r}3.6 \\
{[+0.6]}\end{array}$ & $\begin{array}{r}2.7 \\
{[+0.3]}\end{array}$ \\
\hline United States & $\begin{array}{r}2.8 \\
{[+0.0]}\end{array}$ & $\begin{array}{r}2.5 \\
{[+0.0]}\end{array}$ & $\begin{array}{r}2.5 \\
{[+0.0]}\end{array}$ & $\begin{array}{r}1.8 \\
{[+0.6]}\end{array}$ & $\begin{array}{r}0.7 \\
{[+0.7]}\end{array}$ & $\begin{array}{r}0.4 \\
{[+0.3]}\end{array}$ & {$\left[\begin{array}{c}0.1 \\
{[-0.1]}\end{array}\right.$} & {$\left[\begin{array}{c}-0.1 \\
{[-1.2]}\end{array}\right.$} & $\begin{array}{r}2.2 \\
{[+0.0]}\end{array}$ & $\begin{array}{r}1.4 \\
{[+0.4]}\end{array}$ & $\begin{array}{c}0.3 \\
{[-1.1]}\end{array}$ & $\begin{array}{c}4.0 \\
{[-0.2]}\end{array}$ & $\begin{array}{r}4.2 \\
{[+0.8]}\end{array}$ & $\begin{array}{r}2.6 \\
{[+0.2]}\end{array}$ \\
\hline Euro Area & $\begin{array}{r}2.7 \\
{[+0.0]}\end{array}$ & $\begin{array}{r}2.1 \\
{[+0.0]}\end{array}$ & $\begin{array}{r}2.2 \\
{[+0.0]}\end{array}$ & $\begin{array}{c}2.0 \\
{[-0.1]}\end{array}$ & $\begin{array}{c}1.5 \\
{[-0.3]}\end{array}$ & $\begin{array}{c}1.3 \\
{[-0.3]}\end{array}$ & $\begin{array}{r}0.4 \\
{[-0.5]}\end{array}$ & $\begin{array}{c}0.2 \\
{[-0.5]}\end{array}$ & $\begin{array}{r}2.6 \\
{[+0.0]}\end{array}$ & $\begin{array}{c}1.7 \\
{[-0.2]}\end{array}$ & $\begin{array}{c}0.3 \\
{[-0.5]}\end{array}$ & $\begin{array}{c}1.6 \\
{[-0.1]}\end{array}$ & $\begin{array}{r}3.3 \\
{[+0.5]}\end{array}$ & $\begin{array}{r}3.2 \\
{[+0.5]}\end{array}$ \\
\hline Japan & $\begin{array}{r}1.9 \\
{[+0.0]}\end{array}$ & $\begin{array}{r}1.4 \\
{[+0.0]}\end{array}$ & $\begin{array}{r}1.1 \\
{[+0.0]}\end{array}$ & $\begin{array}{c}1.6 \\
{[-0.4]}\end{array}$ & $\begin{array}{c}1.5 \\
{[-0.5]}\end{array}$ & $\begin{array}{c}1.0 \\
{[-0.5]}\end{array}$ & $\begin{array}{c}0.5 \\
{[-0.4]}\end{array}$ & $\begin{array}{r}1.0 \\
{[+0.1]}\end{array}$ & $\begin{array}{r}2.0 \\
{[+0.0]}\end{array}$ & $\begin{array}{c}1.3 \\
{[-0.4]}\end{array}$ & $\begin{array}{r}1.0 \\
{[+0.1]}\end{array}$ & $\begin{array}{r}1.6 \\
{[+0.0]}\end{array}$ & $\begin{array}{r}2.1 \\
{[+0.1]}\end{array}$ & $\begin{array}{r}2.0 \\
{[+0.1]}\end{array}$ \\
\hline \multicolumn{15}{|l|}{ CPI Inflation (\% y-o-y) } \\
\hline United States & $\begin{array}{r}2.4 \\
{[+0.0]}\end{array}$ & $\begin{array}{r}4.0 \\
{[+0.0]}\end{array}$ & $\begin{array}{r}4.2 \\
{[+0.0]}\end{array}$ & $\begin{array}{r}4.2 \\
{[+0.4]}\end{array}$ & $\begin{array}{r}5.1 \\
{[+1.3]}\end{array}$ & $\begin{array}{r}4.4 \\
{[+1.4]}\end{array}$ & $\begin{array}{r}3.7 \\
{[+1.4]}\end{array}$ & $\begin{array}{r}2.9 \\
{[+1.0]}\end{array}$ & $\begin{array}{r}2.9 \\
{[+0.0]}\end{array}$ & $\begin{array}{r}4.5 \\
{[+0.8]}\end{array}$ & $\begin{array}{r}2.4 \\
{[+0.6]}\end{array}$ & $\begin{array}{c}1.3 \\
{[-0.4]}\end{array}$ & $\begin{array}{c}2.2 \\
{[-0.3]}\end{array}$ & $\begin{array}{r}2.7 \\
{[+0.0]}\end{array}$ \\
\hline Euro Area & $\begin{array}{r}1.9 \\
{[+0.0]}\end{array}$ & $\begin{array}{r}2.9 \\
{[+0.0]}\end{array}$ & $\begin{array}{r}3.4 \\
{[+0.0]}\end{array}$ & $\begin{array}{r}3.6 \\
{[+0.2]}\end{array}$ & $\begin{array}{r}3.9 \\
{[+0.3]}\end{array}$ & $\begin{array}{r}3.6 \\
{[+0.7]}\end{array}$ & $\begin{array}{r}3.0 \\
{[+0.6]}\end{array}$ & $\begin{array}{r}2.4 \\
{[+0.4]}\end{array}$ & $\begin{array}{r}2.1 \\
{[+0.0]}\end{array}$ & $\begin{array}{r}3.6 \\
{[+0.3]}\end{array}$ & $\begin{array}{r}2.0 \\
{[+0.2]}\end{array}$ & $\begin{array}{r}0.4 \\
{[-0.6]}\end{array}$ & $\begin{array}{c}0.9 \\
{[-0.5]}\end{array}$ & $\begin{array}{r}1.9 \\
{[-0.0]}\end{array}$ \\
\hline Japan & $\begin{array}{c}-0.1 \\
{[+0.0]}\end{array}$ & $\begin{array}{r}0.5 \\
{[+0.0]}\end{array}$ & $\begin{array}{r}1.0 \\
{[+0.0]}\end{array}$ & $\begin{array}{r}1.4 \\
{[+0.2]}\end{array}$ & $\begin{array}{r}1.6 \\
{[+0.3]}\end{array}$ & $\begin{array}{r}1.7 \\
{[+0.5]}\end{array}$ & $\begin{array}{r}1.7 \\
{[+0.5]}\end{array}$ & $\begin{array}{r}1.5 \\
{[+0.3]}\end{array}$ & $\begin{array}{r}0.1 \\
{[+0.0]}\end{array}$ & $\begin{array}{r}1.4 \\
{[+0.3]}\end{array}$ & $\begin{array}{r}1.4 \\
{[+0.3]}\end{array}$ & $\begin{array}{c}0.9 \\
{[-0.0]}\end{array}$ & $\begin{array}{c}0.9 \\
{[-0.1]}\end{array}$ & $\begin{array}{r}1.0 \\
{[-0.0]}\end{array}$ \\
\hline Price of $\mathrm{Oil}(\mathrm{US} \$ /$ barreI) & $\begin{array}{c}73.6 \\
(+0.0)\end{array}$ & $\begin{array}{c}87.6 \\
(+0.0)\end{array}$ & $\begin{array}{c}95.5 \\
(+0.0)\end{array}$ & $\begin{array}{l}121.0 \\
(+0.0)\end{array}$ & $\begin{array}{l}134.0 \\
(+0.0)\end{array}$ & $\begin{array}{l}133.0 \\
(+0.0)\end{array}$ & $\begin{array}{c}134.4 \\
(+0.0)\end{array}$ & $\begin{array}{l}134.7 \\
(+0.0)\end{array}$ & $\begin{array}{c}67.2 \\
(+0.0)\end{array}$ & $\begin{array}{c}120.9 \\
(+0.0)\end{array}$ & $\begin{array}{l}134.5 \\
(+0.0)\end{array}$ & $\begin{array}{l}133.9 \\
(+0.0)\end{array}$ & $\begin{array}{l}133.7 \\
(+0.0)\end{array}$ & $\begin{array}{l}133.7 \\
(+0.0)\end{array}$ \\
\hline \multicolumn{15}{|c|}{ Oil Price Change in Local Currency (\% y-o-y) } \\
\hline United States & $\begin{array}{c}47.1 \\
{[+0.0]}\end{array}$ & $\begin{array}{l}105.4 \\
{[+0.0]}\end{array}$ & $\begin{array}{c}132.5 \\
{[+0.0]}\end{array}$ & $\begin{array}{c}83.0 \\
{[+0.0]}\end{array}$ & $\begin{array}{c}82.2 \\
{[+0.0]}\end{array}$ & $\begin{array}{c}51.8 \\
{[+0.0]}\end{array}$ & $\begin{array}{c}40.8 \\
{[+0.0]}\end{array}$ & $\begin{array}{c}11.3 \\
{[+0.0]}\end{array}$ & $\begin{array}{c}44.4 \\
{[+0.0]}\end{array}$ & $\begin{array}{c}87.2 \\
{[+0.0]}\end{array}$ & $\begin{array}{c}13.2 \\
{[+0.0]}\end{array}$ & $\begin{array}{r}-0.4 \\
{[+0.0]}\end{array}$ & $\begin{array}{c}-0.1 \\
{[+0.0]}\end{array}$ & $\begin{array}{r}0.0 \\
{[+0.0]}\end{array}$ \\
\hline Euro Area & $\begin{array}{c}36.4 \\
{[+0.0]}\end{array}$ & $\begin{array}{c}82.8 \\
{[+0.0]}\end{array}$ & $\begin{array}{c}103.2 \\
{[+0.0]}\end{array}$ & $\begin{array}{c}57.9 \\
{[-4.5]}\end{array}$ & $\begin{array}{l}58.9 \\
{[-5.2]}\end{array}$ & $\begin{array}{l}40.3 \\
{[-3.9]}\end{array}$ & {$\left[\begin{array}{c}35.2 \\
{[-3.6]}\end{array}\right.$} & $\begin{array}{c}11.7 \\
{[+0.2]}\end{array}$ & $\begin{array}{c}31.9 \\
{[+0.0]}\end{array}$ & {$\left[\begin{array}{l}65.0 \\
{[-3.4]}\end{array}\right.$} & $\begin{array}{c}12.7 \\
{[-0.7]}\end{array}$ & {$\left[\begin{array}{c}-0.3 \\
-0.5]\end{array}\right.$} & {$\left[\begin{array}{l}-1.8 \\
-0.6]\end{array}\right.$} & {$\left[\begin{array}{l}-1.5 \\
-0.3]\end{array}\right.$} \\
\hline Japan & $\begin{array}{c}49.2 \\
{[+0.0]}\end{array}$ & $\begin{array}{c}97.3 \\
{[+0.0]}\end{array}$ & $\begin{array}{l}104.8 \\
{[+0.0]}\end{array}$ & $\begin{array}{c}58.2 \\
{[+3.3]}\end{array}$ & $\begin{array}{c}65.1 \\
{[+9.0]}\end{array}$ & $\begin{array}{c}43.5 \\
{[+9.0]}\end{array}$ & $\begin{array}{c}42.9 \\
{[+9.1]}\end{array}$ & $\begin{array}{c}13.9 \\
{[+5.0]}\end{array}$ & $\begin{array}{c}45.2 \\
{[+0.0]}\end{array}$ & $\begin{array}{c}67.8 \\
{[+5.3]}\end{array}$ & $\begin{array}{c}14.6 \\
{[+3.8]}\end{array}$ & $\begin{array}{r}0.9 \\
{[+0.5]}\end{array}$ & $\begin{array}{r}0.5 \\
{[+0.7]}\end{array}$ & $\begin{array}{c}-1.0 \\
{[+0.3]}\end{array}$ \\
\hline
\end{tabular}

Note: July 18 Conditional as a deviation from July 18 Unconditional: (percent deviation) or [percentage point deviation] 
Figure 27: Forecast Results [2]

United States: July 182008 Conditional Compared to July 182008 Unconditional

(Solid line $=$ July 18 Conditional with $30 \%, 50 \%, 70 \%$ and $95 \%$ confidence bands; dashed line $=$ July 18 Unconditional)
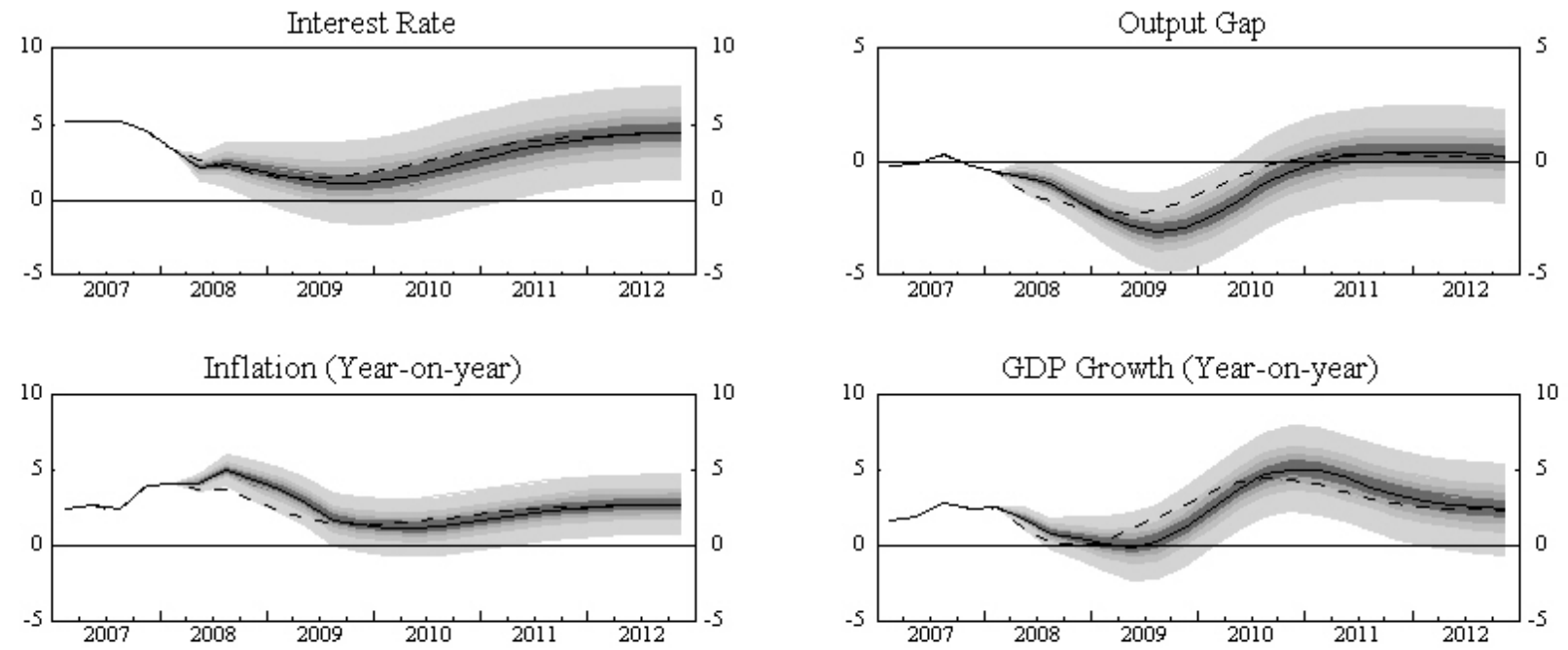

\begin{tabular}{|c|c|c|c|c|c|c|c|c|c|c|c|c|c|c|}
\hline & \multicolumn{8}{|c|}{ Quarterly } & \multicolumn{6}{|c|}{ Annual } \\
\hline & \multicolumn{2}{|c|}{2007} & \multicolumn{3}{|c|}{2008} & \multicolumn{3}{|c|}{2009} & \multirow[b]{2}{*}{$\underline{2007}$} & \multirow[b]{2}{*}{$\underline{2008}$} & \multirow[b]{2}{*}{$\underline{2009}$} & \multirow[b]{2}{*}{$\underline{2010}$} & \multirow[b]{2}{*}{2011} & \multirow[b]{2}{*}{$\underline{2012}$} \\
\hline & Q3 & Q4 & Q1 & $\mathrm{Q} 2$ & Q3 & $\mathrm{Q} 4$ & Q1 & $\mathrm{Q} 2$ & & & & & & \\
\hline Short-term Interest Rate & $\begin{array}{r}5.2 \\
{[+0.0]}\end{array}$ & $\begin{array}{r}4.5 \\
{[+0.0]}\end{array}$ & $\begin{array}{r}3.2 \\
{[+0.00}\end{array}$ & $\begin{array}{r}2.1 \\
{[-0.5]}\end{array}$ & $\begin{array}{r}2.3 \\
{[+0.1]}\end{array}$ & $\begin{array}{r}1.9 \\
{[+0.2]}\end{array}$ & $\begin{array}{r}1.6 \\
{[+0.1]}\end{array}$ & $\begin{array}{r}1.3 \\
-0.1]\end{array}$ & $\begin{array}{r}5.0 \\
{[+0.0]}\end{array}$ & $\begin{array}{r}2.4 \\
{[-0.0]}\end{array}$ & $\begin{array}{r}1.3 \\
{[-0.3]}\end{array}$ & $\begin{array}{r}1.8 \\
{[-0.8]}\end{array}$ & $\begin{array}{r}3.5 \\
{[-0.4]}\end{array}$ & $\begin{array}{r}4.3 \\
{[-0.0]}\end{array}$ \\
\hline Bank Lending Tightening & $\begin{array}{c}17.8 \\
{[+0.0]}\end{array}$ & $\begin{array}{c}32.2 \\
{[+0.0]}\end{array}$ & $\begin{array}{c}52.4 \\
{[+0.0]}\end{array}$ & $\begin{array}{r}63.6 \\
\{12.2]\end{array}$ & $\begin{array}{r}67.9 \\
\{20.4]\end{array}$ & $\begin{array}{r}64.0 \\
\{24.5]\end{array}$ & $\begin{array}{r}53.9 \\
\{24.4]\end{array}$ & $\begin{array}{c}40.1 \\
\{21.3]\end{array}$ & $\begin{array}{c}19.4 \\
{[+0.0]}\end{array}$ & $\begin{array}{r}62.0 \\
\mathbf{f} 14.3]\end{array}$ & $\begin{array}{r}33.1 \\
+[18.0]\end{array}$ & $\begin{array}{r}0.5 \\
{[+1.6]}\end{array}$ & $\begin{array}{l}-1.6 \\
{[-2.5]}\end{array}$ & $\begin{array}{r}2.0 \\
{[-1.7]}\end{array}$ \\
\hline \multicolumn{15}{|l|}{ Real GDP Growth } \\
\hline$\% y-0-y$ & $\begin{array}{r}2.8 \\
{[+0.0]}\end{array}$ & $\begin{array}{r}2.5 \\
{[+0.0]}\end{array}$ & $\begin{array}{r}2.5 \\
{[+0.0]}\end{array}$ & $\begin{array}{r}1.8 \\
{[+0.6]}\end{array}$ & $\begin{array}{r}0.7 \\
{[+0.7]}\end{array}$ & $\begin{array}{r}0.4 \\
{[+0.3]}\end{array}$ & $\begin{array}{r}0.1 \\
{[-0.1]}\end{array}$ & $\begin{array}{l}-0.1 \\
{[-1.2]}\end{array}$ & $\begin{array}{r}2.2 \\
{[+0.0]}\end{array}$ & $\begin{array}{r}1.4 \\
{[+0.4]}\end{array}$ & $\begin{array}{c}0.3 \\
{[-1.1]}\end{array}$ & $\begin{array}{r}4.0 \\
{[-0.2]}\end{array}$ & $\begin{array}{r}4.2 \\
{[+0.8]}\end{array}$ & $\begin{array}{r}2.6 \\
{[+0.2]}\end{array}$ \\
\hline$\%$ q@ar & $\begin{array}{r}4.9 \\
{[+0.0]}\end{array}$ & $\begin{array}{r}0.6 \\
{[+0.0]}\end{array}$ & $\begin{array}{r}0.9 \\
{[+0.0]}\end{array}$ & $\begin{array}{r}1.0 \\
{[+2.5]}\end{array}$ & $\begin{array}{r}0.5 \\
{[+0.1]}\end{array}$ & $\begin{array}{l}-0.6 \\
{[-1.5]}\end{array}$ & $\begin{array}{c}-0.6 \\
{[-1.7]}\end{array}$ & $\begin{array}{r}0.4 \\
{[-1.8]}\end{array}$ & & & & & & \\
\hline $\begin{array}{l}\text { Potential GDP Growth } \\
\% y-0-y\end{array}$ & $\begin{array}{r}3.2 \\
{[+0.0]}\end{array}$ & $\begin{array}{r}3.1 \\
{[+0.0]}\end{array}$ & $\begin{array}{r}2.8 \\
{[+0.0]}\end{array}$ & $\begin{array}{r}2.4 \\
{[+0.0]}\end{array}$ & $\begin{array}{r}2.1 \\
{[+0.0]}\end{array}$ & $\begin{array}{r}1.9 \\
{[+0.0]}\end{array}$ & $\begin{array}{r}2.0 \\
{[+0.0]}\end{array}$ & $\begin{array}{r}2.1 \\
{[+0.0]}\end{array}$ & $\begin{array}{r}3.1 \\
{[+0.0]}\end{array}$ & $\begin{array}{r}2.3 \\
{[+0.0]}\end{array}$ & $\begin{array}{r}2.2 \\
{[+0.0]}\end{array}$ & $\begin{array}{r}2.6 \\
{[-0.0]}\end{array}$ & $\begin{array}{r}2.5 \\
{[-0.0]}\end{array}$ & $\begin{array}{r}2.5 \\
{[-0.0]}\end{array}$ \\
\hline \multicolumn{15}{|l|}{ CPI Inflation } \\
\hline$\% y-0-y$ & $\begin{array}{r}2.4 \\
{[+0.0]}\end{array}$ & $\begin{array}{r}4.0 \\
{[+0.0]}\end{array}$ & $\begin{array}{r}4.2 \\
{[+0.0]}\end{array}$ & $\begin{array}{r}4.2 \\
{[+0.4]}\end{array}$ & $\begin{array}{r}5.1 \\
{[+1.3]}\end{array}$ & $\begin{array}{r}4.4 \\
{[+1.4]}\end{array}$ & $\begin{array}{r}3.7 \\
{[+1.4]}\end{array}$ & $\begin{array}{r}2.9 \\
{[+1.0]}\end{array}$ & $\begin{array}{r}2.9 \\
{[+0.0]}\end{array}$ & $\begin{array}{r}4.5 \\
{[+0.8]}\end{array}$ & $\begin{array}{r}2.4 \\
{[+0.6]}\end{array}$ & $\begin{array}{r}1.3 \\
{[-0.4]}\end{array}$ & $\begin{array}{r}2.2 \\
{[-0.3]}\end{array}$ & $\begin{array}{r}2.7 \\
{[+0.0]}\end{array}$ \\
\hline$\%$ q@ar & $\begin{array}{r}2.8 \\
{[+0.0]}\end{array}$ & $\begin{array}{r}5.0 \\
{[+0.0]}\end{array}$ & $\begin{array}{r}4.3 \\
{[+0.0]}\end{array}$ & $\begin{array}{r}4.7 \\
{[+1.6]}\end{array}$ & $\begin{array}{r}6.2 \\
{[+3.6]}\end{array}$ & $\begin{array}{r}2.3 \\
{[+0.4]}\end{array}$ & $\begin{array}{r}1.7 \\
{[+0.2]}\end{array}$ & $\begin{array}{r}1.4 \\
{[+0.0]}\end{array}$ & & & & & & \\
\hline $\begin{array}{l}\text { Real Effective Exchange R } \\
\text { Depreciation }(y-0-y)\end{array}$ & ate 3.6 & 7.6 & 12.4 & $\begin{array}{c}14.3 \\
{[+1.1]}\end{array}$ & $\begin{array}{c}11.2 \\
{[-0.7]}\end{array}$ & $\begin{array}{r}6.0 \\
{[-1.1]}\end{array}$ & $\begin{array}{r}1.2 \\
{[-1.2]}\end{array}$ & $\begin{array}{c}-1.8 \\
{[-2.3]}\end{array}$ & 4.2 & $\begin{array}{c}11.0 \\
{[-0.2]}\end{array}$ & $\begin{array}{c}-0.8 \\
{[-1.1]}\end{array}$ & $\begin{array}{c}-1.2 \\
{[+0.1]}\end{array}$ & $\begin{array}{r}-0.3 \\
{[+0.1]}\end{array}$ & $\begin{array}{r}0.3 \\
{[+0.1]}\end{array}$ \\
\hline \multicolumn{15}{|l|}{ Bilateral Exchange Rate } \\
\hline vs. Euro Area & $\begin{array}{c}0.73 \\
(+0.0)\end{array}$ & $\begin{array}{c}0.69 \\
(+0.0)\end{array}$ & $\begin{array}{c}0.67 \\
(+0.0)\end{array}$ & $(-2.7)$ & $\left(\begin{array}{l}0.63 \\
(-3.2)\end{array}\right.$ & $(-2.7)$ & $\begin{array}{l}0.64 \\
(-2.6)\end{array}$ & $\left(\begin{array}{l}0.64 \\
(-2.6)\end{array}\right.$ & $\begin{array}{c}0.73 \\
(+0.0)\end{array}$ & $\left(\begin{array}{l}0.64 \\
-2.2)\end{array}\right.$ & $\left(\begin{array}{l}0.64 \\
(-2.6)\end{array}\right.$ & $\left(\begin{array}{l}0.64 \\
-3.1)\end{array}\right.$ & $\left(\begin{array}{l}0.63 \\
(-3.7)\end{array}\right.$ & $(-4.0)$ \\
\hline vs. Japan & $\begin{array}{c}117.78 \\
(+0.0)\end{array}$ & $\begin{array}{c}113.06 \\
(+0.0)\end{array}$ & $\begin{array}{c}105.20 \\
(+0.0)\end{array}$ & $\begin{array}{r}104.40 \\
(+2.1)\end{array}$ & $\begin{array}{l}106.70 \\
(+5.8)\end{array}$ & $\begin{array}{c}106.93 \\
(+6.7)\end{array}$ & $\begin{array}{c}106.77 \\
(+6.8)\end{array}$ & $\begin{array}{c}106.80 \\
(+6.8)\end{array}$ & $\begin{array}{l}7.74 \\
(+0.0)\end{array}$ & $\begin{array}{l}105.81 \\
(+3.6)\end{array}$ & $\begin{array}{c}107.00 \\
(+6.8)\end{array}$ & $\begin{array}{c}108.48 \\
(+7.3)\end{array}$ & $\begin{array}{c}109.13 \\
(+8.1)\end{array}$ & $\begin{array}{c}108.03 \\
(+8.4)\end{array}$ \\
\hline Output Gap & $\begin{array}{r}0.3 \\
{[+0.0]}\end{array}$ & $\begin{array}{c}-0.2 \\
{[+0.0]}\end{array}$ & $\begin{array}{c}-0.5 \\
{[+0.0]}\end{array}$ & $\begin{array}{r}-0.7 \\
{[+0.6]}\end{array}$ & $\begin{array}{c}-1.0 \\
{[+0.7]}\end{array}$ & $\begin{array}{c}-1.7 \\
{[+0.3]}\end{array}$ & {$\left[\begin{array}{c}-2.3 \\
-0.1]\end{array}\right.$} & $\begin{array}{c}-2.8 \\
{[-0.6]}\end{array}$ & {$\left[\begin{array}{c}-0.0 \\
{[+0.0]}\end{array}\right.$} & $\begin{array}{c}-0.9 \\
{[+0.4]}\end{array}$ & $\begin{array}{c}-2.8 \\
{[-0.7]}\end{array}$ & $\begin{array}{c}-1.4 \\
{[-0.9]}\end{array}$ & $\begin{array}{c}0.2 \\
{[-0.1]}\end{array}$ & $\begin{array}{r}0.4 \\
{[+0.1]}\end{array}$ \\
\hline
\end{tabular}

Note: July 18 Conditional as a deviation from July 18 Unconditional: (percent deviation) or [percentage point deviation] 
Figure 28: Forecast Results [3]

\section{Euro Area: July 182008 Conditional Compared to July 182008 Unconditional}

(Solid line=July 18 Conditional with $30 \%, 50 \%, 70 \%$ and $95 \%$ confidence bands; dashed line=July 18 Unconditional)
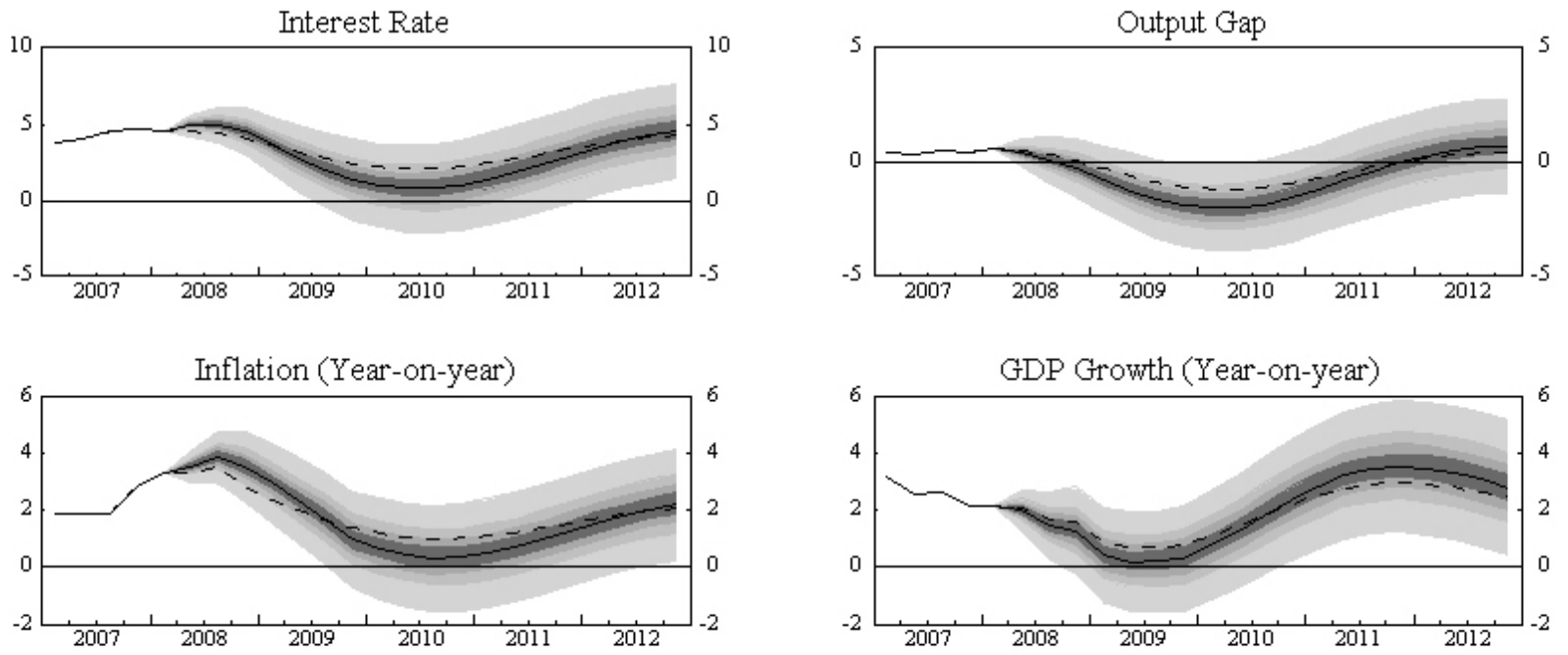

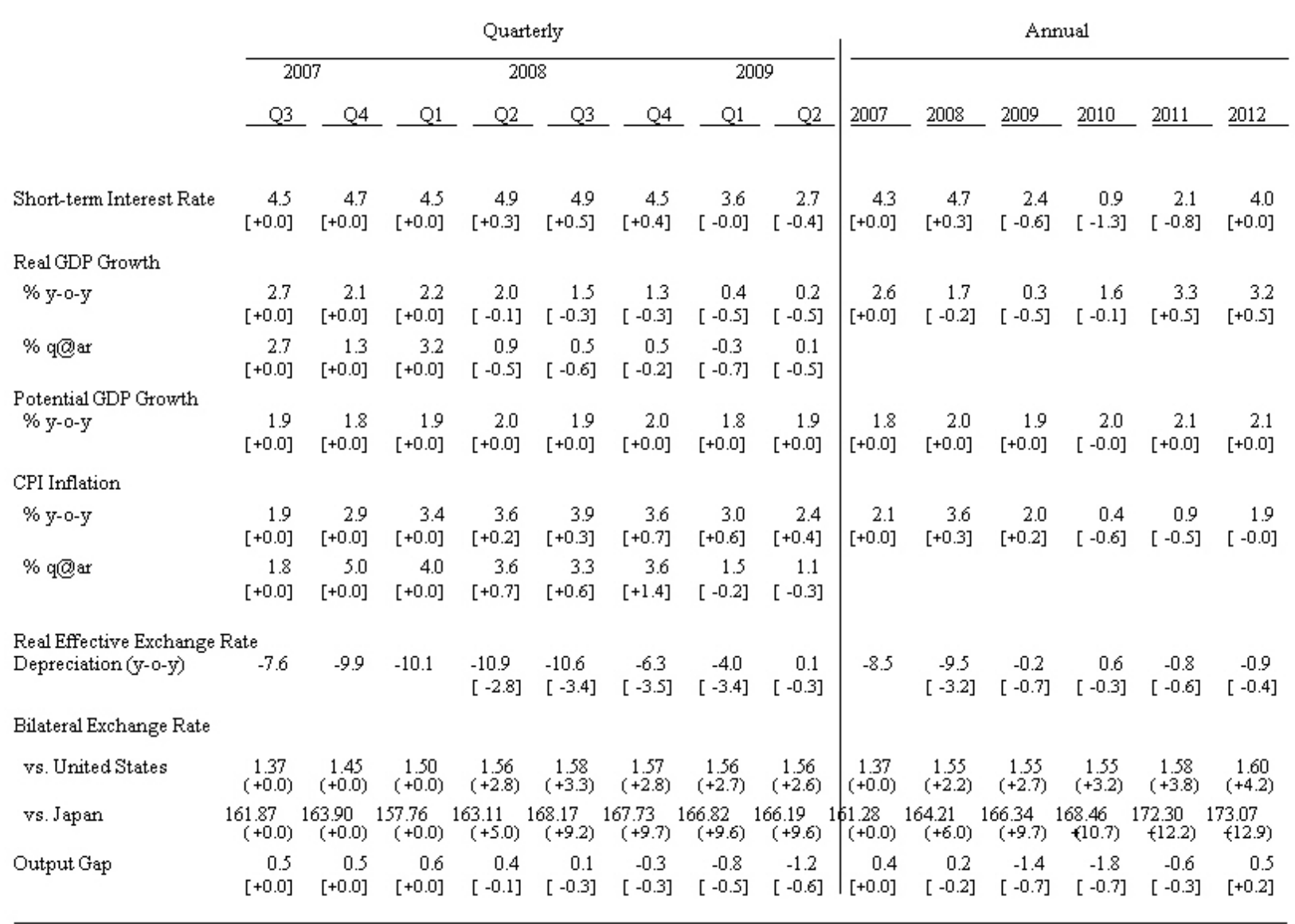

Note: July 18 Conditional as a deviation from July 18 Unconditional: (percent deviation) or [percentage point deviation] 
Figure 29: Forecast Results [4]

\section{Japan: July 182008 Conditional Compared to July 182008 Unconditional}

(Solid line=July 18 Conditional with $30 \%, 50 \%, 70 \%$ and $95 \%$ confidence bands; dashed line=July 18 Unconditional)
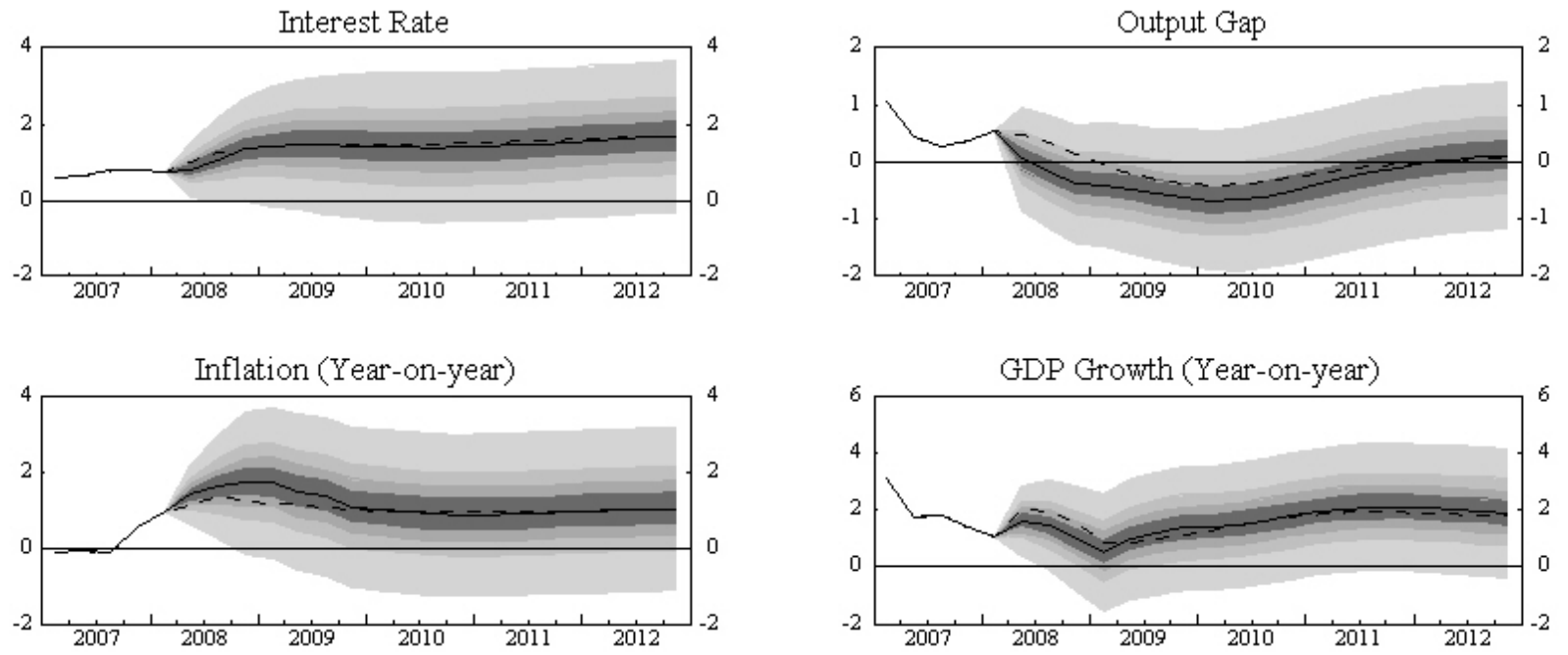

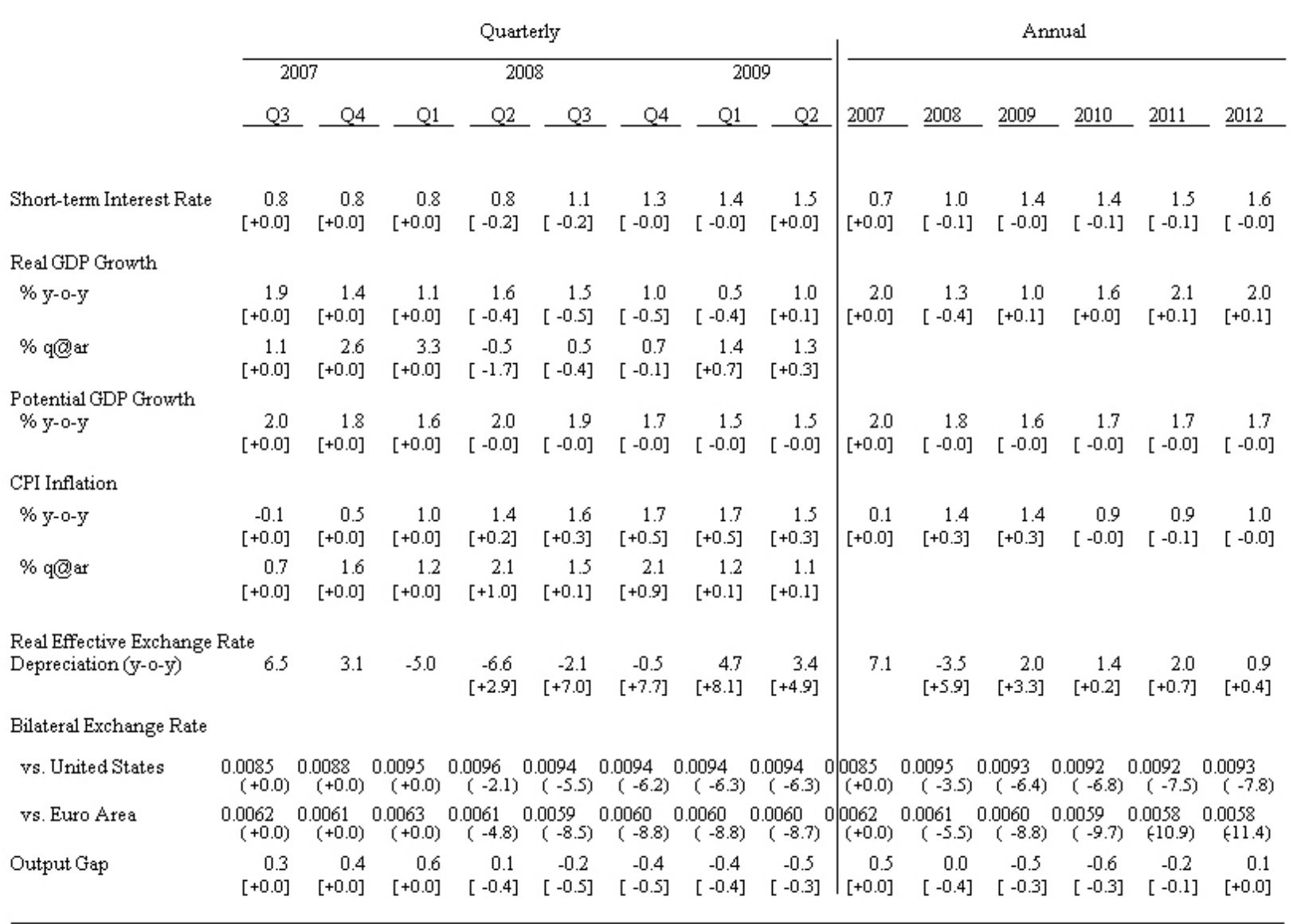

Note: July 18 Conditional as a deviation from July 18 Unconditional: (percent deviation) or [percentage point deviation] 